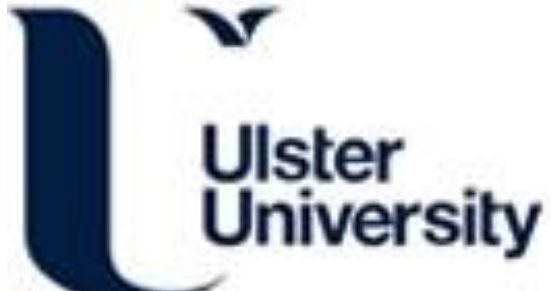

\section{'Something wasn't quite right': a novel phenomenological analysis of internet discussion posts detailing initial awareness of psychosis}

Spikol, A., \& Murphy, J. (Accepted/In press). 'Something wasn't quite right': a novel phenomenological analysis of internet discussion posts detailing initial awareness of psychosis. Clinical Schizophrenia \& Related Psychoses. https://doi.org/10.3371/CSRP.SPJM.031819

Link to publication record in Ulster University Research Portal

\section{Published in:}

Clinical Schizophrenia \& Related Psychoses

\section{Publication Status:}

Accepted/In press: 05/01/2019

DOI:

10.3371/CSRP.SPJM.031819

\section{Document Version}

Author Accepted version

\section{General rights}

Copyright for the publications made accessible via Ulster University's Research Portal is retained by the author(s) and / or other copyright owners and it is a condition of accessing these publications that users recognise and abide by the legal requirements associated with these rights.

\section{Take down policy}

The Research Portal is Ulster University's institutional repository that provides access to Ulster's research outputs. Every effort has been made to ensure that content in the Research Portal does not infringe any person's rights, or applicable UK laws. If you discover content in the Research Portal that you believe breaches copyright or violates any law, please contact pure-support@ulster.ac.uk. 


\section{\begin{tabular}{c|c} 
Clinical Schizophrenia \\
\& Relatied Psychoses
\end{tabular}}

\section{'Something wasn't quite right': a novel phenomenological analysis of internet discussion posts detailing initial awareness of psychosis}

\begin{tabular}{|c|c|}
\hline Journal: & Clinical Schizophrenia \& Related Psychoses \\
\hline Manuscript ID & CSRP-05-18-0505.R2 \\
\hline Manuscript Type: & Original Contribution \\
\hline $\begin{array}{l}\text { Date Submitted by the } \\
\text { Author: }\end{array}$ & $16-N o v-2018$ \\
\hline Complete List of Authors: & $\begin{array}{l}\text { Spikol, Amanda; Ulster University, Psychology } \\
\text { Murphy, Jamie; University of Ulster, School of Psychology }\end{array}$ \\
\hline Keyword: & $\begin{array}{l}\text { early psychosis, social media, interpretative phenomenological analysis, } \\
\text { first episode psychosis, premorbid adjustment }\end{array}$ \\
\hline
\end{tabular}

\section{SCHOLARONE Manuscripts}


'Something wasn't quite right': a novel phenomenological analysis of internet discussion posts detailing initial awareness of psychosis

Amanda Spikol and Jamie Murphy*

School of Psychology, Ulster University, Northern Ireland

*Corresponding Author:

Professor Jamie Murphy

School of Psychology

Ulster University

Derry

Northern Ireland

BT48 7JL

Telephone: +44 (0) 2871375283

Email: ja.murphy@ulster.ac.uk
Text body word count: 4612

Table count: 2 


\begin{abstract}
INTRODUCTION: A significant number of psychosis studies have focussed on and have attempted to model and frame the earliest psychosis experiences. Using a wide array of methodologies and targeting a variety of 'at risk' groups, researchers have offered much to inform our treatment responses, and understanding of psychosis onset and development.
\end{abstract}

OBJECTIVES: Due to the nature of scientific investigation however and investigator led exploration, those who experience psychosis are rarely afforded ultimate free rein to dictate and direct the exchange of information or to impose their unique narrative on that which is being explored. In an attempt to address this, the current study opportunistically harvested rich self-report data from replies to the question, “People that have been diagnosed with schizophrenia, what was the first time you noticed something wasn't quite right?" on the internet discussion forum Reddit.com.

METHODS: User data was analysed using Interpretive Phenomenological Analysis to identify key themes in participants' first experiences and initial awareness of psychosis.

RESULTS: While respondents varied widely in their recounted experiences and chose to describe these experiences in a variety of ways, analysis showed that (i) respondent distress was associated with psychosis onset timeframe, negative-voice auditory hallucinations, visual hallucinations, paranoid delusions, and insight (ii) early childhood psychosis experience resulted in novel explanatory schemas and psychosis/distress progression with contributory factors in adolescence and (iii) $41.3 \%$ of the sample reported self-realisation in gaining insight and greater insight was associated with help-seeking behaviour.

CONCLUSIONS: This novel use of publically shared experiential data might enrich our existing qualitative literature concerning early psychosis. 
Key words: early psychosis, social media, interpretative phenomenological analysis, first episode psychosis; premorbid adjustment 


\section{Introduction}

Early psychosis receives significant attention in the research literature.

Understandably, information, knowledge and clarity about the earliest signs and signals of psychotic experience afford valuable opportunities to inform and achieve successful early intervention and support. They also afford valuable opportunities to understand psychosis onset and development and the aetiological landscape that underpins such experiences. A variety of literatures have attempted to model and frame early psychosis; prodromal studies $^{1}$, first episode psychosis (FEP) studies ${ }^{2}$, ultra-high-risk (UHR) studies ${ }^{3,4}$, clinical-highrisk (CHR) studies ${ }^{5,6}$, duration of untreated psychosis (DUP) studies ${ }^{7}$, first treatment contact studies $^{8,9,10}$, continuum studies and those investigating subclinical/psychosis-like experiences (PLEs) and/or schizotypal traits ${ }^{11,12}$, each attempt to capture the earliest manifestations and expressions of psychosis in the population.

These studies in turn have afforded valuable opportunities to investigate many important clinical issues surrounding early psychosis such as e.g. the reduction of risk for FEP $^{13}$, the prevention of second episodes ${ }^{14}$, pathways to care from FEP ${ }^{15,16}$, the efficacy and safety of psychopharmacological intervention in early psychosis ${ }^{17}$, cognition and neural functioning in early psychosis ${ }^{18,19,20,21}$, premorbid adjustment, symptom development and quality of life in early psychosis ${ }^{22}$, suicide risk $^{23}$, and the environmental context of early psychosis $^{24,25}$.

Our framing and operationalisation of early psychosis however has also been significantly informed by rich qualitative evidence detailing the lived experiences of those who have directly encountered and endured psychosis $^{26}$. Multiple qualitative studies detailing e.g. the subjective experience of FEP $27-29$, service user views on early 
intervention ${ }^{30-32}$, early experiences of help seeking ${ }^{33-36}$, and issues surrounding social relationships in early psychosis 37,38 , have afforded invaluable insights into the personal experiences of individuals, their families and service providers.

Importantly however, much of the evidence we rely upon (both quantitative and qualitative) to inform our understanding of early psychosis, may be somewhat constrained by unavoidable researcher bias ${ }^{39,40}$. Researcher selected methodologies, researcher designed interview schedules, researcher formulated terminology, and general researcher driven enquiry may ultimately limit our understanding of early psychosis. Because researchers frame, direct and focus research, those under investigation must provide information in a manner that conforms to and is consistent with the imposed investigatory framework. Rarely are those who are under investigation afforded ultimate free rein to dictate and direct the exchange of information or to impose their unique narrative on that which is being explored.

The current study, in an attempt to explore early psychosis without the constraints of researcher design bias, opportunistically harvested rich internet discussion content linked to an AskReddit post enquiring about first experiences of psychosis. Given the absence of researcher definition, instruction or clarification regarding e.g. terminology, phenomenology, or time; the freedom to attend to and comment on any aspect of experience; and the anonymity of disclosure, we aimed to (i) more objectively examine the lived experiences and interpretations of those recounting early psychosis, (ii) enrich existing qualitative literature concerning early psychosis, and (iii) establish a coded analytic framework to support further in-depth analysis of this rich data resource. 


\section{Methods}

Medium

Data for this study was sourced from the Internet discussion site reddit (www.reddit.com), specifically the sub-forum AskReddit (www.reddit.com/r/askreddit/). Reddit has approximately 542 million monthly visitors and is ranked the 8th most visited site on the global Internet and 4th in the US ${ }^{41}$. AskReddit, with approximately 18.4 million subscribers, is a sub-forum where any user may post a question for general advice, openended discussion, or lived experience. Users may reply to the question or to other users' replies. Forum rules forbid posting identifying information and users post under a chosen username or create a one-use 'throwaway' account. Users may vote on comments as part of a wider 'karma' system. 'Up-votes' contribute to karma while 'down-votes' take from it, with 'up-votes' generally taken as agreement with the comment or as an expression of respect for or empathy with the poster.

Griffiths $^{42}$ cites several factors supporting Internet collected qualitative data; easy access to wider recruitment, a potential global sample population, cost-effectiveness, reduction in social desirability, data in common digital formats, and accessibility for those uncomfortable with in-person participation. This allows a vulnerable population complete control over their environment and comfort level, avoiding social pressures and self-stigma. Evidence suggests individuals with schizophrenia exhibit Internet use behaviour comparable to a non-clinical sample ${ }^{43}$, incurring no additional risks participating in online research. In this study, reddit users were free to ignore the posed question, thus those who commented truly wanted to share their experiences. 
Sample

At 19:37 GMT on 13 November 2017, a reddit user posted the question "People that have been diagnosed with schizophrenia, what was the first time you noticed something wasn't quite right?" to AskReddit. The user was not a mental health professional using clinical language nor a researcher engaged in hypothesis testing; they were an individual curious about others' experiences. This post carried a [Serious] tag, indicating off-topic or joke replies would be deleted by the moderation team. 4565 users commented, either responding directly or in nested comment threads. The post was sorted by 'top comments' by up-vote and the top 150 replies sourced. Nested comment threads were ignored. Data use permission was granted by the moderation team of AskReddit. Comments were copied without usernames and assigned a 5 character alphanumeric ID as provided by the random sequence generator at random.org ${ }^{44}$. This sample was comprised of reddit users with English fluency who felt their experiences matched the posted question. Reddit terms of service prohibit users < age 13, yielding an approximate age range of 13-90+. 43 individuals provided their age of initial psychosis awareness, showing a range of 7.5-32 years and mean age of $16.34(S D=5.63)$. User demographic information is not required for posting nor made public; therefore, gender, ethnicity and demographic factors were unknown unless a user chose to share that information, though $56 \%$ of reddit users are American, $69 \%$ are male, and $58 \%$ are in the $18-29$ age range ${ }^{45}$. Sample homogeneity was the experience of psychosis.

\section{Measures}


The question posed was a request for lived experience by the original poster and the only measure utilised.

Analysis

Interpretive phenomenological analysis (IPA) is a method of qualitative review focusing on the individual's interpretation of their experiences ${ }^{46}$. IPA differs from other qualitative methods in its combination of philosophies, blending interpretation with psychological and ideographic analysis ${ }^{47}$. The researcher puts aside preconceived notions to review the data in a 'bottom-up' method of thematic coding, generating emergent themes rather than testing pre-existing theories ${ }^{48}$. IPA is usually performed in a focus group or semi structured interview but can be performed with secondary data in larger samples. IPA use in psychosis research has produced "contextually rich" frameworks exploring individuals' selfdefinition of their psychotic experiences ${ }^{26,29,49}$. Transcripts were analysed for general themes in experience, which were then combined into overarching key themes and trends in the sample. 


\section{Results}

Sample

The mean word count for comments was 211.14 words (SD=201.13; range=10-1259). 139 commenters discussed their perception of symptom onset and 4 distinct themes emerged. $20 \%(\mathrm{~N}=30)$ described symptoms being "always present" or "as far back as I can remember", $52.7 \%(\mathrm{~N}=79)$ as "starting slowly" and building to a breakdown, $11.3 \%(\mathrm{~N}=16)$ as "sudden" onset while $8.7 \%(\mathrm{~N}=11)$ stated they were "currently" experiencing symptoms. In discussing distress related to these experiences, lower distress was interpreted as awareness to mild annoyance and moderate/high distress interpreted by descriptive language. Distress varied by onset theme, with lower distress associated with length of exposure to and severity of symptoms. The Always Present onset category showed the lowest overall distress, followed by the Started Slowly category, the Suddenly category, and the Current category (Table 1). Respondents described this distress in the context of the psychotic experience, interpreted as internal when directly related to a distressing symptom and external when related to stigma/fear of stigma/other people. In this sample, $62 \%$ $(\mathrm{N}=93)$ described internal distress, $>1 \%(\mathrm{~N}=1)$ described external distress, $23 \%(\mathrm{~N}=35)$ described both, and $14 \%(\mathrm{~N}=21)$ did not discuss a distress source.

\section{Table 1 here}

In total, 12 commenters shared their age of initial symptom awareness in childhood ( $=7.75$ years $(S D=2.8)$ ) and 43 shared their age of awareness preceding the psychotic event ( $=16.34$ years $(S D=5.63))$. While the posted question was for 'people diagnosed with 
schizophrenia', most respondents interpreted this as 'people who have experienced psychosis'. 44 commenters provided their formal psychiatric diagnosis (Table 2), with only 13 diagnosed with 'schizophrenia' and many commenting their diagnosis had changed several times. Several respondents cited little confidence in the diagnostic process and overall confusion over shifting diagnoses over time.

Table 2 here

Comorbid mental health problems and other related issues were present in the sample. $10 \%(\mathrm{~N}=15)$ mentioned anxiety and $11.3 \%(\mathrm{~N}=17)$ mentioned depression. $4.7 \%$ $(\mathrm{N}=7)$ reported panic attacks, $6 \%(\mathrm{~N}=9)$ reported insomnia/sleep problems, and $7.3 \%(\mathrm{~N}=11)$ mentioned specific trauma with $1.3 \%(\mathrm{~N}=2)$ reporting PTSD as a comorbidity. $8.7 \%(\mathrm{~N}=13)$ reported increased stress/stressful environments directly preceding onset. $6 \%(\mathrm{~N}=9)$ recounted non-alcohol drugs use (cannabis $(N=4), \operatorname{LSD}(N=2)$, multiple $(N=2)$, other $(N=1))$. 4.6\% $(\mathrm{N}=7)$ stated they had made at least 1 suicide attempt. Those who reported these comorbidities cited them in a manner that inferred causality for the psychotic event.

\section{Symptomology}

\section{Auditory Hallucinations: "Hearing my dead best friend screaming for help from Hell."}

Auditory hallucinations were the most prevalent symptom with $56.7 \%(\mathrm{~N}=85)$ reporting hearing either voices $(48 \%, \mathrm{~N}=72)$, noises $(3.3 \%, \mathrm{~N}=5)$, both $(12.7 \%, \mathrm{~N}=19)$, or "things that weren't there" $(5.3 \%, \mathrm{~N}=8)$. Non-voice noises were mundane in nature (television/radio, music, static, footsteps, breathing, environmental sounds) and associated with lower distress. Voice hallucinations produced higher distress, moderated by age of 
onset. The theme of universal experience emerged in those with childhood onset as they assumed that their experience of hearing voices was common. This subset did not feel distress until symptomology evolved during adolescence. Several stated that because no one ever mentioned internal voices, they concluded it was an aspect of life simply not discussed.

23IUX: "I didn't think that the voices in my head were abnormal. I thought everyone had multiple voices in their heads."

69OWD: "I was terrified I would yell at them in public (I didn't know why, but that just wasn't something people did - at this point I still assumed everyone had other people in their heads)."

Several themes arose concerning voice personification and characteristics. Voice identity fell into three groups: 1) unknown voices, 2) friends or family, and 3) God, Satan, or angels/demons. Most described voices 'in their heads' but early childhood onset commenters also described voices coming from 'under the bed'. Superimposition of voice hallucinations over live conversation or television/radio also occurred and many experienced hearing someone call them from another room. While most reported single voices, some experienced multiple voices in chorus or cacophony. Voice content fell into coherent speech, mumbled/whispered gibberish, or repeated phrases. Voice characteristics were largely neutral as $29.1 \%(\mathrm{~N}=21)$ of the voices subsample reported negative characteristics versus $5.5 \%(\mathrm{~N}=4)$ positive. Voices espousing paranoid ideation were common but the commenter's perception of voice personality determined the voice's intent. Negative voices criticised, used vulgar language, and encouraged self-harm, suicide, 
and harm against friends/family. These voices were associated with high levels of distress, self-harm, and suicide attempts. Positive voices were described as helpful or a friend/companion. Voice hallucinations with established identity were salient, often resulting in the respondent viewing the experience as a relationship with the voice(s) and formation of delusional explanation around that relationship.

98II9: "I'm 19 and I've had "voices" for a long time like it will tell me to do stupid things like hit my hand against the wall really hard and that if I don't I'm weak."

69OWD: “I'd ask Him (God) questions and He'd give me answers. There was a sense of trust in that relationship; He was like a mentor."

\section{Visual Hallucinations: "Faces started appearing in my windows."}

Overall, $40 \%(\mathrm{~N}=60)$ of commenters reported visual hallucinations with $6.7 \%(\mathrm{~N}=10)$ seeing 'shadow people'. Hallucinations manifested as normal or abnormal phenomena, with 'normal' being anything expected in the given environment; people walking on the street, birds/animals in an outdoor setting, etc. Normal visual hallucinations were associated with lower distress. Abnormal phenomena included shadow people, orbs/lights, frightening or disgusting visions, shadows with impossible properties, patterns in object textures, or textures in motion.

KWP7V: "Some of them were in my peripheral vision, but I used to see hands snaking over the backs of furniture, like couches or beds. It would terrify me." 
Hallucinations in peripheral vision were common, as were occurrences before sleep or just after waking, though only one commenter mentioned a prior history of sleep paralysis. Frightening visions included demons, human/animal corpses, and supernatural creatures while disgusting visions included maggots, worms, parasites, and an instance of vivisection. Several commenters reported shadows with red eyes whose "physics seemed slightly off". Shadow people were often in motion, walking by doorways/windows, or following and lunging at the commenter. Some experienced visual hallucinations related to and reinforcing pre-existing delusions, and several described immersive, multi-modal hallucinations.

XOYYK: "The easiest way of describing it would be that my brain had changed channel from what I was seeing to something else entirely, but I was unaware of it until it changed back to what was actually in front of me."

Visual hallucinations often resulted in extensive reality-testing behaviours with the respondent unable to fully trust their senses, even during recovery periods.

\section{Paranoia: "There is always someone watching."}

When examined, $30 \%(\mathrm{~N}=45)$ of the sample reported paranoid ideation ( $\mathrm{PI}) . \mathrm{A}$ common theme was being the victim of the attentions of authority figures including parents, the police, or the government. Parents were accused of poisoning food/drink and co-opting confederates to watch/follow/record the individual. The police and government were assumed to be utilising unmarked cars to follow and record commenters, trying to harm them, 'gathering evidence', or employing snipers. 
95TEU: “Actions taken to protect myself from authority led to actions taken to protect myself because authority figures were trying to kill me.

UXDN6: "I would only drink bottled water because I thought the government put a canister on the water lines that was set to release chemicals when I would shower or use the sink."

Peers were implicated at a lesser level of authority. Friends were accused of conspiring, being false friends, talking/laughing behind a commenter's back, or being a paid catspaw of authority. Attempts to help were interpreted as threats, contributing to a lack of trust in others, especially mental health and medical professionals. The fear of being followed, watched, and recorded was pervasive even where no specific agent was identified. Several commenters engaged in complicated driving patterns to lose followers or carried weapons. There was a general sense that unnamed others were plotting against them, threatening physical harm, with television/radio cited as monitoring outlets as well as enabling communication between conspirators. Hidden cameras/microphones were a serious concern to some, often hidden in impossible locations.

EAHLL: "I "knew" where the cameras were. In vents, cracks in walls, old punctures from thumb tacs."

PJSDS: “I always feel like I’m being watch through tiny cameras everywhere (in door hinges, in outlets, in air vents, etc)."

\section{Delusions: "Hidden messages pertaining to me specifically."}


Resulted showed $30 \%(\mathrm{~N}=45)$ of commenters experienced delusions, occurring covalently with paranoia in 43 cases. $7.3 \%(\mathrm{~N}=11)$ reported religious (Judeo-Christian) delusions and $8 \%(\mathrm{~N}=12)$ that they received a special 'message' or 'pattern' to decode. Most described the delusional state as unpleasant with language use comparable to describing dreams/nightmares. Four commenters referenced the film 'The Truman Show', describing life as a simulation where every aspect was scripted and coordinated by an unknown authority towards an unknown goal. The concept of a 'mirror' reality with a decoy population was also prevalent. Many experienced ideas of reference and felt 'special' or 'chosen'. These thematic delusions created a feeling of enhanced perception and a drive to interpret hidden 'messages' for an overarching purpose. Some described their internal world of thoughts and motivations being made public by mind reading or television/radio broadcast. The schema of thought changed on a base level, taking on metaphysical qualities and altering perceptions of reality. Several commenters had insight to these aberrant thoughts but were unable to disengage.

FUK4H: "Then I started giving too much weight to ridiculous thoughts and ideas. Normally humans can dismiss stupid ideas like their thoughts are conspiring with the universe to give people cancer, or that everyone is conspiring against you." Q4NI3: "I suspected what was coming but when I finally had a psychotic break I still had no insight. I walked into the police station and asked to file a report about aliens mind controlling people at my work."

Religious delusions mainly focused on a relationship with God or fight against Satan. 
Fear of angering God and following His precepts to avoid 'punishment' factored into distress, as did fear of sin or temptation by Satan. Both were associated with protective ritualistic behaviour. Some experienced 'universal truth' delusions involving complex nonreligious philosophies.

NQ32L: "Seriously, my brain is an asshole, so it'd send prayers to Satan constantly, and I'd get locked in prayer battles for my poor immortal soul when I was still a kid. I covered my room with crosses. I kept holy water at my bedside."

\section{Minor Symptoms}

Several minor symptoms were present in the sample. $11.3 \%(\mathrm{~N}=17)$ reported disassociation/derealisation, $6 \%(\mathrm{~N}=9)$ reported memory/cognition issues as they approached the initial psychotic event, $4.7 \%(\mathrm{~N}=7)$ reported negative symptoms, and 3.3\% $(\mathrm{N}=5)$ spoke of extreme superstition/magical thinking. $5.3 \%(\mathrm{~N}=8)$ experienced tactile hallucinations and $2.7 \%(\mathrm{~N}=4)$ experienced olfactory hallucinations. $2 \%(\mathrm{~N}=3)$ shared that they had homicidal ideation during their psychotic state. 2 commenters described the synaesthesia effect of ordinal linguistic personification.

Insight

A majority of the sample discussed gaining insight in reference to their experiences. 41.3\% ( $N=62)$ cited self-realisation that what they were experiencing "wasn't right". $18.7 \%$ $(\mathrm{N}=28)$ reported retrospective insight after their breakdown. $16.7 \%(\mathrm{~N}=25)$ shared that another person granted them insight, and $19.3 \%(\mathrm{~N}=29)$ did not discuss it. Higher distress was associated with self-realization and hindsight over those brought insight by another. 
Many delayed disclosing their symptoms for months or even years and expressed regret for having done so. $4.6 \%(\mathrm{~N}=7)$ reported their parents not believing them or refusing them psychiatric treatment. Gaining insight was most meaningful to respondents as a representation of a dividing line between 'ill' and 'well', regardless of diagnosis or recovery process.

\section{Overall Interpretation of Psychosis}

Reflections of 'I tried to ignore it,' 'I knew something was wrong but was powerless' or 'it all made sense at the time' were common. Symptomology was interpreted to fit preexisting cultural values and interpreted through a cultural lens, especially during religious/'universal truth' delusions, AV hallucinations of the supernatural, and surveillance paranoia. 'Hindsight introspection' was common with many reporting being now able to identify and understand the process that preceded their breakdown, favouring lived experiences and environment over more delusional causal theories. Individual interpretation was ultimately a product of each commenter's personal qualia and many respondents explained this in detail in language tailored for general understanding. Though they were answering 'OP' (original poster), they wrote their comments as if addressing the population at large, seeking to clearly communicate these experiences and be understood. 19.3\% $(\mathrm{N}=29)$ expressed they were now 'in a better place' and $6 \%(\mathrm{~N}=9)$ offered encouragement to anyone who might be afraid to seek treatment. While some respondents included their recovery process and any relapses, this was ancillary to the main point of initial awareness of symptomology. 


\section{Discussion}

Sample

Much of the shared content was consistent with what we know from the extant research literature about those who have experienced psychosis or been diagnosed with schizophrenia. For example, reddit commenters were generally typical in comorbidities ${ }^{50,51}$, drugs use ${ }^{52}$, onset age $\mathrm{e}^{53,54}$, and minor symptomology ${ }^{55}$, with the exception of negative symptoms. Prevalent in prodromal/CHR psychosis ${ }^{56}$, negative symptoms are associated with poorer health outcomes ${ }^{57}$ and greater risk of psychosis progression ${ }^{58,59}$. The low prevalence of these symptoms in this sample seems to indicate a cohort better able to support the effort of posting online and finding the motivation to do so. Stress, trauma, and prior adverse experiences were identified as significant contributing factors ${ }^{51,60}$ to psychosis experience in this sample. Regarding suicidality, $4.6 \%$ of the sample described at least 1 suicide attempt, and this was largely consistent with the $5 \%$ prevalence rate that has been recorded in clinical populations ${ }^{61,62}$. Diagnostic variability due to diverse symptomology was also common, and may have reflected commonly reported confusion surrounding the 'accuracy', reliability, or validity of diagnoses of psychotic disorder ${ }^{63,64}$. Notably, while the reddit question referred to schizophrenia specifically, many in the sample opted to refer to psychosis more generally. In general, while there was limited demographic information available, a majority of reddit users are males in the $18-29$ age range ${ }^{45}$, a group with a higher overall prevalence of early psychosis ${ }^{65}$.

During the analysis, 4 distinct onset categories emerged, each differing by duration of symptom exposure and associated distress. It has been widely recognised that most psychotic-like experiences (PLE) are often non-distressing and often do not predict future 
psychopathology ${ }^{66}$. In this sample, it was notable that early subclinical experiences were associated with lower distress until symptom 'evolution' led to increased distress and psychosis development ${ }^{67,68}$. Shared histories included multiple examples of non-distressing subclinical phenomena, which were experienced in early life, but which later became problematic in adolescence and adulthood. It would seem that such accounts may afford useful insight and information for those interested in understanding transitions along the psychosis continuum or charged with early identification, support and treatment.

\section{Symptomology}

Specific auditory hallucination characteristics were framed in the context of commenters' associated distress ${ }^{69,70}$; i.e. non-voice sounds were often described as experiences that evoked lower levels of distress while negative voice hallucinations evoked highest levels ${ }^{71}$. References to early childhood auditory hallucinatory experiences were accompanied by explanations of unique schemas of assumed universality and were believed to be predictive of later psychopathology when persistent ${ }^{72,73}$. Voice hallucinations in this subset of commenters also became distressing as their symptoms evolved into adolescence alongside comorbid factors. The presence also of neutral and positive voices among the sample, and the notable absence of distress in their descriptions of these experiences, seemed to be consistent with the literature regarding the role that voice hallucination and personal interpretation ${ }^{74}$ plays in inducing distress and promoting symptom evolution. It was notable also that while those who hear voices have often been regarded as 'troubled' in the literature ${ }^{75}$ and while researchers often 'sort' individuals using a myriad of criteria, those in the current analysis displayed remarkable variation in auditory hallucinatory experience even within common themes. Respondents also shared their interpretation of 
voice characterisation and intent, showing a depth of introspection into the phenomena and voice aspects seen previously ${ }^{74}$, as similar themed content (advice, guidance) is found in positive, negative, and neutral voices and contextualised by the individual ${ }^{76}$. This finding warrants further focused study.

Visual hallucinations were referred to in two ways, normal and abnormal. Abnormal visual hallucinations (phenomena that included shadow people, orbs/lights, frightening or disgusting visions, shadows with impossible properties, patterns in object textures, or textures in motion) were associated with higher distress, particularly when the phenomenon was frightening, disgusting, or supernatural. These hallucinations also contributed to higher insight, which in turn amplified distress, as individuals interpreted their experiences as symptoms of an underlying mental illness. Normal hallucinations (which included anything expected in the given environment characterised by patterns and textures), factored into aberrant salience delusions of purpose. Diffuse in the general population 77,78 , visual hallucinations have been associated with higher levels of impairment ${ }^{79}$, and this was largely consistent with what was identified among the reddit sample. It is interesting to note that 'normal' hallucinations produced less distress as Líndal, Stefánsson, and Stefánsson found more 'normal' subclinical hallucinations in a general population sample compared with more 'abnormal' visions in a schizophrenic population ${ }^{80}$. Importantly, in most instances of visual hallucinations, commenters used 'not real' or 'not really there' to describe phenomena that were 'real' by nature of their experiencing it. Two levels of paranoid ideation emerged in this sample; being the target of an authority conspiracy or a peer network conspiracy. Both were associated with high distress and defensive/protective behaviours. According to the research literature, PI has been shown to vary along a spectrum in the general population ${ }^{81,82}$, with the nature and severity 
of beliefs forming specific interactions ${ }^{83}$. As an example, it might be regarded as 'normal' for a person to be concerned about the prevalence of CCTV cameras and well-known government monitoring programs. However, there was little mention of these in the sample; only cameras/devices in bizarre, impossible locations. Unspecified personal harm constituted a significant threat and was consistent with Freeman et al.'s paranoia hierarchy ${ }^{81}$. Notably, in this sample, a majority of respondents used the phrase 'out to get me' and described their conspirators' methods for achieving/pursuing persecution however they offered no causal theory/explanation for their status as someone who was a target of conspiracy/persecution. The metacognition of insight was key in respondents contextualising and understanding the experience of their paranoia, a finding similar to Stopa et al.'s exploration of implied threat and reaction in paranoia ${ }^{84}$.

Trends in delusions included ideas of reference, religious/'universal truth', aberrant salience of purpose ${ }^{85}$, and causation seeking. Delusions used as a primary explanation for experiences often led to ideas of reference in the 'hasty conclusions' model ${ }^{86}$. Notably, $95 \%$ of delusions in the reddit sample occurred covalently with paranoia. Many admitted knowing their delusional thoughts were abnormal but were unable to stop the progression of their psychotic episode. Cultural bias factored into delusion formation in the case of religious/'universal truth' delusions and social authority paranoia. Moreover, reinforcing the value of communication in personal interpretation, references to the 'Truman delusion' were a cultural touchstone allowing an individual to concisely describe their experiences and be instantly understood ${ }^{87,88}$. These 'Truman signs' ${ }^{89}$ (strangers are actors, environmental detachment, etc.) could be a valuable tool for clinicians in identifying delusional progression in $\mathrm{CRH}$ individuals. 


\section{Insight and Interpretation}

A significant portion of the sample (41.3\%) gained insight from self-realisation that their experiences were divorced from reality and an indication to seek professional help. In agreement with Perry et al.'s findings of 'normal' versus being 'out of touch'29, insight was perceived as the boundary area between psychosis and wellness. Evidence suggests that insight is positively correlated with better health outcomes ${ }^{90}$ but in the current analysis it was associated with higher distress ${ }^{91,92,93}$, and was a predictor of help-seeking behaviour with internalised stigma ${ }^{94}$ that in turn influenced a varying DUP. Most respondents reported internal distress (85\%) and many experienced external distress (14.6\%) due to stigma or fear of being stigmatised. Insight must be present for self-acceptance, which can be beneficial in recovery ${ }^{95}$, but also means increased awareness of stigma ${ }^{96}$ and further reduces emotional well-being and quality of life ${ }^{97}$. Fear of stigma was frequently mentioned with concerns over self-other perceptions mirroring the superordinate themes of judgement and personal comparison found by Knight, Wykes, \& Hayward ${ }^{98}$. Many commenters expressed regret on not seeking help sooner, though they did not provide a reason for their silence/inaction. Experiences of symptomology insight and outside involvement were largely consistent with Yung and McGorry's prodromal progression model1 through first intervention.

Interpretation and causation seeking ${ }^{99}$ often reflected automatic processes for commenters and seemed to promote self-preservation ${ }^{100}$ with explanation facilitating hindsight acceptance ${ }^{101}$. Lived experience also directly influenced interpretation, and seemed to form a feedback continuum as symptoms evolved. $\underline{\text { A majority of commenters }}$ who shared their causal theories cited adverse life events, stress, and comorbid anxiety and depression reflecting psychosocial and biogenic beliefs in line with Carter's findings ${ }^{99}$. 
Citing these factors, generally considered by This was also largely consistent with the broad literature as factors potentially associated with demonstrating that life events factor into psychosis progression ${ }^{102}=$, over pseudoscience or delusional causal models, demonstrates reality-based insight. A majority of commenters who shared their causal theories cited adverse life events, stress, and comorbid anxiety and depression reflecting psychosocial and biogenic beliefs in line with Carter's findings ${ }^{99}{ }^{9}$.Focus on familial mental illness and trauma history was prevalent among females in Ben-David's study of the subjective experiences of $\mathrm{CRH}$ youth ${ }^{103}$, though gender was largely unknown in this population, generating the need for further research into a potential gender effect in causal theories. Isolating and exploring personal meaning in psychosis has proven beneficial ${ }^{104}$ and the commenters in this sample were eager to share. Many respondents referenced learning to 'ignore' or 'control' lesser symptomology, indicating that this aspect of recovery granted them agency ${ }^{104}$ and resulted in higher self-efficacy during their recovery.

\section{Hindsight Introspection}

The data harvested for this study was retrospective and hindsight bias ${ }^{105}$ is a significant concern in any research. However, the hindsight introspection of respondents here is valuable and comparable to introspection performed during therapy. Obviously, it is reasonable to expect an individual who has experienced psychosis symptoms, in describing the same phenomena experienced at an earlier age, to ascribe those symptoms to psychosis. Clinicians and researchers familiar with prodromal and progression models will recognise such features in the data, confirming the potentially biased assertions of the respondents concerning early experiences. Hindsight introspection into psychosis causation 
exposed multiple instances of trauma, parents with significant mental illnesses, and substance abuse catalysts which align with contemporary contributory theories ${ }^{51,52,106}$.

\section{Limitations}

The results of this study must be taken in light of its limitations. While the medium of the reddit website does encourage sharing, there was no opportunity for clarification or follow-up questions. The anonymity of reddit did prompt commenters to speak without fear of stigma or social repercussions but also meant little demographic or standard measure information was available, limiting some aspects of analysis. As this was a single question and not a structured interview, the only data available for analysis is that which respondents chose to share, meaning the possibility of additional variables/symptoms/environments that went unmentioned. Finally, this was an opportunity sample and the analysis conducted was exploratory as the research question was not part of a planned methodological design.

\section{Conclusions}

This study dealt with trends and key themes in a large qualitative sample to establish a viable framework for further in-depth analysis of this dataset. With this framework in place, work on follow-up studies with this data can begin, covering a variety of issues. The above findings warrant examination into early childhood subclinical experience interpretation, the distress delta between sound and voice hallucinations, power dynamics in paranoia, aberrant salience in 'purpose' delusions, limited-insight prodromal progression, and specific causal interpretations. Symptoms were separated here for preliminary analysis and follow-up studies into relationships and interactions between symptoms, distress, and personal interpretation are forthcoming. As large qualitative studies are costly and time- 
consuming, access to this resource can illuminate lived experiences of initial psychosis awareness, benefitting both the individual service user and wider population. The implications for early intervention and therapeutic treatment are clear, with personal contextualisation of experiences shown to have a beneficial effect on young CHR individuals ${ }^{26,107}$. While the last vestiges of psychology's history transition into a model for mental well-being, the individual must continue to take priority. Research informs paradigm and policy alike but in this study, the best method to understand the initial awareness of psychosis was simply to ask.

Conflict of interest statement:

On behalf of all authors, the corresponding author states that there is no conflict of interest. 


\section{References}

1. Yung AR, McGorry PD. The prodromal phase of first-episode psychosis: past and current conceptualizations. Schizophr Bull. 1996;22:353-70.

2. Menezes NM, Arenovich T, Zipursky RB. A systematic review of longitudinal outcome studies of first-episode psychosis. Psychol Med. 2006;36:1349-62.

3. McGorry PD, Nelson B, Amminger GP, Bechdolf, A, Francey SM, Berger G, et al. Intervention in individuals at ultra-high risk for psychosis: a review and future directions. J Clin Psychiatry. 2009;70:1206-12.

4. Yung AR, Nelson B, Stanford C, Simmons MB, Cosgrave EM, Killackey E, et al. Validation of "prodromal" criteria to detect individuals at ultra high risk of psychosis: 2 year follow-up. Schizophr Res. 2008;105:10-17.

5. Addington J, Penn D, Woods SW, Addington D, Perkins DO. Social functioning in individuals at clinical high risk for psychosis. Schizophr Res. 2008;99:119-24.

6. Cannon TD, Cadenhead K, Cornblatt B, Woods SW, Addington J, Wakler E, et al. Prediction of psychosis in youth at high clinical risk: A multisite longitudinal study in North America. Arch Gen Psychiatry. 2008;65:28-37.

7. Marshall M, Lewis S, Lockwood A, Drake R, Jones P, Croudace T. Association between duration of untreated psychosis and outcome in cohorts of first-episode patients: $A$ systematic review. Arch Gen Psychiatry. 2005;62:975-83.

8. Baldwin P, Browne D, Scully PJ, Quinn JF, Morgan MG, Kinsella A, et al. Epidemiology of first-episode psychosis: Illustrating the challenges across diagnostic boundaries through the Cavan-Monaghan Study at 8 years. Schizophr Bull. 2005;31:624-38.

9. Morgan C, Dazzan P, Morgan K, Jones P, Harrison G, Leff J, et al. First episode psychosis and ethnicity: Initial findings from the AESOP study. World Psychiatry. 2006;5:40-6.

10. Craig TKJ, Garety P, Power P, Rahaman N, Colbert S, Fornells-Ambrojo M, et al. The Lambeth Early Onset (LEO) Team: Randomised controlled trial of the effectiveness of specialized care for early psychosis. BMJ. 2004;329:1067.

11. van Os J, Hanssen M, Bijl RV, Ravelli A. Strauss (1969) revisited: A psychosis continuum in the general population? Schizophr Res. 2000;45:11-20.

12. Linscott RJ, van Os J. An updated and conservative systematic review and meta-analysis of epidemiological evidence on psychotic experiences in children and adults: On the pathway from proneness to persistence to dimensional expression across mental disorders. Psychol Med. 2013;43:1133-49. 
13. McGorry PD, Yung AR, Phillips LJ, Yuen HP, Francey S, Cosgrave EM, et al. Randomized controlled trial of interventions designed to reduce the risk of progression to firstepisode psychosis in a clinical sample with subthreshold symptoms. Arch Gen Psychiatry. 2002;59:921-8.

14. Alvarez-Jiménez M, Parker AG, Hetrick SE, McGorry PD, Gleeson J F. Preventing the second episode: a systematic review and meta-analysis of psychosocial and pharmacological trials in first-episode psychosis. Schizophr Bull. 2009;37:619-30.

15. Singh SP, Grange T. Measuring pathways to care in first-episode psychosis: a systematic review. Schizophr Res. 2006;81:75-82.

16. Anderson KK, Fuhrer R, Malla AK. The pathways to mental health care of first-episode psychosis patients: a systematic review. Psychol Med. 2010;40:1585-97.

17. Zhang JP, Gallego JA, Robinson DG, Malhotra AK, Kane JM, Correll CU. Efficacy and safety of individual second-generation vs. first-generation antipsychotics in firstepisode psychosis: a systematic review and meta-analysis. Int J Neuropsychopharmacol. 2013;16:1205-18.

18. Bozikas VP, Andreou C. Longitudinal studies of cognition in first episode psychosis: A systematic review of the literature. Aust N Z J Psychiatry. 2011;45:93-108.

19. Mesholam-Gately RI, Giuliano AJ, Goff KP, Faraone SV, Seidman LJ. Neurocognition in first-episode schizophrenia: A meta-analytic review. Neuropsychology. 2009;23:315-36.

20. Steen RG, Mull C, McClure R, Hamer RM, Lieberman JA. Brain volume in first-episode schizophrenia: Systematic review and meta-analysis of magnetic resonance imaging studies. Br J Psychiatry. 2006;188:510-18.

21. Borges S, Gayer-Anderson C, Mondelli V. A systematic review of the activity of the hypothalamic-pituitary-adrenal axis in first episode psychosis.

Psychoneuroendocrinology. 2013;38:603-11.

22. MacBeth A, Gumley A. Premorbid adjustment, symptom development and quality of life in first episode psychosis: a systematic review and critical reappraisal. Acta Psychiatr Scan. 2008;117:85-99.

23. Pompili M, Serafini G, Innamorati M, Lester D, Shrivastava A, Girardi P, et al. Suicide risk in first episode psychosis: A selective review of the current literature. Schizophr Res. 2011;129:1-11.

24. Hoy K, Barrett S, Shannon C, Campbell C, Watson D, Rushe T, et al. Childhood trauma and hippocampal and amygdalar volumes in first-episode psychosis. Schizophr Bull. 2011;38:1162-9. 
25. Aas M, Navari S, Gibbs A, Mondelli V, Fisher HL, Morgan C, et al. Is there a link between childhood trauma, cognition, and amygdala and hippocampus volume in firstepisode psychosis? Schizophr Res. 2012;137:73-9.

26. Boydell KM, Stasiulis E, Volpe T, Gladstone B. A descriptive review of qualitative studies in first episode psychosis. Early Interv Psychiatry. 2010;4:7-24.

27. Corcoran C, Davidson L, Sills-Shahar R, Nickou C, MalaspinaD, McGlashan T. A qualitative research study of the evolution of symptoms in individuals identified as prodromal to psychosis. Psychiatr Q. 2003;4:313-32.

28. Moller $P$, Husby R. The initial prodrome in schizophrenia: Searching for naturalistic core dimensions of experience and behaviour. Schizophr Bull. 2000;26:217-32.

29. Perry BM, Taylor D, Shaw SK. 'You've got to have a positive state of mind': An interpretive phenomenological analysis of hope and first episode psychosis. J Ment Health. 2007;16:781-93.

30. Fisher A, Savin-Baden M. The benefits to young people experiencing psychosis, and their families, of an early intervention programme: Evaluating a service from the consumers' and the providers' perspectives. Br J Occup Ther. 2001;64:58-65.

31. Larsen JA. Understanding a complex intervention: person-centred ethnography in early psychosis. J Ment Health. 2007;16:333-45.

32. O'Toole MS, Ohlsen RI, Taylor TM, Walters J, Pilowsky LS. Treating first episode psychosis - the service users' perspective: A focus group evaluation. J Psychiatr Ment Health Nurs. 2004;11:319-26.

33. Bergner E, Leiner AS, Carter T, Franz L, Thompson NJ, Compton MT. The period of untreated psychosis before treatment initiation: A qualitative study of family members' perspectives. Compr Psychiatry. 2008;49:530-6.

34. Boydell KM, Gladstone BM, Volpe T. Understanding help seeking delay in the prodrome to first episode psychosis: A secondary analysis of the perspectives of young people. Psychiatr Rehabil J. 2006;30:54-60.

35. Corcoran C. Trajectory to a first episode of psychosis: A qualitative research study with families. Early Interv Psychiatry. 2007;1:54-60.

36. Gladstone B, Volpe T, Boydell K. Issues encountered in a qualitative secondary analysis of help-seeking in the prodrome to psychosis. J Behav Health Serv Res. 2007;34:43142.

37. Mackrell L, Lavender T. Peer relationships in adolescents experiencing a first episode of psychosis. J Ment Health. 2004;13:467-79. 
38. Woodside H, Krupa T, Pocock K. How people negotiate for success as psychosis emerges. Early Interv Psychiatry. 2008;2:50-4.

39. Haslam N. Bias in psychopathology research. Curr Opinion Psychiatry. 2006;19:625-630.

40. Garb HN. (1998). Studying the clinician: Judgment research and psychological assessment. Washington, DC, US: American Psychological Association; 1998.

41. Alexa Internet Inc. Reddit.com Web Traffic Statistics [Internet]. Alexa c1996-2018 [cited 2017 Nov 25]. Available from: https://www.alexa.com/siteinfo/reddit.com.

42. Griffiths $M$. The use of online methodologies in data collection for gambling and gambling addictions. Int J Ment Health Addiction, 2009;8:8-20.

43. Schrank B, Klose T, Szmukler G, Lloyd K, Koivunen M. How patients with schizophrenia use the Internet: Qualitative study. J Med Internet Res. 2010;12:e70.

44. Haahr M. True Random Number Service [Internet]. Random Org c1998-2018 [cited 2017 Nov 25]. Available from: https://www.random.org/.

45. Mediakix. The Top 8 Reddit Statistics On Uusers, Demographics \& More [Internet]. Mediakix Team c2016. [cited 2017 Nov 25]. Available from: http://mediakix.com/2017/09/reddit-statistics-users-demographics/.

46. Smith J, Jarman M, Osborn M. Doing Interpretative Phenomenological Analysis. In Murray M, Chamberlin K, eds. Qualitative Health Psychology. Thousand Oaks, California, US: Sage; 1999: 218-40.

47. Gill J. The possibilities of phenomenology for organizational research. Organ Res Meth. 2014;17:118-37.

48. Pietkiewicz I, Smith J. A practical guide to using Interpretative Phenomenological Analysis in qualitative research psychology. C Psychologic. 2012;18:361-9.

49. Knight M, Wykes T, Hayward P. 'People don't understand': An investigation of stigma in schizophrenia using Interpretative Phenomenological Analysis (IPA). J Ment Health. 2003;12:209-22.

50. Hanssen M, Peeters F, Krabbendam L, Radstake S, Verdoux H, van Os J. How psychotic are individuals with non-psychotic disorders? Soc Psychiatry Psychiatr Epidemiol. 2003;38:149-54.

51. Read J, van Os J, Morrison A, Ross C. Childhood trauma, psychosis and schizophrenia: A literature review with theoretical and clinical implications. Acta Psychiatr Scan. 2005;112:330-50. 
52. Moore T, Zammit S, Lingford-Hughes A, et al. Cannabis use and risk of psychotic or affective mental health outcomes: A systematic review. Lancet. 2007;370:319-28.

53. Häfner N, Maurer K, Löffler W, Fätenheuer B, an der Heiden W, Riecher-Rössler A, et al. The epidemiology of early schizophrenia: Influence of age and gender on onset and early course. Br J Psychiatry Suppl. 1994;164:29-38.

54. Schultze-Lutter F, Michel C, Ruhrmann S, Schimmelmann B. Prevalence and clinical significance of DSM-5-attenuated psychosis syndrome in adolescents and young adults in the general population: The Bern Epidemiological At-Risk (BEAR) study. Schizophr Bull. 2014;40:1499-1508.

55. Kendler K, Gallagher T, Abelson J, Kessler R. Lifetime prevalence, demographic risk factors, and diagnostic validity of nonaffective psychosis as assessed in a US community sample: The National Comorbidity Survey. Arch Gen Psychiatry. 1996;53:1022-31.

56. Bobes J, Arango C, Garcia-Garcia M, Rejas J, CLAMORS Study Collaborative Group. Prevalence of negative symptoms in outpatients with schizophrenia spectrum disorders treated with antipsychotics in routine clinical practice: Findings from the CLAMORS study. J Clin Psychiatry. 2010;71:280-6.

57. Häfner H, Löffler W, Maurer K, Hambrect $M$, an der Heiden W. Depression, negative symptoms, social stagnation and social decline in the early course of schizophrenia. Acta Psychiatr Scan. 1999;100:105-18.

58. Verdoux $\mathrm{H}$, van Os J. Psychotic symptoms in non-clinical populations and the continuum of psychosis. Schizophr Res. 2002;54:59-65.

59. Piskulic D, Addington J, Cadenhead K, Cannon T, Cornblatt B, Heinssen R, et al. Negative symptoms in individuals at clinical high risk of psychosis. Psychiatry Res. 2012;2:2204.

60. Read J, Bentall R, Fosse R Time to abandon the bio-bio-bio model of psychosis: Exploring the epigenetic and psychological mechanisms by which adverse life events lead to psychotic symptoms. Epidemiol Psichiatr Soc. 2009;18:299-310.

61. Palmer B, Pankratz S, Bostwick J. The lifetime risk of suicide in schizophrenia: A reexamination. Arch Gen Psychiatry. 2005;62:247-53.

62. Hor K, Taylor M. Suicide and schizophrenia: A systematic review of rates and risk factors. J Psychopharmacol. 2010;24:81-90.

63. Cooke A, Kinderman P. "But what about real mental illnesses?" Alternatives to the disease model approach to "schizophrenia". J Human Psychol. 2018;58:47-71. 
64. Jablensky A. Psychiatric classifications: validity and utility. World Psychiatry, 2016;15:2631.

65. Häfner H, Maurer K, Löffler W, Riecher-Rössler A. The influence of age and sex on the onset and early course of schizophrenia. B J Psychiatry. 1993;162:80-6.

66. van Os J, Linscott R, Myin-Germeys I, Delespaul P, Krabbendam L. A systematic review and meta-analysis of the psychosis continuum: Evidence for a psychosis pronenesspersistence-impairment model of psychotic disorder. Psychol Med. 2009;39:179-95.

67. Dominguez $\mathrm{M}$, Wichers $\mathrm{M}$, Lieb R, Wittchen $\mathrm{H}-\mathrm{U}$, van Os J. Evidence that onset of clinical psychosis is an outcome of progressively more persistent subclinical psychotic experiences: An 8-year cohort study. Schizophr Bull. 2011;37:84-93.

68. Murphy J, McBride O, Fried E, Shevlin M. Distress, impairment and the extended psychosis phenotype: A network analysis of psychotic experiences in an US general population sample. Schizophr Bull. 2017;sbx134.

69. Nayani T, David A. The auditory hallucination: A phenomenological survey. Psychol Med. 1996;26:177-89

70. Mawson A, Cohen K, Berry K. Reviewing evidence for the cognitive model of auditory hallucinations: The relationship between cognitive voice appraisals and distress during psychosis. Clin Psychol Rev. 2010;30:248-58.

71. Wong Z, Öngür D, Cohen B, Ravichandran C, Noam G, Murphy B. Command hallucinations and clinical characteristics of suicidality in patients with psychotic spectrum disorders. Compr Psychiatry. 2013;54:611-7.

72. Bartels-Velthuis A, van de Willige G, Jenner J, van Os J, Wiersma D. Course of auditory vocal hallucinations in childhood: 5-year follow-up study. Br J Psychiatry. 2011;199:296-302.

73. Bartels-Velthuis A, van de Willige G, Jenner J, van Os J. Auditory hallucinations in childhood: Associations with adversity and delusional ideation. Psychol Med. 2012;42:583-93.

74. Woods A, Jones N, Alderson-Day B, Callard F, Fernyhough C. Experiences of hearing voices: Analysis of a novel phenomenological survey. Lancet Psychiatry. 2015;2:32331.

75. Link BG, Phelan JC, Bresnahan M, Stueve A, Pescosolido BA. Public conceptions of mental illness: labels, causes, dangerousness, and social distance. Am J Pub Health. 1999;89:1328-33. 
76. Beaven V, Read J. Hearing voices and listening to what they say: The importance of voice content in understanding and working with distressing voices. J Nerv Ment Dis. 2010;198:201-5.

77. Bentall R. The illusion of reality: A review and integration of psychological research on hallucinations. Psychol Bull. 1990;107:82-95.

78. Ohayon M. Prevalence of hallucinations and their pathological associations in the general population. Psychiatry Res. 2000;97:153-64.

79. David C, Greenstein D, Clasen L, Gochman P, Miller R, Tossell JW, et al. Childhood onset schizophrenia: High rate of visual hallucinations. J Am Acad Child Adolesc Psychiatry. 2011;50:681-6.

80. Líndal E, Stefánsson JG, Stefánsson SB. The qualitative difference of visions and visual hallucinations: A comparison of a general-population and clinical sample. Compr Psychiatry. 1994;35:405-8.

81. Freeman D, Garety P, Bebbington P, Smith B, Rollinson R, Fowler D, et al. Psychological investigation of the structure of paranoia in a non-clinical population. Br J Psychiatry. 2005;186:427-35.

82. Freeman D, McManus S, Brugha T, Meltzer $\mathrm{H}$, Jenkins R, Bebbington P. Concomitants of paranoia in the general population. Psychol Med. 2011;41:923-36.

83. Bebbington $P$, McBride O, Steel C, Kuipers E, Radovanovic M, Brugha T, et al. The structure of paranoia in the general population. Br J Psychiatry. 2013;202:419-27.

84. Stopa L, Denton R, Wingfield M, Newman Taylor K. The fear of others: A qualitative analysis of interpersonal threat in social phobia and paranoia. Behav Cogn Psychother. 2013;41:188-209.

85. Kapur S. Psychosis as a state of aberrant salience: A framework linking biology, phenomenology, and pharmacology in schizophrenia. Am J Psychiatry. 2003;160:1323.

86. Freeman D, Garety P, Fowler D, Kuipers E, Bebbington P, Dunn G. Why do people with delusions fail to choose more realistic explanations for their experiences? An empirical investigation. J Consult Clin Psychol. 2004;72:671-80.

87. Gold J, Gold I. The "Truman Show" delusion: Psychosis in the global village. Cogn Neuropsychiatry. 2012;17:455-72.

88. Mishara A, Fusar-Poli P. The phenomenology and neurobiology of delusion formation during psychosis onset: Jaspers, Truman symptoms, and aberrant salience. Schizophr Bull. 2013;39:278-86. 
89. Fusar-Poli $P$, Howes $O$, Valmaggia L, McGuire P. 'Truman' signs and vulnerability to psychosis. B J Psychiatr. 2008;193:168.

90. Lincoln T, Lüllmann E, Rief W. Correlates and long-term consequences of poor insight in patients with schizophrenia: A systematic review. Schizophr Bull. 2007;33:1324-42.

91. Cooke M, Peters E, Fannon D, Anilkumar A, Aasen I, Kuipers E, et al. Insight, distress and coping styles in schizophrenia. Schizophr Res. 2007;94:12-22.

92. Cooke M, Peters E, Fannon D, Aasen I, Kuipers E, Kumari V. Cognitive insight in psychosis: The relationship between self-certainty and self-reflection dimensions and neuropsychological measures. Psychiatry Res. 2010;178:284-9.

93. Peters E, Lataster T, Greenwood K, Kuipers E, Williams S, et al. Appraisals, psychotic symptoms and affect in daily life. Psychol Med. 2011;42:1013-23.

94. Lysaker P, Roe D, Yanos P. Toward understanding the insight paradox: internalized stigma moderates the association between insight and social functioning, hope, and self-esteem among people with schizophrenia spectrum disorders. Schizophr Bull. 2007;33:192-9.

95. Waite F, Knight M, Lee D. Self-compassion and self-criticism in recovery in psychosis: An interpretative phenomenological analysis study. J Clin Psychol. 2015;71:1201-17.

96. Pyle M, Morrison A. "It's just a very taboo and secretive kind of thing": Making sense of living with stigma and discrimination from accounts of people with psychosis. Psychosis. 2014;6:195-205.

97. Hasson-Ohayon I, Kravetz S, Roe D, David A, Weiser M. Insight into psychosis and quality of life. Compr Psychiatry. 2006;46:265-9.

98. Knight MTD, Wykes T, Hayward P. 'People don't understand': An investigation of stigma in schizophrenia using Interpretative Phenomenological Analysis (IPA). J Ment Health. 2003;12:209-22.

99. Carter L, Read J, Pyle M, Morrison A. The impact of causal explanations on outcome in people experiencing psychosis: A systematic review. Clin Psychol Psychother. 2017;24:332-47.

100. Larsen J. Finding meaning in first episode psychosis: Experience, agency, and the cultural repertoire. Med Anthropol Q. 2004;18:447-71.

101. Heriot-Maitland C, Knight M, Peters E. A qualitative comparison of psychotic-like phenomena in clinical and non-clinical populations. Br J Clin Psychol. 2012;51:37-53.

102. Read J, Dillon J. Models of Madness: Psychological, Social and Biological Approaches to Psychosis. London, United Kingdom: Routledge; 2013. 249-268. 
103. Ben-David S, Birnbaum M, Eilenberg M, DeVylder J, Gill K, Schienle J, et al. The subjective experience of youths at clinical high risk for psychosis: A qualitative study. Psychiatr Serv. 2014;65:1499-1501.

104. Windell D, Norman R, Lal S, Malla A. Subjective experiences of illness recovery in individuals treated for first-episode psychosis. Soc Psychiatry Psychiatr Epidemiol. 2015;50:1069-77.

105. Fischhoff B, Beyth R. I knew it would happen: Remembered probabilities of oncefuture things. Org Behav Hum Perform. 1975;13:1-16.

106. Rasic D, Hajek T, Alda M, Uher R. Risk of mental illness in offspring of parents with schizophrenia, bipolar disorder, and major depressive disorder: a meta-analysis of family high-risk studies. Schizophr Bull. 2014;40:28-38.

107. Byrne R, Morrison AP. Young people at risk of psychosis: a user-led exploration of interpersonal relationships and communication of psychological difficulties. Early Interv Psychiatry. 2010;4:162-8. 
'Something wasn't quite right': a novel phenomenological analysis of internet discussion posts detailing initial awareness of psychosis

\author{
Amanda Spikol and Jamie Murphy* \\ School of Psychology, Ulster University, Northern Ireland
}

*Corresponding Author:

Professor Jamie Murphy

School of Psychology

Ulster University

Derry

Northern Ireland

BT48 7JL

Telephone: +44 (0) 2871375283

Email: ja.murphy@ulster.ac.uk
Text body word count: 4612

Table count: 2 


\section{Abstract}

INTRODUCTION: A significant number of psychosis studies have focussed on and have attempted to model and frame the earliest psychosis experiences. Using a wide array of methodologies and targeting a variety of 'at risk' groups, researchers have offered much to inform our treatment responses, and understanding of psychosis onset and development. OBJECTIVES: Due to the nature of scientific investigation however and investigator led exploration, those who experience psychosis are rarely afforded ultimate free rein to dictate and direct the exchange of information or to impose their unique narrative on that which is being explored. In an attempt to address this, the current study opportunistically harvested rich self-report data from replies to the question, "People that have been diagnosed with schizophrenia, what was the first time you noticed something wasn't quite right?" on the internet discussion forum Reddit.com.

METHODS: User data was analysed using Interpretive Phenomenological Analysis to identify key themes in participants' first experiences and initial awareness of psychosis.

RESULTS: While respondents varied widely in their recounted experiences and chose to describe these experiences in a variety of ways, analysis showed that (i) respondent distress was associated with psychosis onset timeframe, negative-voice auditory hallucinations, visual hallucinations, paranoid delusions, and insight (ii) early childhood psychosis experience resulted in novel explanatory schemas and psychosis/distress progression with contributory factors in adolescence and (iii) $41.3 \%$ of the sample reported self-realisation in gaining insight and greater insight was associated with help-seeking behaviour.

CONCLUSIONS: This novel use of publically shared experiential data might enrich our existing qualitative literature concerning early psychosis. 
Key words: early psychosis, social media, interpretative phenomenological analysis, first episode psychosis; premorbid adjustment 


\section{Introduction}

Early psychosis receives significant attention in the research literature.

Understandably, information, knowledge and clarity about the earliest signs and signals of psychotic experience afford valuable opportunities to inform and achieve successful early intervention and support. They also afford valuable opportunities to understand psychosis onset and development and the aetiological landscape that underpins such experiences. A variety of literatures have attempted to model and frame early psychosis; prodromal studies $^{1}$, first episode psychosis (FEP) studies ${ }^{2}$, ultra-high-risk (UHR) studies ${ }^{3,4}$, clinical-highrisk (CHR) studies ${ }^{5,6}$, duration of untreated psychosis (DUP) studies ${ }^{7}$, first treatment contact studies $^{8,9,10}$, continuum studies and those investigating subclinical/psychosis-like experiences (PLEs) and/or schizotypal traits ${ }^{11,12}$, each attempt to capture the earliest manifestations and expressions of psychosis in the population.

These studies in turn have afforded valuable opportunities to investigate many important clinical issues surrounding early psychosis such as e.g. the reduction of risk for FEP $^{13}$, the prevention of second episodes ${ }^{14}$, pathways to care from FEP ${ }^{15,16}$, the efficacy and safety of psychopharmacological intervention in early psychosis ${ }^{17}, \operatorname{cog}$ nition and neural functioning in early psychosis ${ }^{18,19,20,21}$, premorbid adjustment, symptom development and quality of life in early psychosis ${ }^{22}$, suicide risk ${ }^{23}$, and the environmental context of early psychosis $^{24,25}$.

Our framing and operationalisation of early psychosis however has also been significantly informed by rich qualitative evidence detailing the lived experiences of those who have directly encountered and endured psychosis ${ }^{26}$. Multiple qualitative studies 
detailing e.g. the subjective experience of $\mathrm{FEP}^{27-29}$, service user views on early intervention ${ }^{30-32}$, early experiences of help seeking ${ }^{33-36}$, and issues surrounding social relationships in early psychosis ${ }^{37,38}$, have afforded invaluable insights into the personal experiences of individuals, their families and service providers.

Importantly however, much of the evidence we rely upon (both quantitative and qualitative) to inform our understanding of early psychosis, may be somewhat constrained by unavoidable researcher bias ${ }^{39,40}$. Researcher selected methodologies, researcher designed interview schedules, researcher formulated terminology, and general researcher driven enquiry may ultimately limit our understanding of early psychosis. Because researchers frame, direct and focus research, those under investigation must provide information in a manner that conforms to and is consistent with the imposed investigatory framework. Rarely are those who are under investigation afforded ultimate free rein to dictate and direct the exchange of information or to impose their unique narrative on that which is being explored.

The current study, in an attempt to explore early psychosis without the constraints of researcher design bias, opportunistically harvested rich internet discussion content linked to an AskReddit post enquiring about first experiences of psychosis. Given the absence of researcher definition, instruction or clarification regarding e.g. terminology, phenomenology, or time; the freedom to attend to and comment on any aspect of experience; and the anonymity of disclosure, we aimed to (i) more objectively examine the lived experiences and interpretations of those recounting early psychosis, (ii) enrich existing qualitative literature concerning early psychosis, and (iii) establish a coded analytic framework to support further in-depth analysis of this rich data resource. 


\section{Methods}

Medium

Data for this study was sourced from the Internet discussion site reddit

(www.reddit.com), specifically the sub-forum AskReddit (www.reddit.com/r/askreddit/).

Reddit has approximately 542 million monthly visitors and is ranked the 8th most visited site on the global Internet and 4th in the US ${ }^{41}$. AskReddit, with approximately 18.4 million subscribers, is a sub-forum where any user may post a question for general advice, openended discussion, or lived experience. Users may reply to the question or to other users' replies. Forum rules forbid posting identifying information and users post under a chosen username or create a one-use 'throwaway' account. Users may vote on comments as part of a wider 'karma' system. 'Up-votes' contribute to karma while 'down-votes' take from it, with 'up-votes' generally taken as agreement with the comment or as an expression of respect for or empathy with the poster.

Griffiths ${ }^{42}$ cites several factors supporting Internet collected qualitative data; easy access to wider recruitment, a potential global sample population, cost-effectiveness, reduction in social desirability, data in common digital formats, and accessibility for those uncomfortable with in-person participation. This allows a vulnerable population complete control over their environment and comfort level, avoiding social pressures and self-stigma. Evidence suggests individuals with schizophrenia exhibit Internet use behaviour comparable to a non-clinical sample ${ }^{43}$, incurring no additional risks participating in online research. In this study, reddit users were free to ignore the posed question, thus those who commented truly wanted to share their experiences. 
Sample

At 19:37 GMT on 13 November 2017, a reddit user posted the question “People that have been diagnosed with schizophrenia, what was the first time you noticed something wasn't quite right?" to AskReddit. The user was not a mental health professional using clinical language nor a researcher engaged in hypothesis testing; they were an individual curious about others' experiences. This post carried a [Serious] tag, indicating off-topic or joke replies would be deleted by the moderation team. 4565 users commented, either responding directly or in nested comment threads. The post was sorted by 'top comments' by up-vote and the top 150 replies sourced. Nested comment threads were ignored. Data use permission was granted by the moderation team of AskReddit. Comments were copied without usernames and assigned a 5 character alphanumeric ID as provided by the random sequence generator at random. $\mathrm{org}^{44}$. This sample was comprised of reddit users with English fluency who felt their experiences matched the posted question. Reddit terms of service prohibit users < age 13, yielding an approximate age range of 13-90+. 43 individuals provided their age of initial psychosis awareness, showing a range of 7.5-32 years and mean age of $16.34(S D=5.63)$. User demographic information is not required for posting nor made public; therefore, gender, ethnicity and demographic factors were unknown unless a user chose to share that information, though $56 \%$ of reddit users are American, $69 \%$ are male, and $58 \%$ are in the $18-29$ age range ${ }^{45}$ (REFERENCE: Mediakix). Sample homogeneity was the experience of psychosis.

\section{Measures}


The question posed was a request for lived experience by the original poster and the only measure utilised.

\section{Analysis}

Interpretive phenomenological analysis (IPA) is a method of qualitative review focusing on the individual's interpretation of their experiences ${ }^{456}$. IPA differs from other qualitative methods in its combination of philosophies, blending interpretation with psychological and ideographic analysis ${ }^{467}$. The researcher puts aside preconceived notions to review the data in a 'bottom-up' method of thematic coding, generating emergent themes rather than testing pre-existing theories $\stackrel{478}{ } .47$ IPA is usually performed in a focus group or semi structured interview but can be performed with secondary data in larger samples. IPA use in psychosis research has produced "contextually rich" frameworks exploring individuals' self-definition of their psychotic experiences ${ }^{26,29,489}$. Transcripts were analysed for general themes in experience, which were then combined into overarching key themes and trends in the sample. 


\section{Results}

Sample

The mean word count for comments was 211.14 words (SD=201.13; range=10-1259). 139 commenters discussed their perception of symptom onset and 4 distinct themes emerged. 20\% ( $N=30)$ described symptoms being "always present" or "as far back as I can remember", 52.7\% (N=79) as "starting slowly" and building to a breakdown, $11.3 \%(\mathrm{~N}=16)$ as "sudden" onset while $8.7 \%(\mathrm{~N}=11)$ stated they were "currently" experiencing symptoms. In discussing distress related to these experiences, lower distress was interpreted as awareness to mild annoyance and moderate/high distress interpreted by descriptive language. Distress varied by onset theme, with lower distress associated with length of exposure to and severity of symptoms. The Always Present onset category showed the lowest overall distress, followed by the Started Slowly category, the Suddenly category, and the Current category (Table 1). Respondents described this distress in the context of the psychotic experience, interpreted as internal when directly related to a distressing symptom and external when related to stigma/fear of stigma/other people. In this sample, $62 \%$

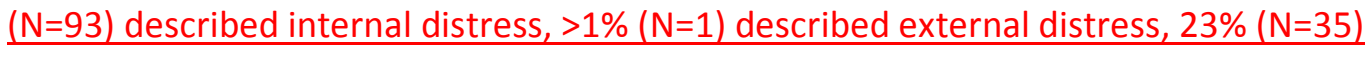
described both, and $14 \%(\mathrm{~N}=21)$ did not discuss a distress source.

Table 1 here

In total, 12 commenters shared their age of initial symptom awareness in childhood $(\bar{m}=7.75$ years $(S D=2.8))$ and 43 shared their age of awareness preceding the psychotic 
event $(\bar{m}=16.34$ years $(S D=5.63))$. While the posted question was for 'people diagnosed with schizophrenia', most respondents interpreted this as 'people who have experienced psychosis'. 44 commenters provided their formal psychiatric diagnosis (Table 2), with only 13 diagnosed with 'schizophrenia' and many commenting their diagnosis had changed several times. Several respondents cited little confidence in the diagnostic process and overall confusion over shifting diagnoses over time.

Table 2 here

Comorbid mental health problems and other related issues were present in the sample. $10 \%(\mathrm{~N}=15)$ mentioned anxiety and $11.3 \%(\mathrm{~N}=17)$ mentioned depression. $4.7 \%$ $(\mathrm{N}=7)$ reported panic attacks, $6 \%(\mathrm{~N}=9)$ reported insomnia/sleep problems, and $7.3 \%(\mathrm{~N}=11)$ mentioned specific trauma with $1.3 \%(\mathrm{~N}=2)$ reporting PTSD as a comorbidity. $8.7 \%(\mathrm{~N}=13)$ reported increased stress/stressful environments directly preceding onset. $6 \%(\mathrm{~N}=9)$ recounted non-alcohol drugs use (cannabis $(N=4)$, $\operatorname{LSD}(\mathrm{N}=2)$, multiple $(\mathrm{N}=2)$, other $(\mathrm{N}=1)$ ). 4.6\% $(\mathrm{N}=7)$ stated they had made at least 1 suicide attempt. Those who reported these comorbidities cited them in a manner that inferred causality for the psychotic event.

\section{Symptomology}

\section{Auditory Hallucinations: "Hearing my dead best friend screaming for help from Hell."}

Auditory hallucinations were the most prevalent symptom with $56.7 \%(\mathrm{~N}=85)$ reporting hearing either voices $(48 \%, \mathrm{~N}=72)$, noises $(3.3 \%, \mathrm{~N}=5)$, both $(12.7 \%, \mathrm{~N}=19)$, or "things that weren't there" $(5.3 \%, \mathrm{~N}=8)$. Non-voice noises were mundane in nature (television/radio, music, static, footsteps, breathing, environmental sounds) and associated 
with lower distress. Voice hallucinations produced higher distress, moderated by age of onset. The theme of universal experience emerged in those with childhood onset as they assumed that their experience of hearing voices was common. This subset did not feel distress until symptomology evolved during adolescence. Several stated that because no one ever mentioned internal voices, they concluded it was an aspect of life simply not discussed.

23IUX: "I didn't think that the voices in my head were abnormal. I thought everyone had multiple voices in their heads."

690WD: “I was terrified I would yell at them in public (I didn't know why, but that just wasn't something people did - at this point I still assumed everyone had other people in their heads)."

Several themes arose concerning voice personification and characteristics. Voice identity fell into three groups: 1) unknown voices, 2) friends or family, and 3) God, Satan, or angels/demons. Most described voices 'in their heads' but early childhood onset commenters also described voices coming from 'under the bed'. Superimposition of voice hallucinations over live conversation or television/radio also occurred and many experienced hearing someone call them from another room. While most reported single voices, some experienced multiple voices in chorus or cacophony. Voice content fell into coherent speech, mumbled/whispered gibberish, or repeated phrases. Voice characteristics were largely neutral as $29.1 \%(\mathrm{~N}=21)$ of the voices subsample reported negative characteristics versus $5.5 \%(\mathrm{~N}=4)$ positive. Voices espousing paranoid ideation were common but the commenter's perception of voice personality determined the voice's 
intent. Negative voices criticised, used vulgar language, and encouraged self-harm, suicide, and harm against friends/family. These voices were associated with high levels of distress, self-harm, and suicide attempts. Positive voices were described as helpful or a friend/companion. Voice hallucinations with established identity were salient, often resulting in the respondent viewing the experience as a relationship with the voice(s) and formation of delusional explanation around that relationship.

98II9: "I'm 19 and I've had "voices" for a long time like it will tell me to do stupid things like hit my hand against the wall really hard and that if I don't I'm weak."

690WD: “I'd ask Him (God) questions and He'd give me answers. There was a sense of trust in that relationship; He was like a mentor."

\section{Visual Hallucinations: "Faces started appearing in my windows."}

Overall, $40 \%(N=60)$ of commenters reported visual hallucinations with $6.7 \%(N=10)$ seeing 'shadow people'. Hallucinations manifested as normal or abnormal phenomena, with 'normal' being anything expected in the given environment; people walking on the street, birds/animals in an outdoor setting, etc. Normal visual hallucinations were associated with lower distress. Abnormal phenomena included shadow people, orbs/lights, frightening or disgusting visions, shadows with impossible properties, patterns in object textures, or textures in motion.

KWP7V: "Some of them were in my peripheral vision, but I used to see hands snaking over the backs of furniture, like couches or beds. It would terrify me." 
Hallucinations in peripheral vision were common, as were occurrences before sleep or just after waking, though only one commenter mentioned a prior history of sleep paralysis. Frightening visions included demons, human/animal corpses, and supernatural creatures while disgusting visions included maggots, worms, parasites, and an instance of vivisection. Several commenters reported shadows with red eyes whose "physics seemed slightly off". Shadow people were often in motion, walking by doorways/windows, or following and lunging at the commenter. Some experienced visual hallucinations related to and reinforcing pre-existing delusions, and several described immersive, multi-modal hallucinations.

XOYYK: "The easiest way of describing it would be that my brain had changed channel from what I was seeing to something else entirely, but I was unaware of it until it changed back to what was actually in front of me."

Visual hallucinations often resulted in extensive reality-testing behaviours with the respondent unable to fully trust their senses, even during recovery periods.

\section{Paranoia: "There is always someone watching."}

When examined, $30 \%(\mathrm{~N}=45)$ of the sample reported paranoid ideation ( $\mathrm{PI})$. A common theme was being the victim of the attentions of authority figures including parents, the police, or the government. Parents were accused of poisoning food/drink and co-opting confederates to watch/follow/record the individual. The police and government 
were assumed to be utilising unmarked cars to follow and record commenters, trying to harm them, 'gathering evidence', or employing snipers.

95TEU: “Actions taken to protect myself from authority led to actions taken to protect myself because authority figures were trying to kill me.

UXDN6: "I would only drink bottled water because I thought the government put a canister on the water lines that was set to release chemicals when I would shower or use the sink."

Peers were implicated at a lesser level of authority. Friends were accused of conspiring, being false friends, talking/laughing behind a commenter's back, or being a paid catspaw of authority. Attempts to help were interpreted as threats, contributing to a lack of trust in others, especially mental health and medical professionals. The fear of being followed, watched, and recorded was pervasive even where no specific agent was identified. Several commenters engaged in complicated driving patterns to lose followers or carried weapons. There was a general sense that unnamed others were plotting against them, threatening physical harm, with television/radio cited as monitoring outlets as well as enabling communication between conspirators. Hidden cameras/microphones were a serious concern to some, often hidden in impossible locations.

EAHLL: "I "knew" where the cameras were. In vents, cracks in walls, old punctures from thumb tacs."

PJSDS: "I always feel like I'm being watch through tiny cameras everywhere (in door hinges, in outlets, in air vents, etc)." 


\section{Delusions: "Hidden messages pertaining to me specifically."}

Resulted showed $30 \%(\mathrm{~N}=45)$ of commenters experienced delusions, occurring covalently with paranoia in 43 cases. $7.3 \%(\mathrm{~N}=11)$ reported religious (Judeo-Christian) delusions and $8 \%(\mathrm{~N}=12)$ that they received a special 'message' or 'pattern' to decode. Most described the delusional state as unpleasant with language use comparable to describing dreams/nightmares. Four commenters referenced the film 'The Truman Show', describing life as a simulation where every aspect was scripted and coordinated by an unknown authority towards an unknown goal. The concept of a 'mirror' reality with a decoy population was also prevalent. Many experienced ideas of reference and felt 'special' or 'chosen'. These thematic delusions created a feeling of enhanced perception and a drive to interpret hidden 'messages' for an overarching purpose. Some described their internal world of thoughts and motivations being made public by mind reading or television/radio broadcast. The schema of thought changed on a base level, taking on metaphysical qualities and altering perceptions of reality. Several commenters had insight to these aberrant thoughts but were unable to disengage.

FUK4H: "Then I started giving too much weight to ridiculous thoughts and ideas. Normally humans can dismiss stupid ideas like their thoughts are conspiring with the universe to give people cancer, or that everyone is conspiring against you."

Q4NI3: "I suspected what was coming but when I finally had a psychotic break I still had no insight. I walked into the police station and asked to file a report about aliens mind controlling people at my work." 
Religious delusions mainly focused on a relationship with God or fight against Satan. Fear of angering God and following His precepts to avoid 'punishment' factored into distress, as did fear of sin or temptation by Satan. Both were associated with protective ritualistic behaviour. Some experienced 'universal truth' delusions involving complex nonreligious philosophies.

NQ32L: "Seriously, my brain is an asshole, so it'd send prayers to Satan constantly, and I'd get locked in prayer battles for my poor immortal soul when I was still a kid. I covered my room with crosses. I kept holy water at my bedside."

\section{Minor Symptoms}

Several minor symptoms were present in the sample. $11.3 \%(\mathrm{~N}=17)$ reported disassociation/derealisation, 6\% (N=9) reported memory/cognition issues as they approached the initial psychotic event, $4.7 \%(\mathrm{~N}=7)$ reported negative symptoms, and $3.3 \%$ $(\mathrm{N}=5)$ spoke of extreme superstition/magical thinking. $5.3 \%(\mathrm{~N}=8)$ experienced tactile hallucinations and $2.7 \%(\mathrm{~N}=4)$ experienced olfactory hallucinations. $2 \%(\mathrm{~N}=3)$ shared that they had homicidal ideation during their psychotic state. 2 commenters described the synaesthesia effect of ordinal linguistic personification.

Insight

A majority of the sample discussed gaining insight in reference to their experiences. 41.3\% ( $N=62$ ) cited self-realisation that what they were experiencing "wasn't right". $18.7 \%$ $(\mathrm{N}=28)$ reported retrospective insight after their breakdown. $16.7 \%(\mathrm{~N}=25)$ shared that another person granted them insight, and $19.3 \%(\mathrm{~N}=29)$ did not discuss it. Higher distress 
was associated with self-realization and hindsight over those brought insight by another. Many delayed disclosing their symptoms for months or even years and expressed regret for having done so. $4.6 \%(\mathrm{~N}=7)$ reported their parents not believing them or refusing them psychiatric treatment. Gaining insight was most meaningful to respondents as a representation of a dividing line between 'ill' and 'well', regardless of diagnosis or recovery process.

Overall Interpretation of Psychosis

Reflections of 'I tried to ignore it,' 'I knew something was wrong but was powerless' or 'it all made sense at the time' were common. Symptomology was interpreted to fit preexisting cultural values and interpreted through a cultural lens, especially during religious/'universal truth' delusions, AV hallucinations of the supernatural, and surveillance paranoia. 'Hindsight introspection' was common with many reporting being now able to identify and understand the process that preceded their breakdown, favouring lived experiences and environment over more delusional causal theories. Individual interpretation was ultimately a product of each commenter's personal qualia and many respondents explained this in detail in language tailored for general understanding. Though they were answering 'OP' (original poster), they wrote their comments as if addressing the population at large, seeking to clearly communicate these experiences and be understood. $19.3 \%(N=29)$ expressed they were now 'in a better place' and $6 \%(N=9)$ offered encouragement to anyone who might be afraid to seek treatment. While some respondents included their recovery process and any relapses, this was ancillary to the main point of initial awareness of symptomology. 


\section{Discussion}

Sample

Much of the shared content was consistent with what we know from the extant research literature about those who have experienced psychosis or been diagnosed with schizophrenia. For example, reddit commenters were generally typical in comorbidities $\stackrel{4509,501}{ }$, drugs use ${ }^{5 \underline{2} 1}$, onset age ${ }^{532,5 \underline{4} 3}$, and minor symptomology ${ }^{5 \underline{5} 4}=$ with the exception of negative symptoms. Prevalent in prodromal/CHR psychosis ${ }^{56}$ (REFERENCE:

Bobes at., 2010), negative symptoms are associated with poorer health outcomes ${ }^{57}$ (REFERENCE: Hafneret al., 2007) and greater risk of psychosis progression ${ }^{58,59}$ (REFERENCE: Verdoux \& van Os, 2001; Piskulic et al., 2012). The low prevalence of these symptoms in this sample seems to indicate a cohort better able to support the effort of posting online and finding the motivation to do so. Stress, trauma, and prior adverse experiences were also identified as significant contributing factors ${ }^{510,6055}$ to psychosis experience in this samplefor these individuals. Regarding suicidality, $4.6 \%$ of the sample described at least 1 suicide attempt, and this was largely consistent with the $5 \%$ prevalence rate that has been recorded in clinical populations ${ }^{6156,6257}$. Diagnostic variability due to diverse symptomology was also common, and may have reflected commonly reported confusion surrounding the 'accuracy', reliability, or validity of diagnoses of psychotic disorder ${ }^{6358,6459}$. Notably, while the reddit question referred to schizophrenia specifically, many in the sample opted to refermake reference to psychosis more generally. In general, while there was limited demographic information available, a majority of reddit users are males in the 18-29 age range ${ }^{45}$ 
(REFERENCE: Mediakix), a group with a higher overall prevalence of early psychosis ${ }^{65}$

(REFERENCE: Hafner et al., 1993).

During the analysis, 4 distinct onset categories emerged, each differing by duration

of symptom exposure and associated distress. It has been widely recognised that most

psychotic-like experiences (PLE) are often non-distressing and often do not a-predict future

psychopathology ${ }^{6 \underline{6} \theta}$. In this sample, it was notable that early subclinical experiences were

associated with lower distress until symptom 'evolution' led to increased distress and

psychosis development ${ }^{671,6 \underline{8 z}}$. Shared histories included multiple examples of non-distressing subclinical phenomena, which were experienced in early life, but which later became problematic in adolescence and adulthood. It would seem that such accounts may afford useful insight and information for those interested in understanding transitions along the psychosis continuum or charged with early identification, support and treatment.

Symptomology

Specific auditory hallucination characteristics were framed in the context of commenters' associated distress ${ }^{693}, 7064 ;$ i.e. non-voice sounds were often described as experiences that evoked lower levels of distress while negative voice hallucinations evoked highest levels ${ }^{7165}$. References to early childhood auditory hallucinatory experiences were accompanied by explanations of unique schemas of assumed universality and were believed to be predictive of later psychopathology when persistent $\underline{\underline{7266,7367}}$. Voice hallucinations in this subset of commenters also became distressing as their symptoms evolved into adolescence alongside comorbid factors. The presence also of neutral and positive voices among the sample, and the notable absence of distress in their descriptions of these experiences, seemed to be consistent with the literature regarding the hrole that voice 
hallucination formand personal interpretation ${ }^{7468}$ plays in inducing distress and promoting symptom evolution. It was notable also that while those who hear voices have often been regarded as 'troubled' in the literature ${ }^{7569}$ and while researchers often 'sort' individuals using a myriad of criteria, those in the current analysis displayed remarkable variation in auditory hallucinatory experience even within common themes. Respondents also shared their interpretation of voice characterisation and intent, showing a depth of introspection into the phenomena and voice aspects seen previously ${ }^{7468}$, as similar themed content (advice, guidance) is found in positive, negative, and neutral voices and contextualised by the individual ${ }^{76}$. This finding but which still-warrants further focused study.

Visual hallucinations were referred to in two ways, normal and abnormal. Abnormal visual hallucinations (phenomena that included shadow people, orbs/lights, frightening or disgusting visions, shadows with impossible properties, patterns in object textures, or textures in motion) were associated with higher distress, particularly when the phenomenon was frightening, disgusting, or supernatural. These hallucinations also contributed to higher insight, which in turn amplified distress, as individuals interpreted their experiences as symptoms of an underlying mental illness. Normal hallucinations (which included anything expected in the given environment characterised by patterns and textures), factored into aberrant salience delusions of purpose. Diffuse in the general population ${ }^{70}$ population ${ }^{77,781}$, visual hallucinations have been associated with higher levels of impairment ${ }^{7 \underline{9} z}$, and this was largely consistent with what was identified among the reddit sample. It is interesting to note that 'normal' hallucinations produced less distress as Líndal, Stefánsson, and Stefánsson found more 'normal' subclinical hallucinations in a general population sample compared with more 'abnormal' visions in a schizophrenic population ${ }^{80}$. 
Importantly, in most instances of visual hallucinations, commenters used 'not real' or 'not really there' to describe phenomena that were 'real' by nature of their experiencing it.

Two levels of paranoid ideation emerged in this sample; being the target of an authority conspiracy or a peer network conspiracy. Both were associated with high distress and defensive/protective behaviours. According to the research literature, PI has been shown to vary along a spectrum in the general population ${ }^{8173,8274}$, with the nature and severity of beliefs forming specific interactions ${ }^{8375}$. As an example, it might be regarded as 'normal' for a person to be concerned about the prevalence of CCTV cameras and wellknown government monitoring programs. However, there was little mention of these in the sample; only cameras/devices in bizarre, impossible locations. Unspecified personal harm constituted a significant threat and was consistent with Freeman et al.'s paranoia hierarchy ${ }^{8173}$. Notably, in this sample, a majority of respondents used the phrase 'out to get me' and described their conspirators' methods for achieving/pursuing persecution however they offered no causal theory/explanation for their status as someone who was a target of conspiracy/persecution. The metacognition of insight was key in respondents contextualising and understanding the experience of their paranoia, a finding similar to $\underline{\text { Stopa et al.'s exploration of implied threat and reaction in paranoia }}{ }^{84}$.

Trends in delusions included ideas of reference, religious/'universal truth', aberrant salience of purpose ${ }^{8576}$, and causation seeking. Delusions used as a primary explanation for experiences often led to ideas of reference in the 'hasty conclusions' model ${ }^{8677}$. Notably, $95 \%$ of delusions in the reddit sample occurred covalently with paranoia. Many admitted knowing their delusional thoughts were abnormal but were unable to stop the progression of their psychotic episode. Cultural bias factored into delusion formation in the case of religious/'universal truth' delusions and social authority paranoia. Moreover, reinforcing the 
value of communication in personal interpretation, references to the 'Truman delusion' were a cultural touchstone allowing an individual to concisely describe their experiences and be instantly understood ${ }^{8778,8879}$. These 'Truman signs' ${ }^{89}$ (strangers are actors, environmental detachment, etc.) could be a valuable tool for clinicians in identifying delusional progression in $\mathrm{CRH}$ individuals.

Insight and Interpretation

A significant portion of the sample (41.3\%) gained insight from self-realisation that their experiences were divorced from reality and an indication to seek professional help. $\underline{\text { In }}$ agreement with Perry et al.'s findings of 'normal' versus being 'out of touch' ${ }^{29}$, insight was perceived as the boundary area between psychosis and wellness. EvidenceEvidence suggests that insight is positively correlated with better health outcomes ${ }^{9080}$ but in the current analysis it was associated with higher distress ${ }^{981,982,983}$, and was a predictor of help-seeking behaviour with internalised stigma ${ }^{984}$ that in turn influenced a varying DUP. Most respondents reported internal distress (85\%) and many experienced external distress (14.6\%) due to stigma or fear of being stigmatised. Insight must be present for self-acceptance, which can be beneficial in recovery ${ }^{95}$ (REFERENCE: Waite, Knight, \& Lee, 2015), but also means increased awareness of stigma ${ }^{96}$ (REFERENCE: Pyle \& Morrison, 2014) and further reduces emotional well-being and quality of life ${ }^{97}$ (REFERENCE: Hasson-Ohayon et al.,2006). Fear of stigma was frequently mentioned with concerns over self-other perceptions mirroring the superordinate themes of judgement and personal comparison found by Knight, Wykes, \& Hayward ${ }^{98}$ (REFERENCE). Many commenters expressed regret on not seeking help sooner, though they did not provide a reason for their silence/inaction. 
Experiences of symptomology insight and outside involvement were largely consistent with Yung and McGorry's prodromal progression model ${ }^{1}$ through first intervention.

Interpretation and causation seeking ${ }^{9985}$ often reflected automatic processes for commenters and seemed to promote self-preservation ${ }^{10086}$ with explanation facilitating hindsight acceptance ${ }^{\underline{10187}}$. Lived experience also directly influenced interpretation, and seemed to form a feedback continuum as symptoms evolved. This was also largely consistent with the broad literature demonstrating that life events factor into psychosis progression ${ }^{10288}$. A majority of commenters who shared their causal theories cited adverse life events, stress, and comorbid anxiety and depression reflecting psychosocial and biogenic beliefs in line with Carter's findings ${ }^{9985}$. Focus on familial mental illness and trauma $\underline{\text { history was prevalent among females in Ben-David's study of the subjective experiences of }}$ CRH youth ${ }^{103}$ (REFERENCE: Ben-David), though gender was largely unknown in this population, generating the need for further research into a potential gender effect in causal theories. Isolating and exploring personal meaning in psychosis has proven beneficial $\underline{10489}$ and the commenters in this sample were eager to share. Many respondents referenced learning to 'ignore' or 'control' lesser symptomology, indicating that this aspect of recovery granted them agency ${ }^{10489}$ and resulted in higher self-efficacy during their recovery., with the mean comment word count at 211.14 (SD-201.13; range-10-1259).

\section{Hindsight Introspection}

The data harvested for this study was retrospective and hindsight bias ${ }^{10590}$ is a significant concern in any research. However, the hindsight introspection of respondents here is valuable and comparable to introspection performed during therapy. Obviously, it is reasonable to expect an individual who has experienced psychosis symptoms, in describing 
the same phenomena experienced at an earlier age, to ascribe those symptoms to psychosis. Clinicians and researchers familiar with prodromal and progression models will recognise such features in the data, confirming the potentially biased assertions of the respondents concerning early experiences. Hindsight introspection into psychosis causation exposed multiple instances of trauma, parents with significant mental illnesses, and substance abuse catalysts which align with contemporary contributory theories ${ }^{510,5 \underline{21}, 10691}$.

\section{Limitations}

The results of this study must be taken in light of its limitations. While the medium of the reddit website does encourage sharing, there was no opportunity for clarification or follow-up questions. The anonymity of reddit did prompt commenters to speak without fear of stigma or social repercussions but also meant little demographic or standard measure information was available, limiting some aspects of analysis. The user who posed the question was not a mental health professional using clinical language nor a researcher engaged in hypothesis testing; they were a curious individual who wanted to know about others' experiences and asked any who cared to answer. As this was a single question and not a structured interview, the only data available for analysis is that which respondents chose to share, meaning the possibility of additional variables/symptoms/environments that went unmentioned. Finally, this was an opportunity sample and the analysis conducted was exploratory as the research question was not part of a planned methodological design.

\section{Conclusions}

This study dealt with trends and key themes in a large qualitative sample to establish a viable framework for further in-depth analysis of this dataset. With this framework in 
place, work on follow-up studies with this data can begin, covering a variety of issues. The above findings warrant examination into early childhood subclinical experience interpretation, the distress delta between sound and voice hallucinations, power dynamics in paranoia, aberrant salience in 'purpose' delusions, limited-insight prodromal progression, and specific causal interpretations. Symptoms were separated here for preliminary analysis and follow-up studies into relationships and interactions between symptoms, distress, and personal interpretation are forthcoming. As large qualitative studies are costly and timeconsuming, access to this resource can illuminate lived experiences of initial psychosis awareness, benefitting both the individual service user and wider population. The implications for early intervention and therapeutic treatment are clear, with personal contextualisation of experiences shown to have a beneficial effect on young CHR individuals ${ }^{26,107}$. While the last vestiges of psychology's history transition into a model for mental well-being, the individual must continue to take priority. Research informs paradigm and policy alike but in this study, the best method to understand the initial awareness of psychosis was simply to ask.

\section{Conflict of interest statement:}

On behalf of all authors, the corresponding author states that there is no conflict of interest. 


\section{References}

1. Yung AR, McGorry PD. The prodromal phase of first-episode psychosis: past and current conceptualizations. Schizophr Bull. 1996;22:353-70.

2. Menezes NM, Arenovich T, Zipursky RB. A systematic review of longitudinal outcome studies of first-episode psychosis. Psychol Med. 2006;36:1349-62.

3. McGorry PD, Nelson B, Amminger GP, Bechdolf, A, Francey SM, Berger G, et al. Intervention in individuals at ultra-high risk for psychosis: a review and future directions. J Clin Psychiatry. 2009;70:1206-12.

4. Yung AR, Nelson B, Stanford C, Simmons MB, Cosgrave EM, Killackey E, et al. Validation of "prodromal" criteria to detect individuals at ultra high risk of psychosis: 2 year follow-up. Schizophr Res. 2008;105:10-17.

5. Addington J, Penn D, Woods SW, Addington D, Perkins DO. Social functioning in individuals at clinical high risk for psychosis. Schizophr Res. 2008;99:119-24.

6. Cannon TD, Cadenhead K, Cornblatt B, Woods SW, Addington J, Wakler E, et al. Prediction of psychosis in youth at high clinical risk: A multisite longitudinal study in North America. Arch Gen Psychiatry. 2008;65:28-37.

7. Marshall M, Lewis S, Lockwood A, Drake R, Jones P, Croudace T. Association between duration of untreated psychosis and outcome in cohorts of first-episode patients: A systematic review. Arch Gen Psychiatry. 2005;62:975-83.

8. Baldwin P, Browne D, Scully PJ, Quinn JF, Morgan MG, Kinsella A, et al. Epidemiology of first-episode psychosis: Illustrating the challenges across diagnostic boundaries through the Cavan-Monaghan Study at 8 years. Schizophr Bull. 2005;31:624-38.

9. Morgan C, Dazzan P, Morgan K, Jones P, Harrison G, Leff J, et al. First episode psychosis and ethnicity: Initial findings from the AESOP study. World Psychiatry. 2006;5:40-6.

10. Craig TKJ, Garety P, Power P, Rahaman N, Colbert S, Fornells-Ambrojo M, et al. The Lambeth Early Onset (LEO) Team: Randomised controlled trial of the effectiveness of specialized care for early psychosis. BMJ. 2004;329:1067.

11. van Os J, Hanssen M, Bijl RV, Ravelli A. Strauss (1969) revisited: A psychosis continuum in the general population? Schizophr Res. 2000;45:11-20.

12. Linscott RJ, van Os J. An updated and conservative systematic review and meta-analysis of epidemiological evidence on psychotic experiences in children and adults: On the pathway from proneness to persistence to dimensional expression across mental 
disorders. Psychol Med. 2013;43:1133-49.

13. McGorry PD, Yung AR, Phillips $\amalg$, Yuen HP, Francey S, Cosgrave EM, et al. Randomized controlled trial of interventions designed to reduce the risk of progression to firstepisode psychosis in a clinical sample with subthreshold symptoms. Arch Gen Psychiatry. 2002;59:921-8.

14. Alvarez-Jiménez M, Parker AG, Hetrick SE, McGorry PD, Gleeson J F. Preventing the second episode: a systematic review and meta-analysis of psychosocial and pharmacological trials in first-episode psychosis. Schizophr Bull. 2009;37:619-30.

15. Singh SP, Grange T. Measuring pathways to care in first-episode psychosis: a systematic review. Schizophr Res. 2006;81:75-82.

16. Anderson KK, Fuhrer R, Malla AK. The pathways to mental health care of first-episode psychosis patients: a systematic review. Psychol Med. 2010;40:1585-97.

17. Zhang JP, Gallego JA, Robinson DG, Malhotra AK, Kane JM, Correll CU. Efficacy and safety of individual second-generation vs. first-generation antipsychotics in firstepisode psychosis: a systematic review and meta-analysis. Int J Neuropsychopharmacol. 2013;16:1205-18.

18. Bozikas VP, Andreou C. Longitudinal studies of cognition in first episode psychosis: A systematic review of the literature. Aust N Z J Psychiatry. 2011;45:93-108.

19. Mesholam-Gately RI, Giuliano AJ, Goff KP, Faraone SV, Seidman LJ. Neurocognition in first-episode schizophrenia: A meta-analytic review. Neuropsychology. 2009;23:315-36.

20. Steen RG, Mull C, McClure R, Hamer RM, Lieberman JA. Brain volume in first-episode schizophrenia: Systematic review and meta-analysis of magnetic resonance imaging studies. Br J Psychiatry. 2006;188:510-18.

21. Borges S, Gayer-Anderson C, Mondelli V. A systematic review of the activity of the hypothalamic-pituitary-adrenal axis in first episode psychosis. Psychoneuroendocrinology. 2013;38:603-11.

22. MacBeth A, Gumley A. Premorbid adjustment, symptom development and quality of life in first episode psychosis: a systematic review and critical reappraisal. Acta Psychiatr Scan. 2008;117:85-99.

23. Pompili M, Serafini G, Innamorati M, Lester D, Shrivastava A, Girardi P, et al. Suicide risk in first episode psychosis: A selective review of the current literature. Schizophr Res. 2011;129:1-11.

24. Hoy K, Barrett S, Shannon C, Campbell C, Watson D, Rushe T, et al. Childhood trauma and hippocampal and amygdalar volumes in first-episode psychosis. Schizophr Bull. 
2011;38:1162-9.

25. Aas M, Navari S, Gibbs A, Mondelli V, Fisher HL, Morgan C, et al. Is there a link between childhood trauma, cognition, and amygdala and hippocampus volume in firstepisode psychosis? Schizophr Res. 2012;137:73-9.

26. Boydell KM, Stasiulis E, Volpe T, Gladstone B. A descriptive review of qualitative studies in first episode psychosis. Early Interv Psychiatry. 2010;4:7-24.

27. Corcoran C, Davidson L, Sills-Shahar R, Nickou C, MalaspinaD, McGlashan T. A qualitative research study of the evolution of symptoms in individuals identified as prodromal to psychosis. Psychiatr Q. 2003;4:313-32.

28. Moller P, Husby R. The initial prodrome in schizophrenia: Searching for naturalistic core dimensions of experience and behaviour. Schizophr Bull. 2000;26:217-32.

29. Perry BM, Taylor D, Shaw SK. 'You've got to have a positive state of mind': An interpretive phenomenological analysis of hope and first episode psychosis. J Ment Health. 2007;16:781-93.

30. Fisher A, Savin-Baden M. The benefits to young people experiencing psychosis, and their families, of an early intervention programme: Evaluating a service from the consumers' and the providers' perspectives. Br J Occup Ther. 2001;64:58-65.

31. Larsen JA. Understanding a complex intervention: person-centred ethnography in early psychosis. J Ment Health. 2007;16:333-45.

32. O'Toole MS, Ohlsen RI, Taylor TM, Walters J, Pilowsky LS. Treating first episode psychosis - the service users' perspective: A focus group evaluation. J Psychiatr Ment Health Nurs. 2004;11:319-26.

33. Bergner E, Leiner AS, Carter T, Franz L, Thompson NJ, Compton MT. The period of untreated psychosis before treatment initiation: A qualitative study of family members' perspectives. Compr Psychiatry. 2008;49:530-6.

34. Boydell KM, Gladstone BM, Volpe T. Understanding help seeking delay in the prodrome to first episode psychosis: A secondary analysis of the perspectives of young people. Psychiatr Rehabil J. 2006;30:54-60.

35. Corcoran C. Trajectory to a first episode of psychosis: A qualitative research study with families. Early Interv Psychiatry. 2007;1:54-60.

36. Gladstone B, Volpe T, Boydell K. Issues encountered in a qualitative secondary analysis of help-seeking in the prodrome to psychosis. J Behav Health Serv Res. 2007;34:43142.

$\underline{\text { 37. Mackrell L, Lavender T. Peer relationships in adolescents experiencing a first episode of }}$ 
psychosis. J Ment Health. 2004;13:467-79.

38. Woodside H, Krupa T, Pocock K. How people negotiate for success as psychosis emerges. Early Interv Psychiatry. 2008;2:50-4.

39. Haslam N. Bias in psychopathology research. Curr Opinion Psychiatry. 2006;19:625-630.

40. Garb HN. (1998). Studying the clinician: Judgment research and psychological assessment. Washington, DC, US: American Psychological Association; 1998.

41. Alexa Internet Inc. Reddit.com Web Traffic Statistics [Internet]. Alexa c1996-2018 [cited 2017 Nov 25]. Available from: https://www.alexa.com/siteinfo/reddit.com.

42. Griffiths $M$. The use of online methodologies in data collection for gambling and gambling addictions. Int J Ment Health Addiction, 2009;8:8-20.

43. Schrank B, Klose T, Szmukler G, Lloyd K, Koivunen M. How patients with schizophrenia use the Internet: Qualitative study. J Med Internet Res. 2010;12:e70.

44. Haahr M. True Random Number Service [Internet]. Random Org c1998-2018 [cited 2017 Nov 25]. Available from: https://www.random.org/.

45. Mediakix. The Top 8 Reddit Statistics On Uusers, Demographics \& More [Internet]. Mediakix Team c2016. [cited 2017 Nov 25]. Available from: http://mediakix.com/2017/09/reddit-statistics-users-demographics/.

46. Smith J, Jarman M, Osborn M. Doing Interpretative Phenomenological Analysis. In Murray M, Chamberlin K, eds. Qualitative Health Psychology. Thousand Oaks, California, US: Sage; 1999: 218-40.

47. Gill J. The possibilities of phenomenology for organizational research. Organ Res Meth. $\underline{2014 ; 17: 118-37 .}$

48. Pietkiewicz I, Smith J. A practical guide to using Interpretative Phenomenological Analysis in qualitative research psychology. C Psychologic. 2012;18:361-9.

49. Knight M, Wykes T, Hayward P. 'People don't understand': An investigation of stigma in schizophrenia using Interpretative Phenomenological Analysis (IPA). J Ment Health. 2003;12:209-22.

50. Hanssen M, Peeters F, Krabbendam L, Radstake S, Verdoux H, van Os J. How psychotic are individuals with non-psychotic disorders? Soc Psychiatry Psychiatr Epidemiol. 2003;38:149-54.

51. Read J, van Os J, Morrison A, Ross C. Childhood trauma, psychosis and schizophrenia: A literature review with theoretical and clinical implications. Acta Psychiatr Scan. 2005;112:330-50. 
52. Moore T, Zammit S, Lingford-Hughes A, et al. Cannabis use and risk of psychotic or affective mental health outcomes: A systematic review. Lancet. 2007;370:319-28.

53. Häfner N, Maurer K, Löffler W, Fätenheuer B, an der Heiden W, Riecher-Rössler A, et al. The epidemiology of early schizophrenia: Influence of age and gender on onset and early course. Br J Psychiatry Suppl. 1994;164:29-38.

54. Schultze-Lutter F, Michel C, Ruhrmann S, Schimmelmann B. Prevalence and clinical significance of DSM-5-attenuated psychosis syndrome in adolescents and young adults in the general population: The Bern Epidemiological At-Risk (BEAR) study. Schizophr Bull. 2014;40:1499-1508.

55. Kendler K, Gallagher T, Abelson J, Kessler R. Lifetime prevalence, demographic risk factors, and diagnostic validity of nonaffective psychosis as assessed in a US community sample: The National Comorbidity Survey. Arch Gen Psychiatry. 1996;53:1022-31.

56. Bobes J, Arango C, Garcia-Garcia M, Rejas J, CLAMORS Study Collaborative Group. Prevalence of negative symptoms in outpatients with schizophrenia spectrum disorders treated with antipsychotics in routine clinical practice: Findings from the CLAMORS study. J Clin Psychiatry. 2010;71:280-6.

57. Häfner H, Löffler W, Maurer K, Hambrect M, an der Heiden W. Depression, negative symptoms, social stagnation and social decline in the early course of schizophrenia. Acta Psychiatr Scan. 1999;100:105-18.

58. Verdoux $\mathrm{H}$, van Os J. Psychotic symptoms in non-clinical populations and the continuum of psychosis. Schizophr Res. 2002;54:59-65.

59. Piskulic D, Addington J, Cadenhead K, Cannon T, Cornblatt B, Heinssen R, et al. Negative symptoms in individuals at clinical high risk of psychosis. Psychiatry Res. 2012;2:2204.

60. Read J, Bentall R, Fosse R Time to abandon the bio-bio-bio model of psychosis: Exploring the epigenetic and psychological mechanisms by which adverse life events lead to psychotic symptoms. Epidemiol Psichiatr Soc. 2009;18:299-310.

61. Palmer B, Pankratz S, Bostwick J. The lifetime risk of suicide in schizophrenia: A reexamination. Arch Gen Psychiatry. 2005;62:247-53.

62. Hor K, Taylor M. Suicide and schizophrenia: A systematic review of rates and risk factors. J Psychopharmacol. 2010;24:81-90.

63. Cooke A, Kinderman P. "But what about real mental illnesses?" Alternatives to the disease model approach to "schizophrenia". J Human Psychol. 2018;58:47-71. 
64. Jablensky A. Psychiatric classifications: validity and utility. World Psychiatry, 2016;15:26$\underline{31 .}$

65. Häfner H, Maurer K, Löffler W, Riecher-Rössler A. The influence of age and sex on the onset and early course of schizophrenia. B J Psychiatry. 1993;162:80-6.

66. van Os J, Linscott R, Myin-Germeys I, Delespaul P, Krabbendam L. A systematic review and meta-analysis of the psychosis continuum: Evidence for a psychosis pronenesspersistence-impairment model of psychotic disorder. Psychol Med. 2009;39:179-95.

67. Dominguez $M$, Wichers $M$, Lieb R, Wittchen $\mathrm{H}-\mathrm{U}$, van Os J. Evidence that onset of clinical psychosis is an outcome of progressively more persistent subclinical psychotic experiences: An 8-year cohort study. Schizophr Bull. 2011;37:84-93.

68. Murphy J, McBride O, Fried E, Shevlin M. Distress, impairment and the extended psychosis phenotype: A network analysis of psychotic experiences in an US general population sample. Schizophr Bull. 2017; sbx134.

69. Nayani T, David A. The auditory hallucination: A phenomenological survey. Psychol Med. 1996;26:177-89

70. Mawson A, Cohen K, Berry K. Reviewing evidence for the cognitive model of auditory hallucinations: The relationship between cognitive voice appraisals and distress during psychosis. Clin Psychol Rev. 2010;30:248-58.

71. Wong Z, Öngür D, Cohen B, Ravichandran C, Noam G, Murphy B. Command hallucinations and clinical characteristics of suicidality in patients with psychotic spectrum disorders. Compr Psychiatry. 2013;54:611-7.

72. Bartels-Velthuis A, van de Willige G, Jenner J, van Os J, Wiersma D. Course of auditory vocal hallucinations in childhood: 5-year follow-up study. Br J Psychiatry. 2011;199:296-302.

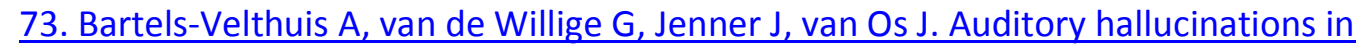
childhood: Associations with adversity and delusional ideation. Psychol Med. 2012;42:583-93.

74. Woods A, Jones N, Alderson-Day B, Callard F, Fernyhough C. Experiences of hearing voices: Analysis of a novel phenomenological survey. Lancet Psychiatry. 2015;2:323$\underline{31 .}$

75. Link BG, Phelan JC, Bresnahan M, Stueve A, Pescosolido BA. Public conceptions of mental illness: labels, causes, dangerousness, and social distance. Am J Pub Health. 1999;89:1328-33. 
76. Beaven V, Read J. Hearing voices and listening to what they say: The importance of voice content in understanding and working with distressing voices. J Nerv Ment Dis. 2010;198:201-5.

77. Bentall R. The illusion of reality: A review and integration of psychological research on hallucinations. Psychol Bull. 1990;107:82-95.

78. Ohayon M. Prevalence of hallucinations and their pathological associations in the general population. Psychiatry Res. 2000;97:153-64.

79. David C, Greenstein D, Clasen L, Gochman P, Miller R, Tossell JW, et al. Childhood onset schizophrenia: High rate of visual hallucinations. J Am Acad Child Adolesc Psychiatry. 2011;50:681-6.

80. Líndal E, Stefánsson JG, Stefánsson SB. The qualitative difference of visions and visual hallucinations: A comparison of a general-population and clinical sample. Compr Psychiatry. 1994;35:405-8.

81. Freeman D, Garety P, Bebbington P, Smith B, Rollinson R, Fowler D, et al. Psychological investigation of the structure of paranoia in a non-clinical population. Br J Psychiatry. 2005;186:427-35.

82. Freeman D, McManus S, Brugha T, Meltzer $H$, Jenkins R, Bebbington P. Concomitants of paranoia in the general population. Psychol Med. 2011;41:923-36.

83. Bebbington $\mathrm{P}$, McBride $\mathrm{O}$, Steel $\mathrm{C}$, Kuipers $\mathrm{E}$, Radovanovic $\mathrm{M}$, Brugha $\mathrm{T}$, et al. The structure of paranoia in the general population. Br J Psychiatry. 2013;202:419-27.

84. Stopa L, Denton R, Wingfield M, Newman Taylor K. The fear of others: A qualitative analysis of interpersonal threat in social phobia and paranoia. Behav Cogn Psychother. 2013;41:188-209.

85. Kapur S. Psychosis as a state of aberrant salience: A framework linking biology, phenomenology, and pharmacology in schizophrenia. Am J Psychiatry. 2003;160:13$\underline{23 .}$

86. Freeman D, Garety P, Fowler D, Kuipers E, Bebbington P, Dunn G. Why do people with delusions fail to choose more realistic explanations for their experiences? An empirical investigation. J Consult Clin Psychol. 2004;72:671-80.

87. Gold J, Gold I. The "Truman Show" delusion: Psychosis in the global village. Cogn Neuropsychiatry. 2012;17:455-72.

88. Mishara A, Fusar-Poli P. The phenomenology and neurobiology of delusion formation during psychosis onset: Jaspers, Truman symptoms, and aberrant salience. Schizophr Bull. 2013;39:278-86. 
89. Fusar-Poli P, Howes O, Valmaggia L, McGuire P. 'Truman' signs and vulnerability to psychosis. B J Psychiatr. 2008;193:168.

90. Lincoln T, Lüllmann E, Rief W. Correlates and long-term consequences of poor insight in patients with schizophrenia: A systematic review. Schizophr Bull. 2007;33:1324-42.

91. Cooke M, Peters E, Fannon D, Anilkumar A, Aasen I, Kuipers E, et al. Insight, distress and coping styles in schizophrenia. Schizophr Res. 2007;94:12-22.

92. Cooke $M$, Peters E, Fannon D, Aasen I, Kuipers E, Kumari V. Cognitive insight in psychosis: The relationship between self-certainty and self-reflection dimensions and neuropsychological measures. Psychiatry Res. 2010;178:284-9.

93. Peters E, Lataster T, Greenwood K, Kuipers E, Williams S, et al. Appraisals, psychotic symptoms and affect in daily life. Psychol Med. 2011;42:1013-23.

94. Lysaker P, Roe D, Yanos P. Toward understanding the insight paradox: internalized stigma moderates the association between insight and social functioning, hope, and self-esteem among people with schizophrenia spectrum disorders. Schizophr Bull. 2007;33:192-9.

95. Waite F, Knight M, Lee D. Self-compassion and self-criticism in recovery in psychosis: An interpretative phenomenological analysis study. J Clin Psychol. 2015;71:1201-17.

96. Pyle M, Morrison A. "It's just a very taboo and secretive kind of thing": Making sense of living with stigma and discrimination from accounts of people with psychosis. Psychosis. 2014;6:195-205.

97. Hasson-Ohayon I, Kravetz S, Roe D, David A, Weiser M. Insight into psychosis and quality of life. Compr Psychiatry. 2006;46:265-9.

98. Knight MTD, Wykes T, Hayward P. 'People don't understand': An investigation of stigma in schizophrenia using Interpretative Phenomenological Analysis (IPA). J Ment Health. 2003;12:209-22.

99. Carter L, Read J, Pyle M, Morrison A. The impact of causal explanations on outcome in people experiencing psychosis: A systematic review. Clin Psychol Psychother. 2017;24:332-47.

100. Larsen J. Finding meaning in first episode psychosis: Experience, agency, and the cultural repertoire. Med Anthropol Q. 2004;18:447-71.

101. Heriot-Maitland C, Knight M, Peters E. A qualitative comparison of psychotic-like phenomena in clinical and non-clinical populations. Br J Clin Psychol. 2012;51:37-53.

102. Read J, Dillon J. Models of Madness: Psychological, Social and Biological Approaches to Psychosis. London, United Kingdom: Routledge; 2013. 249-268. 
103. Ben-David S, Birnbaum M, Eilenberg M, DeVylder J, Gill K, Schienle J, et al. The subjective experience of youths at clinical high risk for psychosis: A qualitative study. Psychiatr Serv. 2014;65:1499-1501.

104. Windell D, Norman R, Lal S, Malla A. Subjective experiences of illness recovery in individuals treated for first-episode psychosis. Soc Psychiatry Psychiatr Epidemiol. 2015;50:1069-77.

105. Fischhoff B, Beyth R. I knew it would happen: Remembered probabilities of oncefuture things. Org Behav Hum Perform. 1975;13:1-16.

106. Rasic D, Hajek T, Alda M, Uher R. Risk of mental illness in offspring of parents with schizophrenia, bipolar disorder, and major depressive disorder: a meta-analysis of family high-risk studies. Schizophr Bull. 2014;40:28-38.

107. Byrne R, Morrison AP. Young people at risk of psychosis: a user-led exploration of interpersonal relationships and communication of psychological difficulties. Early Interv Psychiatry. 2010;4:162-8.

\section{References}

1. Yung AR, McGorry PD. The prodromal phase of first-episode psychosis: past and current conceptualizations. Schizophr Bull. 1996;22:353-70.

Z. Menezes NAM, Arenovich T, Zipursky RB. A systematic review of longitudinaloutcome studies of firstepisode psychosis. Psychol Med. 2006;36:1349-62.

\section{ACGorry PD, Nelson B, Amminger GP, Bechdolf, A, Francey SM, Berger G, et at. Intervention in individuals at ultra-high risk for psychosis: a review and future directions. JClin Psychiatry. 2009;70:1206-12.}

4. Yung AR, Nelson B, Stanford C, Simmons AB, Cosgrave EM, Killackey E, et al. Validation of "prodromal" criteria to detect individuals at ultra high risk of psychosis: 2 year follow-up. Schizophr Res. 2008;105:10-17. 
5. Addington J, Penn D, Woods SW, Addington D, Perkins DO. Social functioning in individuals at clinical high risk for psychosis. Schizophr Res. 2008;99:119-24.

6. Cannon TQ, Cadenhead K, Cornblatt B, Woods SW, Addington, Wakler E, et al.Prediction of psychosis in youth at high clinical risk: A multisite longitudinal study in North America. Arch Gen Psychiatry. 2008;65:28-37.

7. Marshall M, Lewis S, Lockwood A, Drake R, Jones P, Croudace T. Association between duration of untreated psychosis and outcome in cohorts of firstepisode patients: A systematic review. Arch Gen Psychiatry. 2005;62:975-83.

8. Baldwin P, Browne D, Scully PJ, Quinn JF, Morgan MG, Kinsella A, et al. Epidemiology of first-episode psychosis: Illustrating the challenges across diagnostic boundaries through the Cavan-Monaghan Study at 8 years. Schizophr Bull. 2005;31:624-38.

9. Morgan C, Dazzan P, Morgan K, Jones P, Harrison G, Leff J, et al. First episode psychosis and ethnicity: Initial findings from the AESOP study. World Psychiatry. 2006;5:40-6.

10. Craig TKJ, Garety P, Power P, Rahaman N, Colbert S, Fornells Ambrojo M, et al. The tambeth Early Onset (LEO) Team: Randomised controlled trial of the effectiveness of specialized care for early psychosis. BAJ. 2004;329:1067.

11. van OS J, Hanssen M, Bijl RV, Ravelli A. Strauss (1969) revisited: A psychosis continuum in the general population? Schizophr Res. 2000;45:11-20.

12. Linscott RJ, van OSJ. An updated and conservative systematic review and meta-analysis of epidemiological evidence on psychotic experiences inchildren and adults: On the 
pathway from proneness to persistence to dimensional expression across mental disorders. Psychol Med. 2013;43:1133-49.

13. McGorry PD, Yung AR, Phillips L, Yuen HP, Francey S, Cosgrave EM, et al. Randomized controlled trial of interventions designed to reduce the risk of progression to firstepisode psychosis in a clinical sample with subthreshold symptoms. Arch Gen Psychiatry. 2002;59:921-8.

14. Alvarez-Jiménez $M$, Parker $A G$, Hetrick SE, McGorry PD, Gleeson JF. Preventing the second episode: a systematic review and meta-analysis of psychosocial and pharmacological trials in first-episode psychosis. Schizophr Bull. 2009;37:619-30.

15. Singh SP, Grange T. Measuring pathways to care in first-episode psychosis: a systematic review. Schizophr Res. 2006;81:75-82.

16. Anderson KK, Fuhrer R, Malla AK. The pathways to mental health care of first-episode psychosis patients: a systematic review. Psychol Med. 2010;10:1585-97.

17. Zhang JP, Gallego JA, Robinson DG, Malhotra AK, Kane IA, Correll CU. Efficacy and safety of individual second-generation vs. first-generation antipsychotics in firstepisode psychosis: a systematic review and meta-analysis. Int Neuropsychopharmacol. 2013;16:1205-18.

18. Bozikas VP, Andreou C. Longitudinal-studies of cognition in first episode psychosis: A systematic review of the literature. Aust N Z J Psychiatry. 2011;45:93-108.

19. Mesholam-Gately RI, Giuliano AJ, Goff KP, Faraone SV, Seidman LJ. Neurocognition in first-episode schizophrenia: A meta-analytic review. Neuropsychology. 2009;23:315-36. 
20. Steen RG, Mull C, MCClure R, Hamer RM, Lieberman JA. Brain volume in first-episode schizophrenia: Systematic review and meta-analysis of magnetic resonance imaging studies. Br J Psychiatry. 2006;188:510-18.

21. Borges S, Gayer-Anderson C, Mondelliv. Asystematic review of the activity of the hypothalamic-pituitary-adrenal axis in first episode psychosis. Psychoneuroendocrinology. 2013;38:603-11.

22. MacBeth A, Gumley A. Premorbid adjustment, symptom development and quality of life in firstepisode psychosis: a systematic review and critical reappraisal. Acta Psychiatr Scan. 2008;117:85-99.

23. Pompili M, Serafini G, Innamorati M, Lester D, Shrivastava A, Girardi P, et al. Suicide risk in first episode psychosis: A selective review of the current literature. Schizophr Res. $2011 ; 129: 1-11$

24. Hoy K, Barrett S, Shannon C, CampbellC, Watson D, Rushe T, et al. Childhood trauma and hippocampal and amygdalar volumes in first-episode psychosis. Schizophr Bull. 2011;38:11629.

25. Aas M, NavariS, Gibbs A, Mondelliv, Fisher HL, Morgan C, et al. Is there a link between childhood trauma, cognition, and amygdala and hippocampus volume in firstepisode psychosis? Schizophr Res. 2012;137:73-9.

26. Boydell KM, Stasiulis E, Volpe T, Gladstone B. A descriptive review of qualitative studies in first episode psychosis. Early Interv Psychiatry. 2010;4:7-24.

27. Corcoran C, Davidson L, Sills-Shahar R, Nickou C, MalaspinaD, McGlashan T. A qualitative 
research study of the evolution of symptoms in individuals identified as prodromal to psychosis. Psychiatr Q. 2003;4:313-32.

28. Moller $P$, Husby $R$. The initial prodrome in schizophrenia: Searching for naturalistic core dimensions of experience and behaviour. Schizophr Bull. 2000;26:217-32.

29. Perry BA, Taylor D, Shaw SK. 'You've got to have a positive state of mind': An interpretive phenomenological analysis of hope and first episode psychosis. J Ment Health. 2007;16:781-93.

30. Fisher A, Savin-Baden M. The benefits to young people experiencing psychosis, and their families, of an early intervention programme: Evaluating a service from the consumers' and the providers' perspectives. Br JOccup Ther. 2001;64:58-65.

31. Larsen JA. Understanding a complex intervention: person-centred ethnography in early psychosis. J Alent Health. 2007;16:333-45.

32. O'Toole MS, Ohlsen RI, Taylor TM, Walters J, Pilowsky LS. Treating first episode psychosis - the service users' perspective: A focus group evaluation. J Psychiatr Ment Health Nurs. 2004;11:319-26.

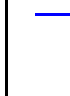

33. Bergner E, Leiner AS, Carter T, Franz L, Thompson NJ, Compton MT. The period of untreated psychosis before treatment initiation: A qualitative study of family members' perspectives. Compr Psychiatry. 2008;49:530-6.

\footnotetext{
34
}

$$
\text { to }
$$

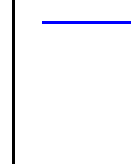

4. Boydell KM, Gladstone BM, Volpe T. Understanding helpseeking delay in the prodrome o first episode psychosis: A secondary analysis of the perspectives of young people. Psychiatr Rehabil J. 2006;30:54-60. 
35. Corcoran C. Trajectory to a first episode of psychosis: A qualitative research study with families. Early Interv Psychiatry. 2007;1:54-60.

36. Gladstone B, Volpe T, Boydell K. Issues encountered in a qualitative secondary analysis of help-seeking in the prodrome to psychosis.J Behav Health Serv Res. 2007;34:131= 42.

37. Mackrell $L$, Lavender $T$. Peer relationships in adolescents experiencing a first episode of psychosis. J Ment Health. 2004;13:467-79.

38. Woodside H, Krupa T, Pocock K. How people negotiate for success as psychosis emerges. Early Interv Psychiatry. $2008 ; 2: 50=4$.

39. Hastam N. Bias in psychopathology research. Curr Opinion Psychiatry. 2006;19:625-630.

40. Garb HN. (1998). Studying the clinician: Judgment research and psychologicat assessment. Washington, DC, US: American Psychological Association; 1998.

41. Alexa Internet Inc. Reddit.com Web Traffic Statistics [Internet]. Alexa c1996-2018 [cited Z017 Nov 25]. Available from: https://ww.alexa.com/siteinfo/reddit.com.

42. Griffiths $M$. The use of online methodologies in data collection for gambling and gambling addictions. Int J Ment Health Addiction, 2009;8:8-20.

43. Schrank B, Klose T, Szmukter G, Lloyd K, Koivunen M. How patients with schizophrenia use the Internet: Qualitative study. J Med Internet Res. 2010;12:e70. 
44. Haahr M. True Random Number Service [Internet]. Random Org c1998-2018 [cited 2017 Nov 25]. Available from: https:// random.org/.

45. Smith J, Jarman M, Osborn M. Doing Interpretative Phenomenological Analysis. In Murray M, Chamberlin K, eds. Qualitative Health Psychology. Thousand Oaks, Ealifornia, US: Sage; 1999: 218-40.

46. Gill J. The possibilities of phenomenology for organizational research. Organ Res Meth. 2014;17:118-37.

47. Pietkiewicz I, Smith J. A practical guide to using Interpretative Phenomenological Analysis in qualitative research psychology. C Psychologic. 2012;18:361-9.

48. Knight $M$, Wykes T, HaywardP. 'People don't understand': An investigation of stigma in schizophrenia using Interpretative Phenomenological Analysis (IPA). J Ment Health. $2003 ; 12: 209-22$.

49. Hanssen M, Peeters F, Krabbendam L, Radstake S, Verdoux H, van Os J. How psychotic are individuals with non-psychotic disorders? Soc Psychiatry Psychiatr Epidemiol. 2003;38:149-54.

50. Read J, van Os J, Morrison A, Ross C. Childhood trauma, psychosis and schizophrenia: A literature review with theoretical and clinical implications. Acta Psychiatr Scan. $2005 ; 112: 330-50$

51. Moore T, Zammit S, Lingford-Hughes $A$, et al. Cannabis use and risk of psychotic of affective mental health outcomes: A systematic review. Lancet. 2007;370:319-28. 
52. Häfner $N$, Maurer $K$, Löffler W, Fätenheuer B, an der Heiden W, Riecher-Rössler A, et al. The epidemiology of early schizophrenia: Influence of age and gender on onset and earlycourse. Br J Psychiatry Suppl. 1994;164:29-38.

53. Schultze-Lutter F, MichelC, RuhrmannS, Schimmelmann B. Prevalence and clinical significance of DSA-5-attenuated psychosis syndrome in adolescents and young adults in the general population: The Bern Epidemiological At-Risk (BEAR) study. Schizophr Bull. 2014;40:1499-1508.

54. Kendler K, Gallagher T, Abelson J, Kesster R. Lifetime prevalence, demographic risk factors, and diagnostic validity of nonaffective psychosis as assessed in a US community sample: The National Comorbidity Survey. Arch Gen Psychiatry. 1996;53:1022-31.

55. Read J, Bentall R, Fosse R Time to abandon the bio-bio-bio model of psychosis: Exploring the epigenetic and psychological mechanisms by which adverse life events lead to psychotic symptoms. Epidemiol Psichiatr Soc. 2009;18:299-310.

56. Palmer B, Pankratz S, Bostwick J. The lifetime risk of suicide in schizophrenia: A reexamination. Arch Gen Psychiatry. 2005;62:247-53.

57. Hor K, Taylor M. Suicide and schizophrenia: A systematic review of rates and risk factors. JPsychopharmacol. 2010;24:81-90.

58. Cooke A, Kinderman P. "But what about real mental illnesses?" Alternatives to the 
disease model approach to "schizophrenia”. J Human Psychol. 2018;58:47-71.

59. Jablensky A. Psychiatric classifications: validity and utility. World Psychiatry, 2016;15:26-

31.

60. van Os J, Linscott R, Myin-Germeys I, DelespaulP, Krabbendam L. A systematic review and meta analysis of the psychosis continumm: Evidence for a psychosis pronenesspersistence-impairment model of psychotic disorder. Psychol Med. 2009;39:179-95.

61. Dominguez $M$, Wichers $M$, Lieb $R$, Wittchen $H-U$, van Os J. Evidence that onset of clinical psychosis is an outcome of progressively more persistent subclinical psychotic experiences: An 8 yearcohort study. Schizophr Bull. 2011;37:84-93.

62. Murphy J, MGBride O, Fried E, Shevlin M. Distress, impairment and the extended psychosis phenotype: A network analysis of psychotic experiences in an US general population sample. Schizophr Bull. 2017;sbx134.

63. NayaniT, David A. The auditory hallucination: A phenomenological survey. Psychol Med. $1996 ; 26: 177-89$

64. Mawson A, Cohen K, Berry K. Reviewing evidence for the cognitive model of auditory hallucinations: The relationship between cognitive voice appraisals and distress during psychosis. Clin Psychol Rev. 2010;30:248-58.

65. Wong Z, Öngür D, Cohen B, Ravichandran C, Noam G, Murphy B. Command 
hallucinations and clinical characteristics of suicidality in patients with psychotic spectrum disorders. Compr Psychiatry. 2013;54:611-7.

66. Bartels-Velthuis $A$, van de Willige $G$, Jenner J, vanOSJ, Wiersma D. Course of auditory vocal hallucinations in childhood: 5-year follow-upstudy. Br J Psychiatry. 2011;199:296-302.

67. Bartels-Velthuis $A$, van de Willige G, Jenner J, vanOs J. Auditory hallucinations in ehildhood: Associations with adversity and delusional ideation. Psychol Med. 2012;42:58393.

68. Woods $A$, Jones $\mathrm{N}$, Alderson-Day B, Callard F, Fernyhough $C$. Experiences of hearing voices: Analysis of a novel phenomenological survey. Lancet Psychiatry. 2015;2:323-31.

69. Link BG, Phelan JC, Bresnahan M, Stueve A, Pescosolido BA. Public conceptions of mental illness: labels, causes, dangerousness, and social distance. Am J Pub-Health. $1999 ; 89: 1328-33$

70. Bentall R. The illusion of reality: A review and integration of psychological research on hallucinations. Psychol Bull. 1990;107:82-95.

71. Ohayon M. Prevalence of hallucinations and their pathological associations in the general population. Psychiatry Res. 2000;97:153-64.

72. David C, Greenstein D, Clasen L, Gochman P, Miller R, Tossell IW, et al.Childhood onset schizophrenia: High rate of visual hallucinations. J Am Acad Child Adolesc Psychiatry. $2011 ; 50: 681-6$. 
73. Freeman D, Garety P, Bebbington P, Smith B, Rollinson R, Fowler D, et al. Psychological investigation of the structure of paranoia in a non-elinical population. Br J Psychiatry. $2005 ; 186: 427-35$

74. Freeman D, MCManus S, Brugha T, Meltzer H, Jenkins R, Bebbington P. Concomitants of paranoia in the general population. Psychol Med. 2011;11:923-36.

75. Bebbington P, McBride O, Steel C, Kuipers E, Radovanovic M, Brugha T, et al. The structure of paranoia in the general population. Br J Psychiatry. 2013;202:419-27.

76. Kapur S. Psychosis as a state of aberrant salience: A framework linking biology, phenomenology, and pharmacology in schizophrenia. Am J Psychiatry. 2003;160:1323.

77. Freeman D, Garety P, Fowler D, Kuipers E, Bebbington P, Dunn G. Why do people with delusions fail to choose more realistic explanations for their experiences? An empirical investigation. J Consult Clin Psychol. 2004;72:671-80.

78. Gold J, Gold 1. The "Truman Show" delusion: Psychosis in the global village. Cogn Neuropsychiatry. 2012;17:455-72.

79. Mishara A, Fusar-Polip. The phenomenology and neurobiology of delusion formation during psychosis onset: Jaspers, Truman symptoms, and aberrant salience. Schizophr Bull. 2013;39:278-86.

80. Lincoln T, Lüllmann E, Rief W. Correlates and long-term consequences of poor insight in patients with schizophrenia: A systematic review. Schizophr Bull. 2007;33:1324-42. 
81. Cooke M, Peters E, Fannon D, Anilkumar A, Aasen I, Kuipers E, et al. Insight, distress and coping styles in schizophrenia. Schizophr Res. 2007:94:12-22.

82. Cooke M, Peters E, Fannon D, Aasen 1, Kuipers E, Kumari V.Cognitive insight in psychosis: The relationship between self-certainty and self-reflection dimensions and neuropsychologicalmeasures. Psychiatry Res. 2010;178:284-9.

83. Peters E, Lataster T, Greenwood K, Kuipers E, Williams S, et al. Appraisals, psychotic symptoms and affect in daily life. Psychol Med. 2011;42:1013-23.

84. Lysaker P, Roe D, Yanos P. Toward understanding the insight paradox: internalized stigma moderates the association between insight and social functioning, hope, and selfesteem among people with-schizophrenia spectrum disorders. Schizophr Bull. 2007;33:192 9.

85. Carter L, Read J, Pyle M, Morrison A. The impact of causalexplanationson outcome in people experiencing psychosis: Asystematic review. Clin Psychol Psychother. 2017;24:332 47.

86. Larsen J. Finding meaning in firstepisode psychosis: Experience, agency, and the cultural repertoire. Med AnthropolQ. 2004;18:447-71.

87. Heriot-Maitland C, Knight M, Peters E. A qualitative-comparison of psychotic-like phenomena in clinical and non-clinical populations. Br JClin Psychol. 2012;51:37-53.

88. Read J, Dillon J. Models of Madness: Psychological, Social and Biological Approaches to 
Psychosis. London, United Kingdom: Routledge; 2013. 249-268.

89. Windell D, Norman R, LalS, Malla A. Subjective experiences of illness recovery in individuals treated for first-episode psychosis. Soc Psychiatry Psychiatr Epidemiol. $2015 ; 50: 1069-77$.

90. Fischhoff B, Beyth R. I knew it would happen: Remembered probabilities of once-future things. Org Behav Hum Perform. 1975;13:1-16.

91. Rasic $D$, Hajek T, Alda M, Uher R. Risk of mental illness in offspring of parents with schizophrenia, bipolar disorder, and major depressive disorder: a meta-analysis of family high-risk studies. Schizophr Bull. 2014;40:28-38. 
Table 1. Symptom distress by onset category

\begin{tabular}{|c|c|c|c|}
\hline Onset & Reaction & Frequency & Percentage \\
\hline \multirow{5}{*}{$\begin{array}{l}\text { Always } \\
\text { Present }\end{array}$} & Low Distress & 15 & 50 \\
\hline & Moderate Distress & 14 & 46.7 \\
\hline & High Distress & 0 & 0 \\
\hline & Not Mentioned & 1 & 3.3 \\
\hline & Total & 30 & 100 \\
\hline \multirow{5}{*}{$\begin{array}{l}\text { Started } \\
\text { Slowly }\end{array}$} & Low Distress & 19 & 24.1 \\
\hline & Moderate Distress & 50 & 63.3 \\
\hline & High Distress & 7 & 8.9 \\
\hline & Not Mentioned & 3 & 3.8 \\
\hline & Total & 79 & 100 \\
\hline \multirow{5}{*}{ Suddenly } & Low Distress & 2 & 11.8 \\
\hline & Moderate Distress & 9 & 52.9 \\
\hline & High Distress & 4 & 23.5 \\
\hline & Not Mentioned & 2 & 11.8 \\
\hline & Total & 17 & 100 \\
\hline \multirow{5}{*}{ Current } & Low Distress & 2 & 15.4 \\
\hline & Moderate Distress & 11 & 84.6 \\
\hline & High Distress & 0 & 0 \\
\hline & Not Mentioned & 0 & 0 \\
\hline & Total & 13 & 100 \\
\hline \multirow{5}{*}{ Undefined } & Low Distress & 5 & 45.5 \\
\hline & Moderate Distress & 4 & 36.4 \\
\hline & High Distress & 0 & 0 \\
\hline & Not Mentioned & 2 & 18.2 \\
\hline & Total & 11 & 100 \\
\hline
\end{tabular}


Table 2. Psychiatric diagnoses

\begin{tabular}{lrr}
\hline Diagnosis & Frequency & Percentage \\
\hline Schizophrenia & 13 & 29.5 \\
Schizoaffective Disorder & 12 & 27.3 \\
Schizoaffective Disorder with Depression & 4 & 9.1 \\
Bipolar Disorder & 4 & 9.1 \\
Schizoaffective Bipolar Type & 2 & 4.5 \\
Schizotypal & 2 & 4.5 \\
Psychosis & 2 & 4.5 \\
Schizoid Personality Disorder & 1 & 2.3 \\
Bipolar Psychosis & 1 & 2.3 \\
Personality Disorder & 1 & 2.3 \\
Borderline Personality Disorder & 1 & 2.3 \\
Schizophrenia with Borderline Personality Disorder & 1 & 2.3 \\
\hline Total & 44 & 100
\end{tabular}


3C6O0: I don't hear voices - just noises and sounds. Like the faucet running, window taps, footsteps, doors closing. There's always a television on. I think the first kind of event I guess was when I was 20 living with a roommate. I'd been hearing a radio playing loud music outside in the middle of the night. It had been playing for an hour or two and I snapped. Jumped out of bed and tore through the house to get outside and ask them to turn it down. There was no radio and when I opened the door everything was quiet. Roomie was upset that I woke her up. Though before that I'd see shadow people when I drove. They'd be jaywalking across the street. Ladies holding children's hands, men pushing a shopping cart. That and the stupid cameras. Always assume a room has a camera. In the vents usually. There is always someone watching.

VXU88: "There's always someone watching." This. Since I was very young I have had this sensation. All of my thoughts are being monitored in some way. My private thoughts are public somehow, so self policing my mind was one of my 'fixes'. My intrusive thoughts never seemed 'outside' of me, but many of my paranoid delusions still exist. They never go away, but I have learned to limit the amount of influence they have on me. Many of my thoughts are beneficial as well, kind of like a super brutal coach. Not polite and soothing, but in many cases accurate.

I6T3W: I wasn't social because voices told me people were plotting against me. After being in enough situations where I was forced to be social I noticed that a lot of people were actually pretty nice and the ones who weren't didn't care enough about me to do anything. Once I realized that was a lie I started looking for other things to be suspicious about. I'm in a much better place now.

RO194: I had an early onset of symptoms, at the age of 12. I was stressed out for different reasons and lived with only my mum, who also has schizophrenia. It skewed my baseline a bit. I don't remember the exact first thing that changed, but there were milder early signs. If I stepped on the pavement in this particular pattern, my mum would get better. I walked very strangely as a result, turned around one afternoon and a group of boys from school were laughing at me. I could sense that someone was in the room with me, sometimes. I'd turn on the television, and somebody would say something on the sitcom that matched up exactly with what I was thinking, like we were having a conversation. I'd open a book and there would be a very specific message that seemed like too much of a coincidence. Hallucinations in schizophrenia are usually auditory, but all of mine have tactile and visual. I found lots of tiny pieces of paper stuck on my bedroom wall and when I drew closer to read them, they'd divide by 2 . When I went even closer, they'd divide by 2 again. So I could never read what was written on them. I ended up as an involuntary inpatient at a children's psychiatric ward when I was 14, which exacerbated the symptoms further. I read a paper in my psychology minor where a group of researchers asked for childhood home videos of people who would later be diagnosed with schizophrenia. It was a blinded study, and researchers found that they could pick which child would 
grow up to be diagnosed with psychosis based on their motor patterns. The children tended to be clumsier and walk in a stereotypical fashion. Not surprising since the motor system is neurological. The gut system (enteric nervous system) is also neurological, and has been implicated in schizophrenia and more commonly developmental disorders like autism. It's kind of interesting, because it's believed that the first signs of schizophrenia aren't positive symptoms (hallucinations, delusions), but negative symptoms like withdrawal, anhedonia (feeling flat), social interaction issues. So perhaps there's a step even before that. I'm in med school now and a bit nervous about my psychiatry rotation actually, because I know patients in the public system aren't always treated with dignity. Fortunately my cohort of students and the staff in my hospital placement are absolutely wonderful people who I trust will treat patients with respect.

RL92O: $\quad$ The space under my bed began talking to me in my dreams, then not in my dreams. The first thing I ever remember it saying was "don't worry I'm not going to kill your mom". I was 8 or 9 years old.

JM2RC: $\quad$ My first symptoms were visual and auditory illusions, specifically speech, I didn't hear anything else at the start. I found out something is up when during a conversation with my friends. A person just randomly joined in the conversation, and since no one acted I thought I was the only one who didn't know the person and rolled with it. A bit later my friends asked me who I am speaking to, concerned. I pointed to the newcomer, and he gave a little wave back. Of course, I was the only one who "saw" him. Ironically at the time I thought everyone but me was crazy. After being diagnosed with schizophrenia the guy accepted himself as a part of my imagination. Or technically I imagined a guy who accepted himself as my imagination. Psychology dealing with schizophrenia is mind boggling.

KWP7V: I'm on medication for schizoaffective disorder and it's helped tremendously.

However. Before I was diagnosed I spent most days in fear of being alone in my home (even though I would isolate myself to my bedroom) because of the visual hallucinations. Some of them were in my peripheral vision, but I used to see hands snaking over the backs of furniture, like couches or beds. It would terrify me. Also, as soon as I would begin to relax, especially before bed, I would hear voices and deep, loud growls. Once I had a friend staying with me and she didn't respond to it and I realized that maybe something was wrong. It took 3 years after that for me to seek medical attention. I would think I was getting better because it would stop, just to return a few days or weeks later.

FUK4H: I've been diagnosed as Schizoaffective (Bi-Polar type). Basically means that symptoms of the two disorder present themselves. Something wasn't quite right when my memory started to decline. Then my cognition got worse, if that makes sense. I'd start walking somewhere, and 
halfway there, I'd forget how I'd arrived at my location, or why I was even there. I thought I had stumbled out of a dream. Then I started giving too much weight to ridiculous thoughts and ideas. Normally humans can dismiss stupid ideas like their thoughts are conspiring with the universe to give people cancer, or that everyone is conspiring against you, but...sometimes it went a little too far. I didn't see anything explicitly wrong because I was still functioning well enough. I just chalked it up to my over-active imagination. I should have gotten help when I started seeing and hearing things. Shadow people lunging at me, following me...Bugs on my skin. Took a certain episode until I did. Meds were tremendous help, and now in my life, I am doing very well.

HMNI6: $\quad$ I'm diagnosed schizoaffective. It started with a bipolar diagnosis when I was a teenager, so I knew I wasn't all there to begin with. I went off my meds for a few years and had pretty mild symptoms. I was going to school and doing well. In my junior year of college I started getting paranoia pretty badly. It started off mild enough, I think I've always been a little paranoid. It got progressively worse over the course of a couple months and got to the point where I constantly thought I was being followed or on the verge of being physically attacked. Then I started seeing things. Just little things at first. Bugs crawling on the wall or flying around in the corner of my eye. I would think I saw people and then I'd focus on them and there would be nothing there. Mostly standing on sidewalks while I was driving, which was fun. It crept up on me to where I didn't think a whole lot about it at first. Maybe a little "that's odd" or thinking something was unusual. Then I kinda took a step back and realized, "Hey. That's not right. I'm freaked out all the time and constantly feel like I'm being hunted down. Maybe I should go back to the doctor." And now I've been medicated for a couple years. It keeps creeping back up little by little and we just kinda throw more meds at it. I'm pretty functional and as far as I know only a select few know about it, except all of reddit.

UKGEM: I am schizo-affective. It all started with depression, which in hindsight might be the deficit, that people who are schizo develop prior to positive symptoms or hearing things. I ve always been the quiet boy. I don't know if my quiet personality let me develop depression or if my depression caused my quietness. I realized something was wrong early in my childhood, cause I always saw people do things all the time, that I wouldn't have done or said in my wildest dreams. I to this day can not figure out how to live a life you want to live or how to "dream". It's not that I don't want a happy life with a wife, kids etc. It's just, that I can not ever imagine asking girls out, saying what I think about that selfish, self-centered co-worker I have to sit next to or generally doing anything, that is meaningful to someone else or myself. But enough with the bragging. First time I heard voices was in my apartment and it was always whispers of neighbors I heard. At first I wasn't able to understand them. Then I thought I did. They sounded real, because by the loudness of their voices, they could in fact have been my neighbors talking about me. But one day I drove alone in the car and still heard voices. I turned off the radio to hear the voices and realized, that there can in fact be no people 
whispering outside my car, since I was driving all the time. That's when I realized, I'm not only depressed and a siciophobic, but am completely nuts. It starts making me even more depressed thinking about, that I have no chance of ever escaping that disease and having to deal with it the rest of my life.

VACPJ: I was in college, so much stress and anxiety was the cause of it. I began first seeing shadow people. Some passing by on a whim. I can clearly remember one that look like it was wearing a dress, going so quickly down the hall but w it came voices. Jumbled gibberish w high notes of laughter. Then came the name whispers. I got on medication soon after. During this time my anxiety wouldn't let up. Also saw many things as a child too.

GVETJ: The whispers were the worst for me.. and I'd hear breathing under my bed.. at its worst I felt, literally felt, something crawl up my bed and lay next to me. I started freaking out and my parents were holding me telling me no one was there. It was awful.

TADC9: $\quad$ Oh, oh yay I can answer this! I noticed something wasn't right probably around 19 years old. Because schizophrenia makes you think your hallucinations are normal, the first time I heard a random voice talking to me I didn't realize it shouldn't be happening or that it wasn't real, I thought there was really a woman talking to me despite the fact there wasn't anyone there, eh. Anyway I still am not sure how much of my major depression and serious unhappiness was due to the abusive relationship I was in, and how much of it was from the schizophrenia but around 19 years old everything hit the fan. I couldn't put up with everything that was happening. I had this disconnected from reality feeling happening and was starting to act strangely like sending cryptic messages to my ex's friends. I was slowly starting to go downhill. There were signs that I didn't realize, like people were telling me I was blacking out and doing strange things like staring out windows for an hour just standing there while a group of people outside look at me like what is she doing...or putting cigarettes out on my bare foot...didn't realize it was happening AT ALL...like when I black out my mind creates an alternate reality that seems totally normal...like when I put the cigarette out on my foot I was thinking about it but I didn't realize I was doing it, I thought I was just walking down the sidewalk. Little stuff like this just kept building and building until I felt I was losing my mind and I had to go see a doctor. He diagnosed me depression and mild psychosis, that diagnosis has changed to schizoaffective with depression which is basically schizophrenia combined with a mood disorder. It really stinks to this type of sick...even medicated I'm not fully normal.

6VVJC: Im not your typical case i was 30 years old when i started to hear voices. I was getting ready for a camping trip with the family when i herd someone say "You are doing it wrong". I was in my garage by myself getting my boat ready, it made my blood run cold. I looked everywhere thinking 
someone was playing a trick on me but found nobody. The next 4 months where a living hell at my house. I started seeing people in my house at work even outside. They would just stand in corners or walk by a doorway i was literally freaking out non-stop. I thought it would go away but it didnt. I finally told my wife when the voices started telling me to kill my wife and daughter. She was very supportive even went to the doctor appointments with me. After a brief saty in the hospital they got my meds worked out and the voices and people stopped manifesting. From time to time i will hear something or see something and $\mathrm{i}$ know its not real $\mathrm{i}$ just ignor them and move on with what ever im doing

EAHLL: There's already 200+ comments at this point but screw it. When I knew something was wrong it was so brief. After that I was just sucked into the delusions and fear. Time was passing strangely and my memories are fuzzy about the worst of it. I remember realizing I couldn't function at work. I asked my boss if I could leave and walked home ( I didn't live far). I called either my boyfriend at the time or my mom on the way and said something was wrong and I needed help. I had been prescribed some anti-anxiety medication shortly before that but it put me into a downward spiral. I was trying to save the world. I wanted to solve major problems like world hunger. Problems I had no business trying to figure out. Something had happened with my vision. I have NEVER experienced this before and it was so bizarre. I don't know if it had anything to do with schizophrenia or if it was a side effect of the medication but lights...just regular lights in an office or the sun outside...they were so BRIGHT. I remember when I finally went into a treatment center to speak with someone I had to squint everywhere I went. It was painful. Also I remember being asked why I couldn't look at the person who was giving me a questionnaire (it was so bright) so I'm pretty sure that I really did go through that. No one ever explained to me why I went through this. If anyone knows anything about this or has experienced something similar, I'm all ears. Anyway...the main parts. Feeling watched. And for some reason I "knew" where the cameras were. In vents, cracks in walls, old punctures from thumb tacs. Radio, movies and television was tough. I remember being in my car and hearing a voice coming out of my radio talking TO me. Some voice explaining that they were just checking up on me and that they'd be back later. It was hard to watch TV and enjoy my shows. I did get hospitalized when this happened. On the way when I was in the ambulance I thought that I was on my way to become part of a team that was going to save the world. Obama was leading it and picked me. :/ Yeah i know... What else... I didn't think my mother was really my mother. She was chosen to take care of me. And my father (parents had seperated when I was very young) had really only left because he was testing my character and once I was proven a "good person" he would come back into my life with plenty of money I could live off of. That delusion is pretty embarrassing. I'm glad there was at least some part of me that said "help" while it was all happening and I was able to get some medication to help. It's the most frightening thing I've ever been through and I feel fortunate that I've been able to gain stability and work and be happy since all that. 
NJUWL: I'm schizotypal. When I was 12, I stopped going to school. I can't really pinpoint what exactly made me stop going other than perhaps an instinct that something wasn't right. I felt uncomfortable all the time, it felt like too much effort to keep up with the social things of school (even though nothing out of the ordinary had happened) and I didn't want to be part of it anymore and became depressed. I think the great discomfort and this really deep feeling of not being like everyone else were the first signs. I was a totally normal kid but I just always had this feeling that there was something off about who I was. I remember having paranoid thoughts that I was actually two years older than my parents told me I was, sometimes other people seemed cartoonish and one-dimensional to me, even sometimes questioned if other people were real, and I was genuinely convinced that nobody actually liked me (I had plenty of friends). Sometimes my tongue would feel huge in my mouth, or I would feel like my feet were miles apart even though I could clearly see they were right next to each other. But of course as a kid I didn't know that any of these things were abnormal and you don't really tell people either, so it wasn't until I stopped going to school that my parents had any idea that something was wrong. I went through psychoeducation (not sure if that's the english term though) in the psychiatry a few years back and it was really helpful for me to learn about the typical early signs of psychosis, so I know what to pay attention to and when to slow down.

HRFAZ: When I was 13 I was officially diagnosed with schizoid personality disorder. I spent so much time in my own head, hearing my LCSW actually describe it as a condition with a name and description was the first time I realized these worlds were not real. I think people underestimate delusions they see in movies and tv as 'epic productions', or a 'breathtaking spectacle' with production values and entertaining plot, but always with a set of clear 'rules' for how to behave within them. This is not true. Lucid dreaming is a type of self-controlled fantasy where world building is possible, but schizophrenic delusions...don't work this way. I can't really explain it as a memory palace, or like an encyclopedia where you can organize or look up information, a story, narrative, or an Inception-level linear state. And it is not necessarily a fun or entertaining state. I felt like I only had a fragile grip in every situation, and with control I could never prepare for. This state is something that eclipsed external senses and put a barrier between perceptions of things outside myself...I feel like I need to backtrack a bit. Being schizoid is not necessarily a precursor, but by the time I was 17 I was almost catatonic. There are a lot of similar tendancies. A whole lot of other factors, abuse, suicide and mutilation got me hospitalized, in and out of reality. I am 30 now, medicated, married and stable. I was diagnosed with dyschonesia, still with memory loss from ECT. My first psychiatrist offered the comparison: starting as a schizoid is like having one foot out the door, and going through it can be an easier choice. I remember hearing voices and noises I did not trust. Actually hearing my LCSW's voice when I was 13 is something I will never forget. It is scary how much I do remember about this mode of thinking, and how easily it is to slip back into that cocoon when I am not careful. I don't trust 
ANYONE with the more concrete details of my delusions, except my husband. I am paranoid, a loner, but a survivor. There are alot of tendencies I still don't understand. I can't think of a tl; dr, but thankyou to anyone who made it to the end of this post.

5U784: I've had Voices All My Life. And at times in my life have been absolutely terrifying. I wake up many many many times in my life thinking that events have happened when they haven't at all and only sometimes even years later I realize that something that I thought had happened never happened. I'm a songwriter and will wake up with songs fully formed not only versus but choruses, rhythms Melodies and everything complete and for a long time I thought my brain was just running a song that I had heard at some point on the radio or whatever but I only after time that I realized that these were originals and I just started catching them. Remember waking up one time thinking that I had nervously pulled out all the hair of half of one of my eyebrows and I walked around for a week waiting for the hair to grow back and being just self-conscious about it.. Then only realize that at the end of the week when I took a look in the mirror I hadn't pulled any out and I must have dreamt it and thought it was real.

C3WNP: Comment may get buried, but here I go. The aliens I was able to see in patterns of furniture, flooring, walls directed me to decipher a code. So I wrote up a notebook of total nonsense and then tried to decipher it. At the back of my mind during this, I was able to see logically that it didn't make sense, but I still had psychosis.

ALOSO: I spent 30 minutes hovering over my sleeping boyfriend with a pillow. He was a heavy sleeper. I could have killed him. I almost did. I woke him up, sent him home (much to his confusion), spent 10 minutes on hold with my psychiatrists' nurse (I was already being treated for depression), booked an appointment, hauled ass to the clinic, waited 3 hours to be seen, told him everything, got a script, went straight to pharmacy, got my pills, and took them immediately. I've done my absolute best to try and stay medicated properly ever since. Of course I grew up knowing my mother had mental illness, so I was a-typically very educated about the whole thing. Otherwise, he'd likely been dead since 2008 .

PCOM9: I'm not sure what the first time was, but there are certainly some things that stand out in my mind. When I was 12-ish, I was terrified of the spiders in my room. My mom thought it was because I was afraid of spiders, but individually, I didn't mind them. However, I strongly believed that the spiders on my ceiling and walls coordinated to do me harm. I pretended to be sick in bed one day because there was a spider directly over my door frame, and one beside my light switch, and I could smell an ambush. Another time, I was in the shower, and something told me that I was dead, very convincingly. I checked the mirror immediately, because TV has conditioned me to think that dead 
people don't have reflections, I guess. So I finished up in the shower, and got out, and went out into the living room where my family was. Of course, I wasn't dead, but they didn't really acknowledge me when I walked in the room, so I just kind of accepted that I was dead. I went to bed, and for the whole night I thought that I had died, until morning came around. Those two anecdotes are kind-of litemode, I think. The one thing that has really always been present, is music. I hear music almost 24/7. I didn't even realize it was a weird thing, until I started questioning why other people wore headphones. Finally, when I was around 17, I really started to get paranoid. Like, ludicrously paranoid. I had a small apartment on the second floor of a building, and I kept the blinds and windows closed $100 \%$ of the time. I expected, at any moment, for a grenade to be chucked in. I hated leaving my apartment, because there were so many people. I devised strategies for passing them when meeting on a sidewalk. I checked windows and rooftops for snipers. One time, there were too many people on a bus I was supposed to take, so I ended up walking about $40 \mathrm{~km}$ instead. At one point, I think I really started to break from reality, actually... because I vividly remember trying to work out where the stones on the path in front of me stopped, and the air began, and not really figuring it out. Shortly thereafter, I completely broke down and went about rebuilding myself.

CXNSB: I started noticing the symptoms during my first year of high school but was not diagnosed until grade 12. It started off with being fearful of what other people think which was innocent and later progressed into not wanting to go to school in the 12th grade. I began to hear multiple voices from a woman and she used to laugh at me all the time and tell me I was worthless. She would mentally abuse me and make me think that people were after me. Whenever I would go to school, she would put the fear in me that other people could read my thoughts and use them against me. I legitimately thought that people were listening to what I was thinking and whenever someone would laugh, I would automatically think that they are laughing at me. I would listen attentively in class, but couldn't pay attention properly because I was tired from the night before from all the laughing, insults, and general scary nature of it all. Before I was diagnosed with schizophrenia I had no clue that those that suffer from this illness, go through this. When the radio would turn on, I thought the announcer would be directly talking to me and trying to embarrass me to the whole world by revealing details about my life to all of the people listening to that station. When I was at home with my family, I thought they were all plotting against me and were in on some conspiracy to get me arrested by the police. It was the same case at school. I began to suspect friends were turning on me (although they were not), I highly believed that my teachers were picking on me (although they were not), and I believed that little tweaks such as making me answer the questions on the board, and to read out loud were the result of listening to my thoughts and knowing that the voice wanted me to not read due to the sleepless nights. I thought that my food was being poisoned, I saw things such as things moving which were not actually moving. I thought that the government was after me, and I thought that people genuinely hated me. To this day, I still don't know if people are against me or with 
me because whenever I want to hang out with old friends, it seems like they act differently or it could just be my mind playing games on me. Luckily, I live in a beautiful country that supports the rights and freedoms of mentally ill individuals and have support systems in place so that they can live a healthy, well-rounded life and not worry about becoming homeless and dying on their own. I am now on the road to recovery. I take meds for schizophrenia and they work like a charm. I haven't had hallucinations or the voices in a very long time and I hope that they do not come back again but there is a chance of relapsing. My plans for the future is to go back to school (I start in the new year), to hopefully find a career in my chosen major, and to actually find love in my life. To all who are reading this comment, if you suspect that you are suffering with some sort of mental illness, you should not panic as panicking makes things worse, you should consult your GP and ask to be assessed if you are indeed sure that you are suffering. Please, don't suffer with this alone, and remember there is a light at the end of the tunnel :)

40FYE: I was in college and I recounted to a teammate about a person who visited me sometimes and they were trying to kill me - this person floated and looked half dead. It never occurred to me that this was a strange thing but the look of shock I was given was really curious to me. It made me think they must never experience something like that. That was the first time I thought maybe something was up. I was referred to a psychiatrist but I didnt talk about the visitations because I didnt think it was any different then talking about people on my sports team. I also started to notice people mentioning that I never talked. It actually took another five years, and an experience I had when I attempted suicide, for me to realize that my experiences and my emotional state were not experienced by most people and that I needed to get help.

M2IEY: At some point when I was young, I read about imaginary friends and was surprised to learn that they usually went away and didn't actually tell you things. I didn't tell my parents until much older and faces started appearing in my windows.

EM2RN: Finally something for me to answer. I was in the prodrome phase which was early signs. I was constantly going to doctors complaining about suicidal thoughts, anxiety, stomach problems. I was always brushed off cause I have a degree and a good job, but I was psychotic. I knew things were off and there was something severely wrong with me but one second i believed in Mental health and the next second the delusions took over and meds where a sham perpetrated by "the man" Cool fact. I actually predicted my hospitalization here on Reddit. I made a post asking when I should go to the loony bin and sure enough later within the week I was hospitalized for my first time ever.

IYOOV: I used to think I could see people that weren't there. The girl from the ring used to stand in the corner of my room and point at me while I tried to sleep. That and an old guy that would 
show up from time to time and wave. I also thought my mother was trying to poison me with her food, so I taught myself to cook (for other reasons as well) to make sure the food was safe. I wasn't diagnosed as schizoaffective until I had my first psychotic break a couple years ago when I thought people were watching me through the television and following me everywhere I went. I still fight with the paranoia on a seemingly daily basis and as such I don't leave the house for usually more than an hour to go to the gym or twenty minutes to go to the store a few times a week. It doesn't help that my dad built spy software for the government when we first moved to the us. It makes for a shadowy group of people potentially working for the government following you around asking you very personal questions when you're sitting at a cafe almost plausible which is just fucking terrible to deal with when you have to question reality all the time.

69OWD: As far back as I could remember, there were two voices in my head. They'd keep me company, but sometimes they'd say weird things or be annoying. When I had sleepovers they'd tell me stories and I'd relay them to everyone else (pretending they were my own ideas, which they technically were I guess), and everyone enjoyed them. Since they were only in my head, I'd also only speak to them in my head - that was just how it worked, I didn't question it. When they told me things, they were almost always right, so I believed them without question. Sometimes it was just straight-up paranoia, though, which got me into a lot of trouble on occasion (blaming my brothers for random things, like losing my favorite pencil or tripping and spraining my ankle). I didn't have a strong sense of morality growing up, so if it was suggested that I rip the wings off the fly that was buzzing around, I'd catch it and do that (which also got me in trouble, because my parents believed all life was important and I should've let it go outside). When I was 13, the issue was exacerbated. Suddenly, there weren't two voices, there were seven. One of them was God. I'd ask Him questions and he'd give me answers. There was a sense of trust in that relationship; he was like a mentor. If I did something wrong, He'd "punish" me (though it wasn't always rational, like if I took the last slice of cake that was for me, without sharing it) by making me feel terribly nauseated, to the point that it was debilitating ("He" also traumatized me from masturbation through the same punishment system). The thing is, that voice was always telling me to do the right thing, not the wrong thing. Five of the other voices were quiet for the most part, though they were always having conversations in the background. Sometimes they would get so loud that I'd scream in my head for them to shut up so I could think (mostly when they got bored, like when I was working on school assignments). I was terrified I would yell at them in public (I didn't know why, but that just wasn't something people did — at this point I still assumed everyone had other people in their heads). I walked oddly, I know that for sure, and I always had to look down at the ground and make sure I didn't step on any branches, I always stepped where there were the least leaves, no matter what I couldn't step on cracks in pavement, and if there was a series of lines (like at the street crossing), I had to always step on those lines only. At one point I hallucinated that there was something in a cup I was drinking out of (it was really disgusting but I 
don't know what it was), and from that point forward, even now, I can't use a dish, glass, or utensil if it has even a speck or a water stain on it. The seventh voice was that of the Devil, always trying to get me to let him have my soul or my body, or both. I was terrified I'd let up in a moment of weakness, especially when I was around other people, so I was always tense and uneasy. I knew that if he took over, he'd kill everyone around me. It's awful to say this, but I think he was my uninhibited side. When I was around 14, I started having more physical hallucinations. I'd hear voices or music (the voices in my head would also on occasion play music for me). I saw someone open an employeesonly door and leave it open, but when I turned to go tell them, the door was shut. I heard people asking questions through doors, often people I knew, but when I asked who it was I would get no answer (which kind of freaked me out, to be honest; I started thinking there were imitations living around me). When I was just turning 15, I finally started getting help after the symptoms became much worse. Everyone was out to get me; I hated leaving the house, so much so that I'd argue vehemently against it. I heard people breathing behind me. When I was walking outside, there were always footsteps behind me that were just a bit out of sync from and went on just a bit longer than mine. I started using "incantations" to ward off the Devil and spirits-I would speak gibberish in the bathroom, and sometimes outside. When I looked into a mirror, there were sometimes shapes behind me, and my face would suddenly change into terrifying things. The turning point was when I started seeing a white werewolf in the house (I knew that shouldn't exist, so I started suspecting around then), and at one point when I went to the restroom I suddenly felt it pressed against me, breathing down on my head (it was around 8 feet tall). I couldn't move, I had an utter panic attack and broke down yelling for someone to help. Naturally, there was nothing really there. I started medication for it after that, and they worked to get rid of most of the physical hallucinations and all of the voices in my head (which was kind of lonely, and I hated that "God" left me). I had a sense that I wasn't "me", though, that I was one of the voices that was in my head before. I acted oddly sometimes, making no sense, and I would get confused about how my body was supposed to move. When I saw characters on TV that, for example, had kidney failure or were blind, I thought to myself, "it'd be so much simpler to be like that". I tried to make both happen, terrible experiences. I'm now terrified something will happen to my eyes, ironically. At the same time, I had "episodes" of homicidal ideations. They would last for days or weeks, and during the hours or days I was "lucid", I felt terrible. I would remember the detailed plans I made to become a serial killer when I moved out (worse than most serial killers, to be quite honest; among the worst). I trained myself in an undoubtedly toxic form of meditation during that time, one that sealed away my emotions and made my thoughts seem like they weren't mine. It was awkward to move like that, because it was hard to force those thoughts that didn't belong to me into my body. I relapsed occasionally, especially during times when I was happy (which made me hate myself, and the fear of being happy is something I'm still struggling to work through). I decided I needed help during one of those times, and I told my parents. We went to the psychiatrist again, where I told her I was fine, but fortunately my parents were there to argue against that, knowing how upset I 
was and that I wasn't lucid again. I started a medication that tanked my memory and emotions. It was terribly hard to think at all, I was like a zombie. I've gradually worked my way off it and I haven't relapsed (likely due to the other medication finally working as it should). I still feel like I'm not the "me" I used to be, though, and I sometimes get the desire to self-mutilate again, often in other ways. That's my story.

P62IG: I can't quite remember. My first symptoms were negative symptoms. Um, maybe when I first attempted suicide because my voices told me to? I still didn't think that was weird though, my dx kind of surprised me.

Z44P1: Schizoaffective here... I don't hear voices but have massive delusions that the world around me is totally construct and I'm actually a homeless person living behind a dumpster or a prostitute in a seedy motel. I also have delusions that if I kill myself and my children I will move on to the next "string of life" and jump ahead or over. It's hard to explain. I will also drive aimlessly without realizing until I'm miles away from my destination. But my meds work wonders!!! I'm all good right now as long as I don't resist treatment.

4K0UY: When I was younger, I was in the living room at around 5-6 AM, just when the sun was coming up and everything was all blue. I looked down for a second and saw a pale white girl with sunken in eyes staring back at me. It took around 5 seconds of frozen staring for me to blink and for the figure to just be a vacuum cleaner. A few years later I was diagnosed with paranoid schizophrenia for some other reasons, for example...I've been seeing floating orbs and shadow people/animals for a while. Kind of trying to be careful describing it because I don't want to bring them back. If I were to describe them, they're like flowing water, in a way. Pitch black, slightly see-through and they move in very unnatural ways, the physics are always slightly off. They usually vanish once you look straight at them, but occasionally they've been there for hours and only when I reach out to pet them (thinking they're my actual animals), I realize they were never there. I'm pretty sure most people who have lived in a haunted house have some form of mild psychosis or schizophrenia.

6VJM4: For me personally, I have partial schizophrenia due to PTSD. It came as an unwarranted side effect of severe trauma for different reason, which is why It was so severe. I was around 13 or 14, and sitting in a computer class. It started out as small tv static noises here and there, almost like a loud white noise. Eventually I began hearing whispers behind my ear like someome got a little too close for comfort. I would see a single black shadow that would always engulf a corner of a room in liquid looking black smoke. It didnt really have a form, but it would always have red eyes coming out of it somewhere, followed with the tv static noises. I finally said something to my parents 
one night after waking up to seeing it standing in my room, telling me to burn the house down with my family in it. I'm much better now and on meds, so I havent really had problems since.

ZMQIE: I'm diagnosed as Schizoaffective, meaning I experience symptoms of Schizophrenia and Bipolar Disorder both. I noticed something wasn't right when I started to think (especially during times $i$ had ingested psychedelics) that people were taking pictures of me (i would see flashes of lights outside the windows) and talking about me behind my back. It just kept getting worse after that one time and it kept spiraling downwards. It went from slightly paranoid thoughts to full blown delusions and ultimately insane beliefs. I started to really withdraw from the people i had called my best friends and hung out with on a daily basis because i was convinced they were plotting against me. I $\square$ think this all just got significantly worse after my last bout with psychedelics. We went camping and had a tent to do our drugs in during the day and night. I $\square$ remember taking 2 tabs of acid and then I $\square$ have no clue whether the 3 water bottles I $\square$ drank were laced with more. I $\square$ thought that while i was in the tent by myself that all of my 'friends' were on the outside mocking me and making fun of me all while pushing on the tent. At one point $\mathrm{I} \square$ looked outside and saw people walking in lines with big branches in their hands singing "kumbayah" (I $\square$ could not make this shit up). If you've ever seen the movie "The Truman Show" that's exactly what everyday life feels like, as if someone or something is constantly watching you (i would look for hidden cameras everywhere i went for around a 4-6 month period) and you are there for other people to watch you. I've had delusions to the point of believing that $\mathrm{i}$ was the second coming of Jesus, or just a messiah of sorts. I've thought that the Truman Show was a metaphorical documentary for my life(meaning I thought $\mathrm{i}$ was like Truman in that my entire life is a TV show and a lie). Imagine if every single person in the world was talking about you at once, people at school, teachers during lectures, reporters on the news, actors in movies and tv shows. That is paranoid schizophrenia/psychosis. I would turn on the TV and think that every single show and movie had euphemisms and hidden messages pertaining to me specifically, messages that they wanted me to know about the "big reveal" where everything would be revealed to me finally. I've thought that i had super powers or that I $\square$ have some sort of special purpose in life that I'm being pushed towards. I realized when i started to distrust my closest friends, some of whom I'd known for more than 3/4 of my life, and my girlfriend who sat with me while i bawled and cried for hours about how $\mathrm{i}$ was losing my mind, that I had an illness and I needed to get help. Sorry for the formatting and wall of text, I'm on mobile. I also just wanted to thank anyone that was willing to take the time to read anything in this entire post, including my comment. For people like us, sometimes it means more than anything in the world just to listen.

QO680: I figured something was wrong when I couldn't stop thoughts from entering my mind and it lead to multiple crisises leading to hospitalization. But last year I was drugged with cool and it turned severe. In the aftermath of the drugging I suffered derealization and what I can only describe as 
ego boundries being somewhat lost. Or at least this is what me and my doctors have discussed as possible effects of my mental conditions. Thankfully I am on medications that inhibit the thoughts that are detrimental to my daily life. Making me a high functioning schizophrenic. But thoughts of both paranoia and pronoia come to me because my mental condition is somewhat pattern seeking. Sorry if this doesnfully make sense.

8LP24: I kinda always felt "off" or "distant". When I was eight, I asked to go to therapy because I noticed that my emotions weren't rational. It's been a strange life ever since.

23IUX: I'm schizoaffective depressive type, a kind of schizophrenia. I was being treated for my depression which was pretty severe at the time. Several of the doctors I went through asked me if I was hearing or seeing things they didn't. I said no because I didn't think that the voices in my head were abnormal. I thought everyone had multiple voices in their heads. After being asked that same question like four times I did a little research on it and found out that my voices were not normal at all. I told my doctor about the voices and he changed gave me a low dose of antipsychotics and changed my diagnosis to depression with psychotic features. I was fine (granted I had severe depression and voices in my head telling me terrible things all day) for a while until I started to feel that people were after me. I believed that people wanted to kill me and that I was being indoctrinated into a cult. I told this to my therapist and she became concerned that I might have schizophrenia. To make a long story short, my depression eventually went away for a little bit but my psychosis stayed. Thus I was diagnosed schizoaffective depressive type.

SZQSP: I was 12 or 13 and heard someone's voice in my head that was not my own. It was so clear it sounded like someone was in my room telling me I'm not good enough to be alive. I started freaking the fuck out, crying hysterically and ran to my mom and dad to try to get away from it but it kept following me. They tried to calm me down telling me its not real but it sure as fuck was for me. I calmed down and my parents I guess chalked it up to hormones. It progressively got worse to the point of hallucinations and a suicide attempt that I was admitted to a psych hospital and put on medication.

Q4NI3: I was pretty clued in to what Schizophrenia is and how it effects people. I am a nurse who has always had a keen interest in mental health. The first signs were horrible panic attacks and paranoia that people at work were trying to get me fired. I came to believe they were all there working against me. A friend informed me that I was being very paranoid, and I noticed a lot of negative symptoms, fuzzy thinking, inability to remember simple things. I started to hear voices intermittently. I suspected what was coming but when I finally had a psychotic break I still had no insight. I walked into the police station and asked to file a report about aliens mind controlling people at my work. It 
seemed the only logical explanation to me, it was as though everything finally made sense and that was the truth of the world. In short, I knew it was coming but that didn't stop it.

PTTFF: i started becoming more paranoid. everyone was looking at me, everyone was talking shit on me. cool tones were registered as accusatory. it was a nightmare, and completely differerent from what i had felt even a month before. i was brushed off my my psychiatrist as having anxiety.

D7VXF: Heard my mom scream blood murder from downstairs. Threw pants on, bolted to the living room to see her seated comfortably on the computer browsing facebook. Asked what was wrong in a panicked tone, she just looks at me like I'm crazy. Turned out I was :) A few years "Clean" (no hallucinations or delusions), got some meds lined up that work really well for me, and had some kickass treatment over the years I was figuring shit out.

NBJ9H: I hear singing voices. It's actually quite beautiful but can get so annoying as it can sometimes be quite constant. It's like a choir of people singing. They just comment on things I'm doing in a sing song way. Sometimes it gets to be too much that I have to put headphones on to drown them out. I'm on medication for it now which helps to drown out most of it but man, does it give you the munchies. I have to actively be very aware to not overeat to prevent weight gain.

MIQB5: I found out far too late. I would be talking to someone and hear something completely different than what they said, however I still heard it in their voice clear as if it was a normal conversation. What they said would line up with my delusional reality. I had no way of knowing what I was experiencing wasn't real. My delusions and paranoia were completely real thanks to audio and visual hallucinations. After a 3 month episode I was eventually hospitalized and medicated. This is the first time I realized what was going on. I watched recordings of myself and heard the REAL conversations after I stabilized and that was the most painful thing I have ever experienced in life. By the time I started realising that the life I had been living for three months wasn't real I had already lost my job, my fiance, all my savings, and most of my friends. I'm bankrupt, and no longer have insurance to pay for treatment. It was like waking up from a coma finding myself in hell. I was a successful and happy man, with a bright future ahead of me. I never thought I would ever experience something worse than death, but I honestly did. If it wouldn't hurt my family I would kill myself without hesitation. Washed up at 28, I'm haunted every night with nightmares of the life I lost, and the reality that I have this illness is like a bitter poison coating on the dagger that dug into my being. It destroyed my view of life and the universe. I have to question everything I think and hear. My sentient mind is my prison. I've got a life sentence. Hearing voices is very real. It i's not like thinking to yourself. I also hear whatever anxieties my mind comes up with. If I'm afraid of a bear in the woods I will hear a bear in the woods. visual hallucinations for me are most common on electronic screens. 
the ringing in my ears and skull never stops. I have learned to live with it. the most horrendous audio hallucinations I've experienced are hearing my loved ones screaming in agony from being tortured, and hearing an ambulance siren for three days straight. I tried plugging my ears by day three but it did nothing. I rarely remembered dreams before my 3 month episode. Maybe one or two a year. Now I remember them every day most of my memories are gone from my psychotic break. even on medications I still get mild audio hallucinations, mostly noises like dog barks, high pitched ringing in my ears, or creaking floorboards etc. Otherwise so far I'm as stable as someone could be after experiencing something like this.

0IG7A: My parents divorced when I was 5, my mother was just gone one morning. Nobody ever really talked to me about it and I think that was actually really traumatic but I repressed it. I also remember being very depressed and apathetic from maybe age 14-17 or so, but part of that might just come with being a teenager. Schizophrenia started to set in for me at about 17, but it was pretty gradual. At first I would have these massive paranoia attacks out of nowhere, It was like the feeling you get when you know you're being watched without really looking, only multiply that by like 1000 . My heart started pounding and I guess it's probably the same as an anxiety or panic attack, but the thing I remember the most is definitely the paranoia. Then, I thought there were cameras and microphones all throughout my house that my friends had put there to watch and listen to so they could make fun of me, I thought I was telepathic and that people could hear my thoughts and stuff. They also had put some sort of virus on my computer to watch everything on my screen. After that I started to act on my delusions, I would go on long walks in the snow barefoot, or very very late at night in the country. Eventually a police officer stopped to pick me up, seeing me walking down the road in winter, in new england, without shoes or boots, and I ran. that's how I wound up in a psychiatrists office for the first time. Then I walked a little too far from my mother's home, and I got lost because I wasn't as familiar with that area and wound up getting picked up by cops again. I was taken to another hospital, they saw I had been to a few hospitals at this point, and then I was involuntarily committed. From there it was just wave after wave of hellish delusions, my dad was a serial killer, my whole family had died in a fire, my parents and friends were in some sort of cult or something, some of my delusions are kind of too gruesome or violent to talk about but they were pretty much waking nightmares. Thankfully I was in a hospital when things were this bad, as absolutely horrible as those places are. I was stuck there for about 6 months. It's been about 7 years since things started and I would say I am doing alright. I game, exercise, and I draw a lot. I have my own little place. My symptoms aren't totally gone but they've gone from menacing and nightmarish to helpful, kind little colored lights. Sometimes I'll still hallucinate terrifying things but I'm kind of used to it. I've lost all of my friends since things started but I think that also comes with leaving school and everyone going their own way. At this point, I tend to just avoid people, besides my family I don't really have any friends. I really wish people were more accepting, and it's kind of demoralizing 
whenever someone asks "so what do you do for work?" (I don't,) or when I see my old friends graduating college, getting married and starting families. I try and avoid facebook. Also there have been so, so, many fights with family over my living situation and money, and them trying to force me to work when I couldn't. They only made things harder. Things can get out of control and spiral downward so fast, especially during the first psychotic episode because you are just not prepared for it at all, and your family might not know what to expect or how to handle it either. I wish they had taught me about mental illness and the warning signs in school. I would say I hadn't really noticed it, it was already too late, and I think that happens to a lot of people. I also want to add, if you know someone with schizophrenia, just accept them for who they are. Try and see through the illness and realize they are not that label. it sucks, it really really sucks when people only see and acknowledge that piece of you as if it's all you are, they will disregard everything you say and really over analyze and pick everything apart, looking at you through a schizophrenia lens. Sorry if I ramble.

OQQAS: I have been told I have it, then told I don't, then that I do again, then that I don't again, and repeat about 3 times. 6 diffrent Drs over 15 years. Been prescribes different meds and taken off them a bunch. So I don't really know if I have it or "A hyperactive subconscious". I first went to get checked out because when I was a child, I would lashout at the air randomly. I could not concentrate "Because (some name of someone who wasnt there) wouldn't stop calling me stupid/a failure/Boring."

R08IE: I remember hula hooping with my sisters sometime in elementary school. I stepped through the hula hoop and did not step back out. I immediately knew I was in a parallel dimension where everyone looked the same but was a decoy. It was a trap or some kind of illusion. I stepped back through the hula hoop and tried to wave the thought away but it only grew bigger. I also saw vampires and bears at night. Those memories aren't the first time I noticed "something wasn't right," though. It didn't happen all at once. The discomfort came in waves, rising until it was insurmountable. I accepted the delusions and hallucinations the way I accepted Santa Claus and The Tooth Fairy. This was the world I was given. I did not know so much of my life was made up of symptoms. I didn't know other people didn't see what I did. Ultimately, I accepted it because I thought it was just something everybody lived with and I was just being a wimp. I thought that, and also I often entertained the idea that maybe I was special, that I could see into other dimensions to save people, to save the world like Superman or something, and I had to keep it all a secret, hide everyone from the horrible truth that we were constantly in danger.

YG6ZO: I didn't, wasn't until I was medicated out the wazoo when I could actually look back and realize it was all in my head. Any attempt to help from my friends, family, or medical professionals I just viewed as attempts to brainwash me. 
EI5DJ: When I wanted to live in the different perception because it seemed more happy. I knew the the little girl wasn't real but I want felt like she was my daughter. I wanted to play and frolic at the park with her. I wanted to leave reality and just be here and not worry about anything else. Just want to hear her laugh and play. I knew it wasn't real but it felt like it. It was all feelings. Feelings I couldn't help. She was there outside my therapists office and I wanted to go fishing with her. That's all I felt like I wanted. Her laugh was the greatest sound in the world. I wanted to hear it continuously. It was devasting to walk away into my therapists office. I regret that decision but I know I made the right one.

DRA74: Let me just start by thanking everyone who posted their stories, just reading through a few of these has really helped me come to terms with what im dealing with About a year ago i was heavily experimenting with LSD, which culminated in me dropping about 400 ug all by my lonesome (big mistake). I sat up all night listening to the Beatles and Pink Floyd while watching my 70s popcorn ceiling fractalize into beautiful images, it was like watching a movie screen that reflected the sound of the music i was listening to. At some point during a lull in the music, the fractals all aligned into what looked like a faded picture of a WW1 soldier. I was cast into a void, my room and everything else but the image of the soldier faded away. While this happened my mind was absolutely racing, looking for meaning in what I was seeing. Somehow religion entered my mind, I thought about Jesus' sacrifice, God, heaven, hell, and the like (note i was agnostic at the time). Basically I fell headfirst into a rabbit hole and just kept digging. It felt like i spent an eternity staring at that picture with thoughts passing through my mind faster than I could even process them. I came back to reality with a jerk, and it took a second to fully realize where $i$ was and what was going on. That kind of spooked me so i decided to do something to distract myself. I watched the Cosmos reboot on netflix and let Neil Degrasse Tyson guide me through the rest of the trip. The next morning I met up with my parents and my younger brother/sister and basked in the afterglow of the trip, I dont think ive felt happier than that morning before or since. But what goes up must come down I suppose... That same day I started to get the feeling God himself was communicating with me. Note that I wasnt hearing voices, it was more like just a sensation that correlated with my thoughts, the hair on the back of my neck would stand up and id get chills. This kept happening, and it ALWAYS corresponded to my internal monologue, pretty unsettling. As an example, im sitting at red robin with my parents/siblings, im looking at the menu; look at a burger, nothing; look at a salad, chills. Pretty benign so far, so I got the salad. That was the type of "communication" $i$ was dealing with. Unfortunately for me shit went south quick. Next up I think God is telling me to breakup with my girlfriend, so I did... Called her up and dumped her the day before I was gonna drive to her town to see her for a few weeks over Christmas break. I've no doubt thats the biggest mistake ill ever make in my life, after 2 years with her I thought wed spend our lives together, she was/is the girl of my dreams and I threw it all away smh. Shit keeps going south... I was driving home when i get another sensation, this time its to die.. just to 
die. Finally I grew a spine and put up some resistance, but the sensation just kept growing, and I felt like I could straight feel God getting angrier and angrier with me. So i did what any reasonable person would do and floored it. Got up to about $90 \mathrm{mph}$ before I steered my car right into a telephone pole. I didnt know this at the time, but somehow my car flipped and rolled into a parking lot, crushing 2 other cars (no injuries thank God) in the process. I blacked out instantly, and woke up to the sound of bystanders asking if I was alive. Shortly after firefighters showed up and cut my sorry ass out of the driver seat, which was the only part of the car not completely crushed. After I was discharged from the hospital I went straight to a psych ward because attempted suicide. This is the point where my story becomes relevant to the thread. Likely due to the acid and intense stress of what just happened PLUS being confined to a psych ward isolated from my friends, family, and support network I started to develop signs of schizophrenia. I got the notion a fellow patient was an angel in human form, and he caught on and constantly fucked with me. At one point I was literally kissing the ground at this dude's feet. He advised me not to take my meds, which lengthened my stay in the facility substantially. I started obsessively reading the Bible (they had plenty of those in there lol), stopped eating, stopped sleeping, refused to go to those oh so helpful AA meetings, and would sit in the same position for hours just reading about how God fucked people up and eternal damnation and whatnot. I was pretty relieved when I got to the new testament lol. All the while I'm absolutely convinced Im gonna burn in hell, im seeing flames in the grains of the hardwood floor, I thought the nurses and some of the other patients were demons, I refused to see my parents when they came to visit because I thought they were impostors, shit was fucked up yo. After about a week I got discharged from that facility and put back in the hospital for malnutrition and dehydration. Unfortunately the damage had already been done, I continued to think my loved ones were demons just waiting to drag me to hell, which made for an interesting hospital stay since there were like 8 people there with me. (Which is awesome, thank God for my amazing family). I went from that hospital right back into a different psych ward, did about 14 days there in 2 separate stints with similar paranoid delusions. Its been 9 months since then and all those thoughts and the paranoia are still there. I get the feeling people are conspiring against me, that God is watching and judging me, that people can hear my thoughts, that all of this is a dream and Im in a coma, that my dead body is still in that car and this is the afterlife, that im still laying in bed tripping the fuck out, and many more. I've learned to dismiss these thoughts by applying a rationality filter, because I've got knowledge of how the world works and what makes sense and what doesn't, but I'll still get moments where my heart skips a beat and my mind starts racing through all the aforementioned possibilities. I know I'll never fully shake these feelings, but everyday I get a little better at telling them to fuck off. TLDR: Dont do acid alone kids

95TEU: I was in my mid teens when I first started noticing that I was becoming more cautious of my actions and started overthinking things. At first, I thought I was smartening up and thinking "this is how I don't get the cops on my ass" (I smoked weed at the time and had already been harassed 
by cops for other reasons) or "obviously this person doesn't care for me because X, Y, and Z", but then it started getting worse. Actions taken to protect myself from authority led to actions taken to protect myself because authority figures were out trying to kill me by putting bugs (surveillance, not insects) in my walls, sending undercover cars (from beaters to BMWs) to follow me, and getting people to ask me about myself, so something as innocent as "Are you okay? You seem different" would be interpreted as "I know you're different. I need more information about you." in my eyes. I started hearing voices of people I love and people I didn't know telling me to kill myself or talking in word salad (e.g., "it smells like we've been here before", "fifteen minutes causes the life to dry"), and at the time, I didn't trust professional psychiatric help, so I tried treating what I thought was bipolar disorder (my blood family has it; mom, the sisters, and apparently a couple of other people) with vitamins and sunlight. The paranoia and voices took a seat on the back burner for a while, but I still felt uncontrollable mood swings and couldn't control my paranoia, and it wasn't until I was 20 that I decided that enough was enough and went to a psychiatrist. In between my late teens and the age of 20 though, my symptoms became worse. I didn't know the clinical name for what happened and still don't, so I'm using my own terms I used to my psychiatrist, but I'll define them: Head static: You know that feeling you get in a limb when it falls asleep? It was like that, except it would occur in my brain. I described it to my psychiatrist as a painless brain freeze. Thought deletion: Let's say I'm telling you a story or descibing something. "I can't figure out why she thinks that way, I mean I..." and then that's it. Nothing. If you reminded me of what I was talking about, I wouldn't have remembered it, nor could I have found myself getting back on track and resuming the conversation. It was like losing an essay on Word without a way to recover it. Thought seizures: Out of nowhere I'd start shaking and spouting nonsense, almost like speaking in tongues. If I had to describe it, it'd be like an anxiety attack while shivering and trying to describe how to decline in Latin to a second grader that speaks another language than the one you're used to speaking in. After describing all of this to my psychiatrist, he suggested that my combination of BPD and obvious symptoms of a psychotic mood disorder qualified me for the diagnosis of schizoaffective disorder. It took months of trying new medications (fuck Seroquil and its random stabbing headaches), but I finally suggested trying Thorazine to him, because my next option was going full ECT on my ass, and he agreed. Lo and behold, Thorazine helped me feel normal and steady for the first time since I was a teenager. I'm 22 now, and don't experience any of the symptoms I felt when I was unmedicated anymore, nor do I plan to. Knock on wood, hopefully I'll be able to keep taking my meds and stay this way so I can lead a full, productive life.

EXJYS: I hallucinate people in my vicinity talking to me or about me and it can be hard to know what's real and isn't. Probably almost none of it is real. I knew when I was walking down the street and passing strangers would tell me to kill myself that it couldn't be real. But even now I'm not $100 \%$ sure. I saw it, saw his lips move and heard the words. But there are also times when I'm 
completely alone and I hear voices or see things, so I know I must be hallucinating. Still, I can't just dismiss things I experience as "not real". It happened. Anyway, I was diagnosed as a teenager and while I was homeless but right now I'm just on drugs for depression and anxiety.

71JP7: I didn't notice until I was already hospitalized. Looking back, though, I've seen a lot of warning signs. Shadow people following me around at a young age. They would chase me in my dreams. Now they chase me outside of my dreams sometimes. Walking in particular patterns and being afraid of the consequences of breaking the pattern. I have distinct memories of being assaulted by a young white boy with white parents in the apartment upstairs. According to my parents, the family that lived above us were all African American, and they lived there the whole time we did. Pretty antisocial behavior and personality. Not like dangerous, just apathetic. Hospitalized the first time for suicidal gestures a little over five years ago. Hospitalized last year for a suicide attempt and seratonin syndrome. I had beings telling me where to go and what to do. I was being spoken to out of music on the radio. I had conversations with dead relatives. Then I downed 90 days worth of SSRI's and nearly died. I have cognitive issues now, hard time annunciating words, and will often slip into similar sounding words via loose association. I have some neurological issues which hopefully aren't too severe, and I'm likely to die young due to kidney and/or liver failure due to my suicide attempts. AMA Reddit, it's my time to shine!

YOBGV: I went to see a movie. At one point a teenager in it is beaten with a belt. It triggered a flash back to very similar things happening to younger me. I don't remember the next few days. But the next thing I do remember is a few days later waking up in the middle of the night hearing a collage of voices. I got up and stood in my sisters bedroom doorway, trying to figure out what was happening. I turned on the light to see if she was up. I remember her asking what's wrong and broke into tears and feel on the floor and said "I don't know" I told her things had gotten weird, what had been happening, and she didn't understand any of it because I was crying. A month or 2 later my dad (who I had been talking to about this as well) said he had a podcast I should listen to. He said it might explain things. It talked about a college aged woman as she realized she was schtizo. So much of it was so dead on, even the narrator. Finally agreed to call a therapist. Im so glad I did. Don't be afraid to get help, people. For anything. the therapist helped me with my disorder as well as childhood traumas. Later in life I was raped and shes helping me work through that as well. Tl:dr a movie triggered a bad memory and possibly the onset of my schizophrenia.

UDXYO: Hearing my own name called out to me by people that were nowhere near me. I was once driving in a car by myself at $5 \mathrm{am}$ and I heard my coworker shout my name from my backseat. my coworker was 7 hours of driving away. At worst, several people, that sound like a crowd are shouting my name which can be disorienting. Music playing is also the worst. I live in a dorm and 
even though everyone is pretty much asleep by 11:30-12:00, like clockwork I hear something similar to the Five Nights at Freddy's jingle playing from my walls. It isn't neighbors to the right, left, above, or beneath my dorm. Shadow people walk around in my dreams and then transition into my dorm room and I wake up. They like to watch me when I sleep and stare at me when I am laying in bed in my dreams, then they walk out of my room or into my bathroom and I blink awake. I am currently in therapy for it and there is no shame in looking for help. It is exhausting enough without it having to feel like a secret where I am hiding my "crazy" from my community.

Q7WJM: $\quad$ Great question. I had had what are called psychotic features from age 13-18, but when I was 18 I had a full psychotic break. What were called features included some delusions, paranoia, and audio hallucinations that did not include commands. When I was 18 , I was writing a lot of cryptic poetry about energies in the universe I had come to start thinking about because of a dream. Things in ordinary objects began to stick out to me as significant and meaningful, sometimes like they were messages to me. I started genuinely doubting that my dreams were not reality. I was thinking a lot about the personality of god. For a few days, I cared less and less about anything I had ever known to be reality, and considering the unknowns of god became my sole focus, and I had a visual hallucination one night. The next morning, I was alone in my parents' home, and they were both out of town. I had been smoking a joint and writing and listening to music, and a voice said "you have to quit smoking." I understood it, at the time, to be the voice of god, and my body sprung up from being reclined on my bed, to jumping up and down on all fours, out of excitement that god was real and that he had something to say. I fell on my back on my bed, and had a spontaneous orgasm. For 2.5 years, the voice spoke to me nonstop. I was catatonic and non-lucid. I did stop hearing the voice eventually, and now I have no symptoms of any full-blown psychosis, just occasional audio hallucinations and some disorganized thought at times. But during the days that preceded my psychotic break, I wrote in my notebook that I knew I was losing it, because when you consider your dreams to be reality, you're absolutely, undeniably crazy. But at the same time I believed it to be fully real, merely existing within the structure of what we know as illness. I wrote about how absurd it would be to choose lucidity over magic.

CDQP6: $\quad$ Schizophrenia runs in my family, and usually it's under control but triggers like psychoactives or stress can bring it out. When I smoked weed for the first time with a few friends, I had visual and auditory hallucinations. At first I thought it was perfectly normal, until others said their experience was completely different. We were sitting on the couch watching Tosh.O, during a segment where he was doing an interview suddenly Tosh turned his head towards me and started commenting on what we were doing in a mocking way. At first I thought it was funny, until I told my friends what I saw and they seemed concerned. Ever since then if I feel an episode coming on I'm 
apprehensive about screens and especially faces, because they're an easy medium for my brain to manipulate into a hallucination.

QOVLP: $\quad$ I'm 28 and I don't hear voices regularly but I've had several odd experiences with auditory hallucinations. The first I can remember I was around 7 or 8 and suffered from terrible insomnia. I was anxious about sleeping for some reason and then that lead me to be anxious about getting to sleep. At one point I distinctly remember hearing the phrase "we win" over and over in a decreasing tone. Scared the shit out of me but eventually I got over it. The second was in basic training. It was the 3rd or 4th night and I hadn't slept more than 3 hours the whole time. I was trying to sleep and I heard deafening laughter. Like drown out every thought kind of laughter. I started crying and I don't know what happened but something snapped and reset on me because after that night I slept fine. The last time was on a deployment. I hadn't been able to sleep and started taking unisom (fuck that shit btw) and right before I'd drift to sleep I'd hear someone come in my room and scream. It happened a few times and then stopped. I don't think I'm schizophrenic but could stress or exhaustion be a catalyst for the syndrome? I remember asking my mom if I was crazy as a kid and she would tell me as long as I wonder that I'm okay. It helped me then but I don't know if it was really true haha. I think I've just had pretty bad anxiety. Which worries me because I have 2 little boys and my wife also suffers from anxiety...

BGRQQ: Voices in my head that are very negative and critical of me. Hearing things like an airplane crash into the building I worked at and I'm the only one that notices it. Seeing people who aren't there, have no shadows or shadows are wrong, people walk through them and they walk through walls. Negative thoughts as well. Sometimes my brain emulates other people I know or met and gives me thoughts from them, almost like being in a dream but being awake. I'm not always here like I am part here and part somewhere else.

G0WOQ: Late to the thread but the first time I really noticed it was when I was talking to my neighbor when I was about 16, he said something but the words came out as "They're watching you". There was other stuff before that looking back, I just didn't notice at the time. If I'm stressed it gets worse, I'll look out my window and see what looks like people hiding in the bushes staring at me. One time I looked outside at night and there were a ton of orbs of light or something, I couldn't figure out what it was or think of a logical explanation, I had to get my dad to tell me if what I was seeing was real(it wasn't).

7DHV6: The first time I saw something that didn't belong was when I was 18 and driving home from the casino. It was a very strange light pattern in the middle of an open field. It was moving too fast to be an airplane, and was moving horizontally and vertically so it couldn't be a car. I did my 
best to try to watch it, but I was driving and this was before phones had cameras. I've done the drive countless times in my life, but have only seen it once. The next time I encountered something that didn't belong was 3 months later. It was 2 months before high school graduation and I recently moved out. I was renting a room in a 2 story house and my room was upstairs. It was raining and windy, but clear enough to see into the distance. Just above the tree line, I saw it waving back and forth. It looked like a streetlight, but it was looking at me. I watched it for at least a half an hour before trying to find a roommate. Unfortunately, nobody was home. Two weeks later, it came back. It was waving back and forth again, but it was always facing me. I did the only thing rational at the time, I ran down the street to find it. When I arrived at the location, the only thing there was a streetlight. It didn't move, it didn't wave, it didn't stare. It never came back. I went back to the corner several times to make sure it didn't move. Unfortunately, I haven't seen it again. I want to see it, I want to find it, and I'm always carryied a camera or my phone so that if it does show up, I'd have proof. Deep inside, I know it will never show up. I know this because the pattern is the same pattern I saw when driving. I was first diagnosed with Bipolar psychosis in 2004. In a weird turn of events, immediately after the diagnosis, my doctor ended up going to prison. I ended up in a crisis center. I got stuck with an NP(did not know he wasn't a doctor). He modified my meds, increased the dosages, and thought that I may be developing schizophrenia. The medication made things worse. I would "wake up" standing in the hardware section of Lowes. No idea how I got there, but I knew where my car was in the parking lot. I would have violet outbursts. I became a black-belt in drywall-fu. I would take substantial risks I don't remember most of what happened the next 7-8 years of my life. My medications kept increasing, my doctors changed. In the end, I was taking seroquel xr (800mg), lithium (1200mg), lamictal (300mg), and trazodone (150mg). I also had 25mg seroquel (non-xr) for mornings when I felt like I was losing control. In 2012 it all stopped. I was sitting in my living room and playing on my iPad. I open up notes and there were pages of memories. Some were written in first person, others in third. Some were extremely angry, some were suicidal. Some of them made no sense. Then I heard the voice. I was told that it was my time to steer the ship. It took just over 2 years to get off the medication, and I haven't had anything since. I haven't gotten lost, the light is gone, and the voice hasn't returned. In 2015, I went back to look at the light pole. I wanted to try to figure out if it was an optical illusion. Crazy thing is, it was never there to begin with. Only my first doctor knows about the light. I've never told anyone about the voice. There are still things inside me that I will never be able to tell anyone. I'm very thankful for what I have now.

3P17N: I've never been diagnosed with any mental health issues but here is my story. Not sure where it goes Ever since I was 9 or 10 I hear voices at various times of the day. Usually when I'm laying down at night. I hear screams and many people talking VERY loudly. Can't ever make out what they are saying but it's always very loud. Its been 14 years and they still sporadically occur. 
NBZVF: I started hearing noises, not voices, that no one else could hear. Stuff like horns honking or a radio playing music. This affected me harshly and I ended up fearing that people either constantly thought negatively of me as a crazy person, or would actually plot to kill me.

UEBB6: When I was about 8 I was sleeping on the floor in my parents camping trailer and I heard 6-7 different voices male and female talking to me and each other, I was sick with the flu at the time so I thought it was symptoms of the flu, medication, and lack of sleep. Nothing else really happened until I was 12-13. I started seeing silhouettes of a person standing in weird places, like by my parents bedroom or peering at me from behind the fridge. I would also hear people telling my name when I was alone in the house or at a friends. It got to the point where I convinced myself that certain people were at a different "level" in their abilities to read my mind or know what I was going to do, I would only drink bottled water because I thought the government put a canister on the water lines that was set to release chemicals when I would shower or use the sink. I finally told my mom about it all one night when 15 , I was drunk and I was having another episode. I was sitting in my moms truck and I saw someone standing beside the passenger window staring at me. It looked like a guy in his 40's, and he was just standing there staring. She didn't know if I was being honest or drunkenly rambling but I told her so much detail about everything I saw she couldn't doubt me. She asked me about it in the morning and I was in a counselors office the next afternoon. Since then I've been on and off mess trying to find the right ones that help me. I've tried 8 different medications in the past year and none of them seem to help much. One day at a time

P24IU: $\quad$ Schizophrenia for me was induced by stress followed by a psychotic episode with full blown voices, hallucinations, and odd behavior. It all started when I worked at this odd job with unorthodox businessmen. I was doing okay at first, but as I became more and more engulfed with the job I ended up psychotic. I was doing unorthodox business under their rule and had a gun pointed to me at one point; This constituted as a stressor of course. As I continued head strong working this job, I also began to notice that I was becoming more agitated by their orders and became slower at the job performance. I started thinking to myself how the porn industry, sexual conduct, and biblical lust was the end of the world. This gave me the paranoia when on the job. I would visit clients homes believing they might have something to do with my thoughts on porn- whether they were a porn CEO or actor. In the midst of all this, I told customers I was guilty of watching porn, told them how bad I thought it was, and thought someone would want to have an affair with me. On going, I started thinking how things were interconnected with each other as I did my work in unison with my thoughts on sex. For example, I would insert a bolt on something I was working on and thought I was corrupting a pornstar from performing. There on, I began classes at school and started repeating everything the professor would say under my breath, draw conclusions about things using the lectures being taught, and telling my professor isis is actually wonder woman.(almighty isis!) During this, I drove long distances late at 
night believing it would reset my mindset while in the process almost being arrested for parking at the top of a national forest in the middle of nowhere. I noticed the same model vehicles on the road and associated them with people I knew who owned them and thought they were significant to my delusional mind. My boss recieved texts from me in different languages and rude messages about people. Which led him to believe I was doing acid. I truthfully declined and continued on this way. I spent ridiculous amount money on my credit card buying useless things and didn't think about my future self being in the state of mind I was in. As the days went on, I started hearing voices late at night from all sorts of people I have known. I told my mom that I could hear someone's voice which gave her an idea something wasn't right. Eventually, I was let go from my job because I lost the mental and physical strength to my work. I increasingly got more lazy and slept most the time at home. My parents admitted me to the hospital for evaluation after I started burning books and bible scriptures because I thought God was angry with me. In the hospital was when schizophrenia for me got the worse for my mental state. I started hearing voices, having hallucinations, and remember thinking I am going to het locked up for good. This whole time I did not know what schizophrenia was, so I was just staying head strong in the 51/50 I was transferred to. After a few days of evaluation, I was diagnosed and on medication. (Invega Sustenna) After being released, voices and delusions faded away. I took a year off of school and work to make a full recovery. Now, I am doing better then when I had no symptoms. Definitely the worst time of my life during that job which is what I believe helped bring schizophrenia in me to surface. During this last year, I work full time have lots of friends and graduating from school this year.

Z46ZN: I hear a small collection of voices, like a busy office. If I get stressed or anxious they start to shout and scream at me. About 50 voices.

C9KNF: I'm currently 20, I first noticed my symptoms when I was around 14. It wasn't completely obvious at first, just minor things. Like I would be in a room alone and I'd constantly see things that weren't there, and out of the corner of my eye. I'd have constant and repetitive messages being whispered to me every once in a while, but at the time given my age and Inexperience, I didn't think much of it, just brushed it off. After my parents divorce was when it became much worse. I down spiraled very quickly, seeing and physically feeling things that weren't there in the room. The voices that were once a faint whisper were much louder and constant. All of this along with the divorce gave me a constant state of paranoia and I developed bipolar disorder. Eventually I was hospitalized for it on 3 separate occasions. During that time I tried out countless medicines and Doses to try and help me stay stable. These days I'm doing quite well. I've been on the right medication for 6 years now, and with the help of therapy I truly feel I'm very stable. It's scary when I look back at what happened to a kid that young, but I've learned from it and grown. Parents/family: If your kid comes to you and tells you about symptoms like I had, don't punish them or freak out. These days there are 
hundreds of offices designed specially to help people with this disorder. Reach out and do your best to help them, it may just set them on the right path :)

UXDN6: I have been diagnosed with schizoaffective disorder, depressive type (which is pretty much just means schizophrenia and depression). A bit of background: during childhood, I was diagnosed with OCD and during early adolescence I was diagnosed with depression. In my early 20 s I was diagnosed with generalised anxiety disorder and PTSD. Interestingly enough, shortly before developing full blown symptoms of OCD as a child I had a period where I would get extremely worried that my friends parents were videoing me and could see and hear my thoughts. My onset of schizoaffective disorder was extremely gradual; I had symptoms for several years before being diagnosed. The symptoms began when I was about 22, when I started worrying about putting my hair and fingernail clippings in the bin; I thought people would use a them and place them at a crime scene in order to frame me for a crime. This then turned into what I just thought was a more extreme manifestation of OCD and PTSD: I began to have difficulty sleeping, I was agitated and anxious and I began to feel less comfortable socialising. My brain function slowed down and I could not concentrate and my coping abilities worsened. I began to obsess over religion, worrying that every action I did was offensive to God in some way. I began to believe that I could control what happened in the world with my mind. There was a presence that permeated the atmosphere everywhere and it would send me "signals" of the rituals I had to perform, in order to prevent bad things from happening to me and my family. This could be stuff like repeating the same words over and over, drinking a particular brand of cordial, etc. Over time, I began to scrutinise every action I took, to analyse every possible risk of harm to myself and others. I believed everyone was out to harm me or my family or I worried excessively about upsetting another person. I was constantly on high alert. I thought my colleagues were contaminating my food and drink at work; I believed that one of my colleagues was smearing STD contaminated blood onto the toilets at work to harm me. Then I had to have a performance review at work with a new manager (we have to have them every year and they take a couple of hours - they're extremely thorough and go through in detail all of the feedback they have collated about you). My manager also mentioned at the said review they had something important they wanted to discuss with me but did not specify what. Well, I completely freaked. I was convinced that they thought I had done something wrong. I stopped sleeping more than an hour a night; I was a complete mess, rocking back and forth on my bed. I was convinced my managers were video recording me whenever I left the house and had tapped my phone in order to try and find evidence to fire me. I began to worry if I went outside and a plane flew overhead that it was law enforcement looking for me, convinced I had committed a crime. I drew symbols on my hand in order to "protect" myself in some way and I began accusing my loved ones of thinking/doing bad things about me. I thought the neighbours were spying on me and trying to gather evidence to also get me prosecuted for something when I hadn't done anything wrong. Then I had apparently had a couple of visual hallucinations; I didn't realise that's 
what they were at the time. I also believed I was evil inside and had black creatures inside me. I cut all my hair off. Eventually I ended up seeing a psychiatrist and I'm on medication now. I ended up having a long denial period, thinking what I had was just anxiety or depression. I've relapsed a few times during periods of my life that have been stressful or when I've tried reducing or stopping my medication.

4BV8S: $\quad$ You can experience mild psychosis occasionally. I have from time to time had auditory hallucinations when I'm experiencing extreme stress. I have major depression and anxiety, not schizophrenia. If you can pinpoint a cause like stress you can try to make some lifestyle changes and the hallucinations won't happen. My psychiatrist said antipsychotics are overkill since my hallucinations are so rare and mild.

98II9: I'm 19 and I've had "voices" for a long time like it will tell me to do stupid things like hit my hand against the wall really hard and that if I don't I'm weak. Most of what it tells me is to harm myself or that I shouldn't trust anyone since I'm "too perfect". I should probably get this checked out but I genuinely didn't know that the voices told people to hurt themselves. btw I haven't been diagnosed schizophrenic but I know it runs in the family.

BBMUV: Musical hallucinations. This topic is so interesting to me because there's not a lot of info about it. I have heard songs in my head every day my entire life, in stressful times they can be obnoxious, playing just one refrain over and over. Or I'll hear parts of people talking, like on a radio. I know it's internal and there's no one actually talking, but it's so crisp clear what I hear that I wonder if it would be considered a hallucination? When I first told someone about these voices, they said it sounded exhausting and as though my mind were making up for boredom, just filling in blanks. But the problem is the voices will take over my brain and I can't think around them. They hold me hostage and I can't do anything. Is this something that happens to anyone else?

9G8NL: I've had visual hallucinations (not from schizophrenia... I think...), can't tell if you wanted specificity. Anyways, they manifest as a literal person I can reach out and touch. Primarily appear in dark rooms for me (which helps with hiding the whole not perfectly sharp image part), I've thought friends came over to visit before and said "hi, why are you here?" to them in empty rooms. Scariest experience I've had with it... I hallucinated one of my friends standing about 10 feet from my bed, staring at me, as I opened my eyes while I was trying to fall asleep. About jumped out of my skin. Then I remembered that friend lived in a different state.

VR4YV: I have schizoaffective disorder with bipolar. That's what's frustrating. It seems SO real. As real as you standing in front of me real time having a conversation... I've heard music so loud 
it drowned out everything else. Imagine I'm standing right in front of you yelling and so is your best friend. You can smell his cologne, and my perfume. Then you're asked who you're speaking to, because there is no one there. I've had things pinch me, and could swear the mark showed up or even ache where the injury is. It's chilling. I'm unmedicated and every psychiatry and behavioral specialist wants me on meds. They say I'm like a small brush fire and it only gets worse with age. I don't agree. I do the best I can. Meds can make you worse too. Been through 7 at least, 3-4 at once a couple times. You ever hear the cure is worse than the disease? Feels that way sometimes. And now I know what a guinea pig feels like. I won't ever go back to seroquel or lithium, those drugs can $\mathrm{f}$ off in my life.

QNVPG: I used to cry about people yelling bad things in my ear at night, in 22 and still can't lay in bed without covering my ears... my dad used to complain of the same thing and is a diagnosed with bipolar and depression as far as I'm aware.... shit

Y0MWH: What freaks me the fuck out is this female demonic entity that ill sometimes see after i first walk in a new room in the dark. Its hard to describe her because she's mainly just a shadow figure but when i enter i always interrupt her in the middle of rummaging through something, hunched over and always seen from the side. She then jerks her head at me kinda startled and then screams as her face flies straight toward mine and then the whole manifestation somehow dissipates inches from my eyes and the whole projection is only $2-3$ seconds long. I never like to acknowledge them by giving a reaction, $\mathrm{i}$ just keep plain faced and continue doing whatever $\mathrm{i}$ was doing but it makes my heart stop everytime and though i remain expressionless i always turn sheet white

25RVR: It just had gotten to the point where I couldn't deal anymore. I couldn't. I was so tired of living in constant fear, that I ended up abusing prescription medications in order to make myself sleep. Which was incredibly dangerous. Also, several times voices would say "just end it, no one fucking cares about you, you worthless piece of shit, no wonder everyone leaves you, you're such an ugly cunt, disgusting bitch" and on and on and on and on, until finally I was willing to do anything to make it stop. My mom saved my life both times. She's a literal goddamn angel. Idk. I think the best thing I ever did was get myself medicated, and later on, into rehab. Clean and sober and happy-ish now.

X5Y25: It was a gradual progression I guess. I don't really have anything to measure it by. I just started being less and less in touch with reality as time went on and stressors increased. By December of 2015 and well into 2016, I was starting to see things and hear things that weren't there. During 2016 things started getting weirder for me. Suddenly my thoughts had powers (so I need to think about all the right stuff). I started gradually giving in to the idea that I could effect the world around me, and that people knew. Stopped sleeping, lost a lot of weight...It wasn't fun. Got the cops 
called on me once because I had decided to seek refuge in an empty building and was apparently "threatening" the people who were in it. Worst it ever got the Summer of 2016. I had no job, no friends, nobody to talk to but a therapist, was riding trains back and forth to the city all day, and was on a cycle of meds that weren't treating me right (SSRIs and psychosis are usually a bad combo). I'd run out of the house without a shirt or shoes sometimes, and wander around for hours. At one point that summer I put my head through a wall in my house. Finding the right antipsychotic was tough, but I'm glad I did.

NQ32L: $\quad$ I remember one instance where I used to have pet rats. I was holding one and stroking it, and when I looked down, I saw it had been cut right open down the middle, all the tender meat and muscle exposed. I flung my poor rat across the room. He was okay, but good god that memory stuck with me. I used to think I could hear a radio in my room, especially by my bed.. Some soft whispers that sounded like a deep, boomy radio voice. It wasn't a radio. Used to have to "fight off" Satan with my prayers when I was young. Seriously, my brain is an asshole, so it'd send prayers to Satan constantly, and I'd get locked in prayer battles for my poor immortal soul when I was still a kid. I covered my room with crosses. I kept holy water at my bedside. If the numbers "666" came up in my math homework, I'd flip out and start praying, and then draw crosses on the page. Even my very Catholic mother thought I was going overboard.

R2FSX: It was people, shapes and figures made out of shadows. When it first started, I thought I "just wanted to see things. " So I'd always feel like I saw little animals in my peripherals, watching me, and I'd look and see nothing there, but as time went on, I found myself taking second glances at things because I was constantly going "holy fuck did I just see that?" It was like they were creeping in on me. I was doing this all the time in fact, just double checking to make sure that nothing was actually there. So in my everyday life (ESPECIALLY when I didn't sleep) I'd start seeing indistinct "people" made out of shadows who weren't there. Waiting under porches, in the corner of my room, in coffee shops and libraries, standing in classrooms, pressed against walls...always watching me. When they became more robust, they started moving around a bit more. Little hands, sometimes walking, sometimes just following me with their heads. Then they started lunging at me, if that makes sense. One time I was out running, and just before I got into a tunnel, I saw one coming at me in a dead sprint. I fell flat on my ass and started screaming. The woman who was running behind me flipped out as well, probably because of what she just saw me do.

UEMLX: $\quad$ BUGS ON SKIN. When I was a kid I OFTEN felt like there were things crawling on my skin. I actually felt them on my skin but when I'd look there was nothing. Now the rational side of me wants to think it's just the clothes and the body hair interacting but it also happens on just bare skin. This continued for a few years and I eventually just grew out of it. Younger me didn't know 
what schizophrenia was, so for the longest time I thought I had bugs INSIDE my skin that were crawling. THAT MADE ME VERY UNCOMFORTABLE AND PISS SCARED, but I never told anyone because I was MORE afraid (straight up phobia) of finding out the possibility of my theory being right. Disclaimer: I don't actually know what happened when I was young, whether it was schizo or not, I'll never find out. I'm just glad it stopped.

9GN9I: I have anxiety and depression and recently some psychosis. My symptoms between just regular anxiety and the psychosis went the exact same way. Forgetting how I arrived or why I arrived somewhere. Easily confused etc. Turns out this was the beginning of the psychotic episode I am currently still in. Anxiety and psychosis is literally the most uncomfortable I've ever felt.

7KG3S: I have diagnosed bipolar, and a lot of these symptoms as well. I see shadow people, so I thought my house was haunted. I had one grab me and I mentally broke down about it. I also have such a bad memory, I often can't recall what I did the day before, I have to write things down, I get so angry about not being able to remember things. I would take medication twice and make myself so sick, I've had to go out of my way to organize my life. The only things I hear are random voices that sound like they're coming from a TV, usually when I'm very tired. I also guard my thoughts because I think people are listening, when I KNOW they aren't, I just do it anyway. It's always made me feel ridiculous. This is crazy, I'm going to speak to my psychiatrist about this. Thank you, this post may have solved these weird things I've been brushing off for too long.

PVPCD: I have a family history of schizophrenia, I often have very confused before bed / after waking up thoughts. I once woke up in the morning where my dreams had me thinking I was a hunk of metal about to be taking to the blacksmith. I was awake and thought I was an inanimate object. But yeah hear things at night and hallucinate a little throughout the days.

950AY: I broke down in tears seemingly from nowhere a few times, in school in front of all my friends, another time in the street playing football with my brothers. People were baffled why I was crying, I didn't/couldn't explain it. But it was because it was just so hard knowing how different I was. Everything seemed to come easy to everyone else, and by that I mean just being, for me it always felt like an effort. I also had this cartoonish mode/fantasy I would drift into. I even gave the episode a name, I would look at someone I know, and either experience them as if I had never seen them before, they would feel and look like a total stranger, or on other occasions, a 2D cartoon. By about age $14 \mathrm{I}$ had given a name for this experience, and I had created names for the alternative selfs my two best friends at the time would shift into. I never told anyone about it. I never got treated, but it just kind of went away. I'm still a bit different than everyone else, I think everyone would say that about me, but it's never held me back, I have plenty of friends and have had good relationships with 
women. A successful career etc. Interestingly/coincidentally/spookily, about 10 years after my episodes stopped happening, one of my best friends was having a kid with his girlfriend, and the name he chose for his baby was the name I had given to my episodic alter-ego of him. I had never told him this name, and it's a very rare name that nobody I'd met had ever had. Anyway, I always just put it all down to introversion and a vivid imagination to be honest.

EVL79: $\quad$ First time was a painting in my friends house talking to me, specifically the cowboy in the painting. Eventually started seeing the cowboy in the windows when walking by and eventually in mirrors. Wasn't frightened but I was sure there was something wrong with me- I was 16.

S8AV0: I was never diagnosed with schizophrenia, I was diagnosed with a personality disorder, and hopefully it's ok if I share my story. When I was 18 I kept feeing like something wasn't right. Like, I kept hearing this person talk to me and I felt like I was kind of befriending this person who wasn't there. I felt it was the only "person" who cared about me, and I was dealing with issues with my mom who honestly didn't care about me. Would buy cigarettes over food for the house and stuff. Long story. Anyway eventually she told me to take all these pills because they would make me feel better and I did. It was about half an hour later that I told me boyfriend at the time and I tried getting him to promise not to tell anyone but he told my mother who called an ambulance and stuff. I got put into a mental institution and I was in there for a month and although my family came to visit me, they kept telling me I just did it for attention and that I was selfish for trying that. Yeah maybe I was, but I felt someone was looking out for me. Someone had to care somewhere. I still to this day hear this persons voice. I still have this voice telling me to jump in-front of that vehicle, throw myself down those stairs. Stab myself with that huge knife. I want to sometimes. But I try my best to ignore it. I've thought about going to talk to someone to get help, I just worry about people not believing me.

W6HWI: Wow so I guess the weirdest thing that makes me think " I think I'm getting sick" was when I was in senior year of high school, western civ class. I was ignoring the teacher and writing in my notebook about how I liked this girl and my hand started writing on its own "Why don't you just try talking to her". Since then I have had like thoughts in my head and a spirit that can kind of talk to me move through me. It's not exactly what I thought would happen with my life but fuck I think I'm more in tune with my soul now so see the good in it.

M0YXR: My mom was fully convinced our house was haunted for years. I would tell her about the woman's voice trying to keep me safe. "Don't touch that". "Don't go in there". Those types of things. I would see her for a second or two and then she would be gone. I have never been to a doctor and honestly I don't plan on it. I feel like I have some control over it. I only hear it occasionally a d I don't see her any more. I don't wanna make mountains out of mole hills. 
JPRD1: $\quad$ I wasn't diagnosed but I'm very very sure it was schizophrenia. Very first time was about 1 week before 'the trigger' which started the whole thing. I felt awkward. Restless like I were craving for a drug. Can't really describe. Also a weird feeling for my body. Never had this that intense and never again.

WGRKE: Schizoaffective Dissorder. When i get overly emotional, I will hear audible whispers/mumbles. At its worse, I see blurred shadows sway and jump. I get super dizzy as well. After an episode, I feel like I hadn't slept and I am achy. First time was when I was 15. One of my friends, whom we trusted, stole my dad's box of lures. My dad was a tournament angler. For anyone that may not know, some lures can be as high as 10-15 bucks. That was the first time I felt truly angry and emotional over something.

VB4AF: $\quad$ Early psychosis here. Biggest thing for me was the emotional disconnect. I told my doctor I dont have feelings. I'm also extremely paranoid about being watched and thinking someone is in the house. First time I noticed these things was about 2 years ago.

Z54ZG: $\quad$ I started seeing numbers and equations on window panes. I started to see photosynthesis happen in broad daylight. I started to wake up and smell the music and hear the coffee.

9WUUF: $\quad$ First time I noticed I was walking to a friends car and it was full of people. I went to drivers window and asked what was up and was told to get in. I asked where, the car was full of people. He said no one was in the car and when I looked again it was just him. After that I would hear voices that sounded like someone was in another room. I felt like I kept hearing my name and thought I was home alone. I went to check and when I found no one decided it must be the neighboring apartment. Then with friends I'd feel like I heard them talking about me when I would leave the room or even look away. When I looked at them and saw their mouths weren't moving it would stop. Those are all most memorable things. I try to keep to myself and work alone because of it. I spend most of my time with my cat.

MWURI: $\quad$ When I was about 6 or 7 , I was sitting in bed at night and there was a woman who walked into my room. She just stood in the doorway, staring at me. I ran into my closet and hid, because she didn't FEEL right. It felt like she wasn't real. Almost like a ghost, like everything around her was fake or had a blue halo. Later, I told my parents, but they told me I hadn't seen anything. I ended up lying to them and my doctors for fear of being locked up. The paranoia started later, when I started driving. I ended up having to memorize the cars behind me. I used to carry a gun in the car for fear people were following me. Were going to do something to me. Since I've gotten older, I've gotten 
much better at recognizing what's real and not real. I'm on medications and things, but I can tell myself they aren't real now and my brain will tune them out.

7EBKN: $\quad$ Technically diagnosed with bipolar disorder, but psychotic symptoms aren't a stranger to me. Some of my earliest memories are of temporarily losing recognition of my parents; freaking out because I was convinced they'd been replaced or something like that. I've also had sleep paralysis as long as I can remember. I was probably 8 or 9 when I got confused as to why my parents got so freaked out when I mentioned that a green man was coming into my room at night, sitting on my bed, and telling me to stay quiet. It started to really become obvious in elementary school; my paranoia became more severe and I was convinced that I was in some sort of 'game' that other people were playing; everyone around me was acting and hiding something from me. There's an educational publisher called 'Heath' that the school got books from. I misread it as "health" and this (apparently) was all the evidence I needed that I was in some sort of medical institution that was running experiments on me. I suspected my parents of putting chemicals in my food and drinks, and at one point I was brought to the doctor for a vaccine, and I ran out of the exam room, through the office and into the parking lot screaming bloody murder. Eventually they put me on drugs, and it started to get better. I stopped taking them in college and went downhill real fast. I had the good sense to know that I needed to see a doctor again and got help, though.

E610H: Started around the age of 13. Gained a voice that would feed me delusional thoughts about how I could see the future and read numbers to find greater meaning in them such as what people are really like or who I was to become. The voice slowly became more sinister saying I must kill myself or I would grow up to be a serial killer or that when I saw certain numbers I was taught to read them and they would tell me about bad things to come or of bad things that happened and why they did or how he told me it would happen from previous number sightings. Thats mainly the beginning, developed into other directions as well but thats how I mainly noticed things as not quite right, of course I kept it to myself which was a mistake as I would learn years later.

WF861: I don't know if I had schizophrenia or not, but as a kid (5-15) I would hear people (typically my mom) call my name. I would go ask them what they wanted and get a response along the lines of "I never called you". I also hear people talking every weekend in the early morning, though it was my brother watching tv, and tried to catch him...never did. I finally just stopped telling people what I was hearing, and either by maturing or what it all went away, well except for the shadows I saw in my really dark period.

9VCH6: I'd see these fucking black birds fly past in my peripheral vision. But shit looks different on different days. Stuff looks inverted, like it's moving, its borders are 'squiggling', I don't 
know. I'm not even technically diagnosed as schizophrenic, I have major anxiety disorder \& clinical depression with 'psychotic' episodes. But of course to every person who knows that means I'm insane.

L26V9: Lately I've begun to wonder if something is wrong with me. I've never talked about this to anyone else before but this seems like most people here have personal experience. I don't normally hear voices, in the same way you actually hear other people talking. But I feel that I don't control my thoughts. My mind is always creating elaborate plots against me that I can still write off as ridiculous so I consider myself normal, but I told myself this a long time ago and it happens almost all day now. The only thing I find really disconcerting though is I've noticed that when I stay up late, say staying awake for 20+ hours straight, I do actually hear voices. They don't feel like they're in my head, but it feels like the same sensation when you hear people actually talking. Only it's never intelligible, it's basically just babbling and shouting. I also feel my communication skills degenerating

45IS5: It happened right after I turned 19. I would hear music in my house at night and accuse my sister of playing music when she never actually did. It then progressed to not another voice in my head, but my own telling me what I do wrong all the time.

FU3S9: I've always been very lonely, and I always talk to myself and make voices for fun, but I started noticing a voice I've never made in my peripheral hearing, just regular things at first but then it would tell me people are betraying me and hated me and I got so paranoid I tried to bleed enough that he'd die and I'd be free. I nearly died, but I never heard him again. I've never been that scared of a friend in my head(makes it less ominous) but I'd get much less real voices telling me to do things, one that never goes away tells me people are going to mollest me if I go into a bathroom alone, assumably because I'm high school I did get sexually assaulted in the bathroom multiple times ( I am bisexual and had a boyfriend, and I went to an all boys high school and someone found out) and I need to wait until someone goes into a public restroom before I can. I'm a functioning human being and no one knows except my parents and my brother, considering he found me yelling at no one in the middle of the night.

751EE: When I lost most of my friends due to my delusions. I became very socially isolated. I began to believe people were all plotting against me. This went on for 2 years before I finally recently started seeking treatment and trying meds.

7PGZP: I I am Schizoaffective (depressive type). My worst and most common symptom is paranoia though I do have a lot of tactile hallucinations. Fingers touching me all over or bugs crawling on my skin. I describe my paranoia as "being in a horror movie at all times." Everything feels threatening even a blank wall. The worst thing for me is someone nervously giggling while I am 
talking to them despite logic and experience telling me otherwise it puts me in fight or flight mode and I have to physically calm myself down or I'll start breaking things out of anger and fear. It started with the delusion that people can hear my thoughts and it makes you feel like you are always naked and people can see through your every intention. I have never attacked a person just broken objects, like I ripped my bedroom door off the wall because of a delusion that someone put a trap on it. I am a 6'2" 300lbs large framed man and I started having schizophrenic symptoms when I was 16, when I went to the hospital the first time my doctor(s) put me on a super strong cocktail of drugs because they were afraid of my size/strength and what I might do and the drugs really messed me up over the years. Mentally ill people like me seem threatening at our worst times but it is not really the true 'us'. I would describe myself as a big kind teddy-bear $98 \%$ of the time, but when I get an episode I might seem scary but if someone I trust just sits and listens to my troubles I can go back to my usual teddybear self.

OKMSI: Scratching noises and knocking sounds in my head. I always think someones at the door, or trying to get my attention. That and like pairs of hands that sit behind me while I am standing. Like, the left and right hands of someone are near my waist until I turn around. It's odd.

DJQUT: $\quad$ Paranoid Schizophrenic here. When I was 19 and smoking weed with my friends, I started experiencing catatonia. Basically I couldn't move or react to what people were saying around me, and I began heating voices talking to me. The voices we're horrible. Not demons or anything like that. For me the voices always belonged to the people around me, they would constantly critique me, tell me to kill myself, tell me to fuck off, etc, etc. I had already known my grandma was a Schizophrenic, so I was already on alert if these issues started appearing. At first I thought my friends were legit fucking with me because I kept freezing up whenever I smoked, but thank god I realized nope I'm beginning to suffer from psychosis. Went to the hospital got diagnosed etc. etc. I'm fine now even though I don't take the antipsychotics. They pretty much turn you into a zombie and cause you to gain a shit ton of weight. I rarely hear voices anymore but if I do I'm able to discern if they're actually real.

L2DD9: Well I had a slow progression into hearing voices. My diagnosis started out with me being extremely paranoid and thinking that my mom had people following me. that lead to uncontrollable crying. Then after months of walking around thinking people were following me I heard a voice when I was leaving home to get my hair done. I thought my mom said something to me but she didnt. I went to the salon and I heard the voices saying all these mean things about me. Then I left I i continued to hear voices. So i went to church because I thought that it was a "gift" from God. I think was under the impression i could hear peoples thoughts. I was still in denial a while. I don't even really remember telling anyone I was hearing voices...I just know I ended up going to the hospital 
after a while. But since I was delusional and I believed that people were actually following me I knew something was really wrong once I started crying uncontrollably.

H8XKG: As a child I couldn't go to bed without saying good night to the cameras in each corner of my room. I thought this was normal. I spent my 20s self medicating so most everything I chalked ipnto being drunk and crazy. It wasn't til I moved to an island and decided to start over and got sober for a while I realized that I still had the dissociative parts I thought were blackout related. I went to a doctor and got on meds and it became more clear I had suffered this all my life. I'm medicated and in a good spot now.

G3OGC: When I was at work, sometimes I'd go outside and everything would look a little too sharp...almost pixelated, like I was in a videogames. Then, I stared feeling like people were following me around outside. And I took more notice of the posters that were stuck up at the mailbox station. They seemed to be in code. And I was plagued by coincidences. Soon, there were so many odd happenings, I began to feel fenced in by them.

VHF3X: I can't quite remember what age I was but as early as the 4th grade, I remember shadows taking form. For example the shadow cast on the wall by the chair, first I would see the shadow on the left, then later I would see it on the right and wonder if the chair had moved? it hadn't. i was there the entire time. Then I would just look at it - kinda like that little kid in the Matrix that bends the spoon and I could make the shadow go from left to right - although slowly. I was convinced I could move things if I tried hard enough, but first the shadow would move and then the chair. I did move things, I know I had, but my parents and siblings never believed me, so I stopped trying. Over the years it has affected my concentration and my memory has always been for shit. I forget people I know. Places I have lived. Jobs I have had. It's gotten worse with the separation from my wife of 15 years. I suffered a nervous breakdown several months ago. I went for a walk, blanked out, was found in a neighboring town, 15 miles away, delirious : (couldn't answer any questions from the paramedics, rushed to the ER where EKG was done and blood drawn, chest x-ray (because I was complaining of chest pain) and a cat scan. Nothing was found wrong with me. I was released to the care of my roommate/slash/brother. I recently made a post that my Dr thinks a therapy pet would be good for me and I will be getting the paperwork for that finalized this week and hopefully heading to the rescue shelter the following week.

IHN11: I remember as a child (like elementary school age) trying to have a conversation with someone across from me in my head or tell them to do something so that I knew they could hear. Then when they wouldn't respond I'd just assume they're being a dick. Later on the paranoia started. I could NOT sleep as a child. I would be terrified that someone would come in while I was sleeping and 
stab me to death. Every night. As a very young child. For a VERY long time and it sometimes still does get to me. I also remember a pretty long overlapping period where I felt like I was being watched and plotted against, all the time, by everyone. Like The Truman Show except the whole point is to see how far everyone can push me until they all get to watch me hang myself. After long enough I started hearing people that weren't there. Though I could tell that part wasn't real. I knew no one was there and what I was hearing wasn't bad anyway. It would be whoever's voice is closest to me and would be reassuring, telling me everything will be okay, that I'm not alone. I'd touch my own face and it would feel like it was them and everything was okay. I knew it wasn't, but I didn't feel so alone. That still continues. I still hear whoever is closest to me (consistently my girlfriend for the last three years and she knows), I still touch my own face. Though there are rare periods where I think I might get stabbed in my sleep one night and less frequent than that there are times where my life feels like a cruel The Truman Show again. Like when I was a child. But mostly just the comforting voice.

EG5DZ: Trick question. I didn't. I had an “interesting” break. Omitting details and getting to point, had many people wanting me fired. (AOL Tech Support) I'd stay on the line until I Fixed the problem. Often meaning over an hour time call. Brought down the team's numbers. The system required them to give me extra training and stage me down over a three month period. They wanted me out and (yes I know how this sounds, believe me, of all people) began doing various things with the goal of making it "look" like I was a psych hazard to the workplace. Enough people do enough even minor stuff (on top of psych damage from probs in high school...) caused an Actual psychotic break. I can Pinpoint (now in retrospect) the Moment they went from doing stuff to me to apparently "doing stuff to me". Had a conference meet at my psychiatrist (schizophrenia is not my first disorder, only the one that shattered my So badly I can't work or function in public...) both parents and my psych tried to tell me "the people at work" (my own personal THEM) weren't doing anything anymore or to the levels I perceived. I was Furious with all three for not believing me! After all, I was the victim of the abuse. I was experiencing it, of Course it was Real. Doc wanted me to try pills. I told her I'd Gladly take them! JUST to prove it wasn't just me, just to prove her Wrong, and that after being on that they'd have to listen. Turned out, the antipsychotics Did help me and let me realize much of what "happened" never did. Then I knew. And knew how shattered my life would forever be.

M5VHW: $\quad$ For me it's the voices telling me people are plotting against me... Well at least two of the voices are. The 3rd one tries to talk me down. I'll have arguments in my head that people will tell me never really happened, but they are completely real for me. I was just $100 \%$ diagnosed last week by the way, before that they weren't 109\% sure, they thought I was just paranoid. But after my recent hospitalization they changed my diagnosis. 
E58LF: Very early in childhood ... I remember associating the numbers that I saw as friends .. and then I quickly realized it wasn't the same for everyone else.. but I never knew what I was seeing wasn't actually real ...

B5J6F: $\quad$ Not schizophrenic but I have hallucinations and delusions- the first delusion I ever recognized was when my dog got heartworms and I became convinced that the worms would dig into my heart if I touched him. My first hallucination was a few days before my eighteenth birthdaydriving to class, saw a dog twitching to death in the middle of the road, very vivid.. Realized it wasn't real when someone drove through it. To this day, I almost exclusively hallucinate dying animals or parasites (sometimes ghost lights- never shadow people, which seems to be the most common).

PJSDS: $\quad$ Hallucinations: When I started seeing this crazy humanoid figures EVERYWHERE. I thought it was my mind playing tricks on me so I just tried to ignore it but, usually when ur mind is playing tricks on $\mathrm{u}$, whatever $\mathrm{u}$ saw goes away when u look back, WELL NOT FOR ME! Audio: all my life I've always heard screaming in my head but most of the time it sounds external. Usually it's incoherent gibberish, angery screaming, or screaming voices saying my name over and over and over again. More recently, I hear like, anything when there's really nothing. Door bells, faucets, radio/tv, sirens, walking/running, tha list goes on. Paranoia: about 2 years ago, I began getting more paranoid than common paranoia. For example: I always feel like a sniper is aiming for me or like whenever I'm in a populated area, I'm gonna get gunned down any second; I always feel like I'm being watch through tiny cameras everywhere(in door hinges, in outlets, in air vents, etc); I feel like I'm being chased everywhere I go, i feel as if 'everyone' is plotting against me, and the list goes on(again). The worst part is that I can n e v e $r$ shake the feeling. I just live my life in fear. My mom doesn't want me to be medicated :(( ( There's so much other things and it's hell. But all I can do is make light of it by laughing at myself. Like once, my friends dropped me off kinda far from my house and as soon as I it out, he ripped off, so in my mind I'm like "wtf was that about??,....wait....he's maybE RUNNING FROM SOMETHING!! QUICK TURN AROUND!!!” So I look and i see this HUGE GRIZZLY BEAR running down the street towards me, so here I am running home in platform boots looking ridiculous. Let me remind $\mathrm{u}$, I live in the urban-suburb part of ga, where the biggest animals we have are deer

H5R1B: I didn't really realize how bad things were until well into my thirties. The -voices- or rather false memories had just become real. To the point where I would find myself in situations I was sure I had been in before. 100\% completely sure. Or I'd see bugs that weren't there. Or be confused on why I couldn't find the thing that was crawling on me. Or asking people if they had called me. Now I still have those issues, but I realize they can be false. Though. Sometimes a spider can actually be crawling on me and I won't pay it any mind until I actually see it. 
1JBQG: I I had enough voices pressuring me that I felt like hurting myself, my parents took note and called the authorities which landed me in the hospital where I was diagnosed, the voices can be pretty demanding and it can become difficult when you're living multiple lives

V9ZVK: I kept asking people if they saw the strange figures in the shadows and if they heard that person talking saying things, but no one else did. The kicker was when I couldn't sleep for 5 days (108 hrs) because I was convinced that my wall was oozing shit from another reality and people would come through and hurt me if I let down my guard.

L52Q5: All my life, I can't remember a time when I didn't hear voices or see stuff. Whenever I said something to my parents they thought I could talk to ghosts and told me I had a gift, fucking hippies. I did not quite believe them but they refused to take me to a doctor (and don't come and fucking say that a 7 year old should book an appointment by herself). It escalated when I was 21 which ended in the mental ward for me and 3 years unemployment while I was tending to myself. Alone of course because my parents still believe I talk to ghosts. Had I gotten help when I was young I do think life would have been a smidge easier during my childhood.

KB1QR: I have been diagnosed with some not so bad schizophrenia and psicosis. Although is not merely schizophrenia since I don't hear anything that's not there, the first time I noticed I needed help was when I was on my early 20 's. I was in college, sitting on a bench and suddenly I started overthinking of linguistics. I couldn't conceive many ideas and my brain started thinking $1000 \%$ faster without going nowhere, suddenly I felt as I went deeper in my own ideas that I could end crazy, my body felt thicker as I could disappear. Thanks God a friend of mine got me out of that loop. Immediately seek for help and the first psychiatrist told me that I had made an schizoid world that could end in schizophrenia and needed immediate treatment in a psyquiatric facility. Nevermind my family helped me a lot and seeked for more opinions. Now I am completely stabilized and studying in other country with an all paid scholarship. As a personal advice, seek for help, family will always be there for you and always, always look for a second opinion. The sensation of loosing who you are and going "crazy" is something nobody has to experience in their lives.

98POB: $\quad$...huh. That's an interesting question. (Also got downgraded to psychotic depressive but whatever, my diagnosis was schizophrenia at one point.) For me, I guess it was starting to think about people reading my thoughts, which ended up being one of my main delusions. The thing is, it wasn't really a big deal at first - it was more like a little story I was telling myself, just a weird thing that popped into my head sometimes. Like when you knock on wood for luck even though you don't actually believe it does anything supernatural. But then the idea slowly got stronger, and showed up 
more frequently, and all of a sudden it was terrifying and too real and I couldn't control it. I knew the whole thing was mental but I was stuck in that gravity well of crazy just the same. That was my first 'something is actually wrong, I want off this ride' moment.

VJAH9: Hey there, Paranoid Schizophrenic here. Age 21. I was working on a drilling rig and was becoming increasingly paranoid that the food was spiked with drugs. The 12 hour days were rough, I was like a zombie and in a constant state of not talking or doing much on my final days, I was hearing voices of my motorhand laughing at me for not being good enough. I felt like everyone in the camp was out to get me, and I was soon "let go". Fast forward a few months, after taking Adderall XR after not being able to afford the prescription for several months because of a previous diagnosis, I had a mental breakdown. Voices kept telling me to "Ride the lightning" so I had my headphones in my iPod with the song on non-stop repeat. For a few weeks I kept seeing "Colors", it always felt like somebody in front of me was wearing green. I made up my own color code for the colors I saw, people wearing red meant "stop", people wearing yellow meant "caution" and blue meant "go" , and white meant "right way" while if I started going the wrong way I'd see more "red" or "black" in my travels. I don't know how to explain it, but it got me home safely when I wasn't able to afford a phone for Maps. I referred to what I saw as "One Direction". I was very reactive during that time, and one day I just totally broke down by going on a bus and I refused to open my eyes, and I eventually ended up in the psych of a hospital for a month. Until the meds stabilized me over time, I thought I was further being "tested" by people which was the result of the traumatizing effects that working on the rigs had on me. I am now on a monthly abilify injection for my paranoid schizophrenia. Even though I feel normal now, I get a little bit shaky on the day I'm due for an injection and my reaction time is much slower than it use to be. I'm 26 now and I'm more motivated and stronger than ever.

J0FOW: $\quad$ I am at present diagnosed with schizoaffective disorder but following my first psychotic break I was diagnosed undifferentiated schizophrenic. I began to notice my mind was not right. I had been trying to develop control over the smoke drifting up from a stick of incense. I also tried dangling my necklace chain from my hand and trying to control it with my mind. I tried listening to a bird singing, thinking about Adam in the garden of Eden, imagining that if I concentrated enough I could decipher and understand what it was saying. I was getting further and further from normal thinking. I had picked up a piece of stepped on paper that I thought looked like a bird, and took it home as if it had talismanic significance. I had met two men passing through campus who talked to me about Jesus, and I became certain they were two of Christ's original disciples. I had been smoking pot weekly since about a year previous to all of this, but even two or three years previous I had become deeply interested in abstract thinking and kept trying to engage my friends in philosophic discussions, after which several of them told me, "you think too much." In order to try on different philosophies I imagined what it would be like to keep a version of my mind with my present Christian 
beliefs and another version with say Buddhist thoughts, and in my spare moments reflect on how things would have taken place differently had my beliefs been different. I did this on a relatively permanent basis for about three years before my breakdown, as a thinking habit, a sort of extended thought experiment. Whenever I had evaluated the philosophy I wanted to try on and decided against adopting it, I reset and started over with a new fresh trying room. That's how I thought of it. Sort of compartmentalized my thinking. I would keep silent about what I was entertaining in the trying room and not act on it, just keep track. I don't recommend this, by the way. As I grew closer to my breakdown, I kept an increasingly different version of reality in my hypothetical trying room. The strain between the two was becoming intense. I was essentially living with two radically different versions of reality inside, one of which was secret and walled off. I had been becoming troubled by this. I had befriended someone I didn't like at all, named Ben. I had been attending a Bible study at college and a friend from Bible study, a girl, asked me if I would talk to this atheist. He was extremely hostile to religion. He treated everyone else as if they were stupid if they weren't atheist. He introduced himself to people like this. "Hi, I'm Ben, and I'm arrogant." With a smile. He selfdescribed as a hedonist. Melodic apostasy was a phrase he coined and was quite happy with. He was the worst person I knew, but I was going to Save him. After all this time going on like this, I was becoming desperate. I wanted to reset my brain. Ben told me he had done LSD with some friends and wanted me to trip with him. He had little bits of paper in a container, triangles. I don't know if it was really LSD. But I tried it. I believed it. I think for him it might have been a prank. Or an experiment. To him I was a plaything. Anyway, I "tripped" with him. I believed the strictures which held my mind were loosed. But things didn't improve. I felt beaten. I went to another person, one who I judged to be smarter than Ben, to take him on in a way, to do acid with me. I couldn't fight the battle I was in. Crazy way to think, I know. This time it was real LSD for sure. Due to the contents of our trip, I became focused on demons and spiritual warfare. I thought I'd seen him showing me a demon inside him. Anyway, the trips went on as I grasped at the straws of my fleeting sanity. What came first, the drugs or the psychosis? At any rate, I was just finished with my second year of college and one and a half years into my break when I was prepared to commit suicide. My life was hell inside, complete with mental anguish and torment, with the devil and demons. I couldn't even hear speech without trying to decipher a second meaning spoken by forked tongues. I believed I was damned. Thankfully, I went to the doctor about my depression after Zoloft had failed to make it better. I felt like being lifted up against a steel plate that was crushing me down. My normal doctor wasn't there that day, and his partner asked me if I'd done drugs. I said yes. He asked which ones. I told him, pot, shrooms, and acid. He asked me if he could tell my mom, who had brought me there. I said yes. Which is why I'm still alive. She brought me straight from the doctor to the hospital where she worked, and the ER took me in with acute LSD-induced psychosis. I was admitted. I was in the psych ward. I stayed 21 days, and didn't want to leave. I've been medicated ever since, except for a three month period after two separate psychiatrists and my counselor decided I was not schizophrenic after all and didn't need 
medication. When I went off my meds, I felt wonderful! I lost a ton of weight. I went from a 34 inch waist to a 32. My mood was wonderful. I felt alive! Then three months later, I had a night where everything fell apart. I ended up back in the psych ward, over ten years later. That was seven years ago. I'm still stable, still medicated, only now my diagnosis is schizoaffective disorder. My doctor said it was possible I was bipolar, as the two diagnoses are similar. So he essentially asked me which of the two it felt like I had. The treatment is about the same. I'm now a size 36. I weigh 205. I take several medicines, two to deal with high blood pressure and high triglycerides and fatty liver, side effects of my psych meds. I only work 20 hours a week. I hadn't intended to write so much. If anyone has any questions I'm happy to answer. I just hope no one I know figures out this is me.

D62J5: Pretty sure I experienced Schizophrenia as a child up until about 13. I would wake up in the middle of the night to the same screaming demonic voice in my head yelling profanities and telling me I was going to burn in hell etc. It would tell me not to mention it to anyone so I never did. Waking up in the morning was fun to as I got to see three shadow figures shoulder to shoulder rush me for the first few seconds of waking. I felt like there was something in the corner of my room that liked to watch me sleep every night but I got used to it to a degree. I would have compulsive images of sexualized religious figures run through my mind which I didn't enjoy or anything it's just that the more wrong the thoughts were, the more persistent they were. I grew up going to church as a kid but participating always made me feel alien and frightened because I didn't understand any of it and thought those compulsive thoughts could be heard by god which in turn fueled them even more. While I'm going I also used to have frequent nightmares involving decapitated heads, always running from someone who was going to decapitate me, or just being a decapitated, living head. When did I find out? I have just recently been wondering whether or not my experiences all of which stopped happening at around 13 (19 now) would be considered schizophrenic. I'm not sure. Can anyone that had the heart to read all of that explain if what I experienced was Schiz? This is my theory as to why it stopped and might help to any of you Reddit M.D.s to figure it out. My theory for as to why it stopped is because at a certain point (around 13) I built up the courage to literally talk back to the voices basically by just cursing back at it (myself?) and allowing the images to just flow instead of fighting them back in my head. Once I won the "battle" with my inner demon it left me alone which then allowed me to realize that the shadow figures didn't have any real control over my life. I realized they couldn't hurt me, send me to hell, possess me, or control me in any way if I just didn't allow it. Sorry for the rambling but to reiterate; Was what I experienced during my childhood schizophrenia or a side effect of an admittedly hectic (and I mean hectic) household I.E. lots of screaming, violence, manipulation?

1A76R: I was super stressed for work and how I was failing to keep up. Been having Sleeping problems. Usually as I was running to work in the morning I started hearing voices of people calling 
my name. And it is pretty unique name. At first I thought coincidence. After happening every day and in random places for a span of few months. I thought someone was joking. Then things started appearing and disappearing in my apartment and at work. I would really believe someone stole my MacBook even if I never bought one. But somehow I saw it on my desk yesterday. I would hear noises in the middle of the night. Shadows of people wandering in my apartment. It took me some time to realize I was hallucinating. Most of the time I thought I was part of a sick joke. Kind of like Truman style. Now I'm much better

E1814: Hearing doors creak open near me, my abusive fathers laugh and name calling long after he left when I was 15. I started hearing a fizzing and seeing shadowy figures at 16 . The shadowy figures gave me a feeling kinda like when you feel you should be able to put a name and voice to someone but you just cant. Like i should recognize them but I don't remember who. At 17 I had a conversation with a voice before realizing I wasnt actually having a conversation, that broke me and got me to go see a doctor. Its alot better now, Im mostly back to normal.

R080L: $\quad$ So I sat here trying to pinpoint the moment I knew something was wrong. I honestly couldn't. It developed so slowly that any slight change from my behavior before, was normal to me. I knew I was 'weird' and that I had 'imaginary friends' but it was so normal to me, I didn't question my sanity. I developed this disorder at a really young age, maybe that's why I didn't realize what was going on?

Q5TPM: In high school my friends and family noticed I would react to sounds, voices, and interact with things that weren't there. I was diagnosed with schizophrenia and borderline personality disorder. Both of these coupled with dissociative amnesia, and the anxiety and depression they produce has led to some scary situations. The worst by far was about six months ago. The voices woke me up screaming at me that someone was coming after me. I sat up in bed and turned on my lamp. Laying in the centre of my room was the mangled body of the coyote I had hit in my truck three months prior. It was dragging its broken body towards me and was trying to crawl on my bed. I yelled for my parents and when my dad opened the door, dozens of dead bloated corpses fell into my room. They were all screaming and moaning and the smell was unimaginable. I don't remember much after that. I know that the police came, transported me to the mental ward at the hospital where I spent a few horrifying days while the doctors sorted out my meds. Mental illness is some scary shit.

U3V2G: I always assumed i just had weird thoughts and extreme anxiety/depression until reading some of the replies on here. I have always given personalities to numbers letter and cars. Like to me a 6 is closely related to a dodge truck and he's strong and rugged he has a certain face and attitude. The letter $\mathrm{E}$ is shy and is close to the number 5. I also have a constant fear of someone 
following me he's behind me. He's in my house. He's watching in the corner of the room. I will have full on melt downs thinking he is about to murder me. As a young child i would convince myself a lump of clothing was a monster head then i would actively see it moving around I remember vividly these memories. Putting it off as just weird kid things . My grandma is diagnosed with schizophrenia and my brother has been diagnosed with bi polar disorder. I'm probably just a weird anxiety mess but I would like to hear some other people's opinion on my situation

IJ25O: $\quad$ You mean when people said I wasnt "quite right"? I feel fine. I couldn't figure why other people didn't see who I was talking to, or understand when lights flickered to get me to react, the people on tv and radio are talking to me just as I would to someone across the table from me, or all the people conspiring to create havoc in my life for their personal amusement, the worst was when I became fed up with people reading my mind so I got in their face about it because they were cowards and wouldn't be open about it. I guess it started about 10 or 11 ....and even with treatment and a tested and trusted sounding board to tell me if it's real or not..... I still know I am right and people are just messing with me, but I'll let it go because I trust my companion who for some Bizaar reason has stuck with me 30 years.

GE6N5: When I started to hear nonsense opera style singing. Before I would never hear voices just random sounds. Tbf the opera singers in my head are not malicious and are on point with the tunes.

PVTVM: $\quad$ I was in Amsterdam doing my internship, then one day I had a fight with my roommate and didn't go to the office. I was roaming around in the streets when I heard my employers name. I thought they were following me. Same happened the next day, when I saw people from my office there. I heard stories of events from my office from random people on the streets. I left the city but the voices kept following me. I thought people were following my actions, my thoughts, I thought cameras were reading me. I left the country and came to India, where it still followed me. I thought they were playing some kind of a joke with me but I wanted it to end but it didn't. 6 months later I decided to go to the psychiatrist only to tell me that I'm schizophrenic. But I can still swear that some people were actually following my actions. Dunno what's real.

IBJ2K: $\quad$ Since a while ago I had a lot of fun fucking other people's minds, making them feel bad, useless, etc. amongst other things. Although the moment I felt something was wrong was when in the psychologist, with my mother, while we were discussing the reasons on why I had developed such critical levels of depression and anxiety, I was smiling so hard I felt like I didn't have enough mouth width to smile harder, and at a moment I starting laughing out loud like I had heard the best joke ever -- all of this because my mom crying her ass not being able to talk properly felt pretty funny. 
LEBC8: I'm not sure where else to post this. And seeing as I'm too poor to get a professional opinion, I guess this is as good a place as any to get advice. As a child, I had a very specific pattern of walking. Left foot forward for every third step, left for the other two. Left foot stepped on cracks right foot never did. If I was walking on tiles I'd only walk on one color. I also occasionally saw a shadow that was that of a man in a top hat with no features other than red eyes. Around puberty this stopped. Cut to age 19. After dealing with quite a few family issues. (restraining order against one parent, and being forced to live with the other who I hadn't seen in 10+ years. After a suicide attempt I moved back in with the first) I start doing drugs, mainly acid. Handled it well minus a few times where being in the bathroom gave me a panic attack. I tried DMT for the first time and had a complete meltdown. Since then, I have frequent audio hallucinations, like hearing my wife screaming my name, or women's laughter, or my children crying. During these panic attacks I become convinced that I'm living in a simulation. Nothing looks real, and I don't feel like I'm one entity. It feels like there is a break in mind/body. Any ideas on what it is or how to cope? Every method I've tried works for a little while, but soon starts failing.

19PVG: When I was younger I often had the thought that people could hear my mind or that there are cameras in my room. Sometimes I acted like a person knowing there are cameras, pretending that there are no cameras. I never really noticed this as being a psychological disorder. When I was getting older these thoughts where pretty much gone. The first time I really noticed something was wrong, was when I was hearing music with headphones in my room and I thought my mother was shouting from downstairs. She wasn't. After this happened a few times I realized something was wrong which only made it worse, because now I was always waiting for this to happen. Now that I'm living alone it still happens but now I'm just ignoring it. It is hard to descripe this feeling: I just KNOW that I wasn't called, but I have the URGE to react to it. All my weird thoughts and feelings are gladly reduced to a minimum. I'm living a normal life, like everyone else. I don't take medication. I can tell schizophrenic thoughts from reality, but sometimes it is exhausting. If there are any further questions feel free to ask. English is not my first language, so I hope this text isn't to hard to understand.

6EDYQ: I don't have schizophrenia, but I have a related illness called schizotypal personality disorder, that is essentially the same, except with less to no delusions. Honestly, nothing has ever been /right/. In hindsight, I can see that I've had some serious issues since I was 10, but the moment I noticed that something wasn't right was when I ended up homeless because I could no longer function properly as an adult. Apparently, I had covered up all my windows with newspaper to block light from coming in at my worst. I've always had audiovisual hallucinations, extreme difficulties holding any sort of tangible control over my own thoughts and a voice in my head I actually sort of like and 
can't really live without at this point. My typical hallucinations are the sounds of doorbells (which is why I tore out the doorbell in my apartment in a fit of rage once, so now I don't have to go to my front door to check if anyone actually rings it anymore, since I know a ring is a hallucination and a knock is the real deal), walls, floors and other stationary objects having their surface "Move around" like in this gif, sensory input crashing into my thoughts, rendering them into mental noise when I'm exhausted (like my senses and thoughts destructively overlap, my sight getting fuzzy under harsh noise levels, thoughts being harder to make out too). Oh, there's always someone standing in the corner of my vision. It makes a great jumpscare every once in a while to see -something- when I'm supposed to be alone in the room. Also, I get immensely uncomfortable when my windows aren't covered up for some reason. I can live with it in other people's apartments and in places like work or other public places, but I can't for the love of me stand having my own windows exposed.

JDHL0: My doctors told me that schizophrenia is becoming an outdated diagnosis. I do have BPD1 with psychotic features and many of the experiences here are the same as my own. I think the earliest example I remember was that I hear music. Not like a song stuck in your head but as if a radio is playing. Except I hear multiple radios sometimes, playing over each other or syncing up and it is incredibly annoying and distracting. I didn't piece together my hallucinations until high school. I didn't realise anything was wrong. I just thought it was all normal. I've talked to people who I could see and discovered they were not there. I've heard sounds and voices. I've felt touch on my skin and seen myself standing in another place when I am out in public; once time, trying to get to work, I was suddenly in an airport. It was so real that I called in and went the fuck home. Another similar occasion was at my desk at work. I looked up to find myself on a beautiful, empty beach. Looked down at the desk. Looked back up at the beach. Back down again and my desk was gone and I was standing. A calm fell over me and all was at peace even as I thought in wonder, "this isn't right. I'm at work right now." I don't know how much time passed but eventually I looked down and was at my desk again, still seated. Also the comments about always assuming there to be a camera or someone/something watching applies STRONGLY to me.

MFU0E: $\quad$ Started off when I was very young. I was about 3 years old and seeing people that look like cartoons, it seemed off to me and it freaked me out so much that I would start crying and my parents didn't know what was going on. Later on during the nights I would hear voices calling my name. Whispers or screaming. They were unfamiliar but sometimes sounded like people I knew, people that have never been to my house. I would respond and say "what?" Or start screaming again. My mom thought nothing of it when I was little. 2 years ago when I was 17 I had the worst panic attack and was sent to the hospital. It took a while to calm me down. My mom scheduled an appointment with a therapist and a psychiatrist. I was diagnosed with schizophrenia, ADHD, bipolar disorder, depression, and anxiety. 
AXYIT: $\quad$ Hearing my dead best friend screaming for help from Hell.

X4P3Y: I am going to get $/ r$ /iamverybadass'ed for this, I'm sure, as it always happens. But, no, I did the US Army thing, nearly died in Iraq, developed schizophrenia around my late-20's (which is apparently when it can happen for males with triggers) along with PTSD, anxiety, depression, paranoia, and a fuckton of anger issues that never go away where Iraq was the trigger. There's that literal and figurative kill switch soldiers and Marines are installed that is normally controllable by the individual: to go from a normal decent and civilized human being one second, to a giggling bloodthirsty mindless berserker the next, then back again as necessary, so you can fight your worst when there are enemies, and be your best when otherwise. My switch is broken thanks to the schizo. I didn't realize how fucked up I was until I ended up in jail for nearly murdering a whole bunch of people in one of those angered, thoughtless rages. I've had to do a LOT of therapy, counseling, and taking a lot of medications alongside being often self-reflective to try and catch the madness before it starts. And I've caught it a few times before; managing to get myself into a VA institution where I couldn't hurt others or myself while the docs tried to figure out what went wrong there. Seems like the medication is working full-time and well now, though. It took years, and a lot of bad experiences, but I live in a state with an exceptionally great VA, so my prognosis isn't like Phoenix, AZ's veterans can be. If if lived in Phoenix, though, I probably wouldn't be here right now, and so wouldn't some other people. I know it's bad when the thought of killing people is like thinking about future sex.

NQ7EP: $\quad$ That's the thing - you don't notice things aren't right. All through highschool on and off I though my friends were paid by my parents just to be my friends and they were recording my conversations. I thought my parents were listening to me or reading the transcripts. I never once thought to tell anyone. It just becomes reality.

Y1YAV: $\quad$ Yes! Always someone watching. My life felt like the Truman show. I saw alot of shadow people. Heard my name being called and could hear music, mostly heavy metal when I would run water. I i thought people could read my mind and was generally paranoid I was part of some psy op. Everyone was part of some operation and knew eachother. No one would fess up to it. My first real realization I was having a schizophrenic episode was at a hospital. It terrified me and I left in only a pair of jeans and a hospital gown and walked across the city barefoot. I thought everyone was video recording me and they were all conspiring with the hospital and police. I hid in my friends basement for a day or so. Found out later that day my friend Kyle hung himself and I bugged out thinking this was another ploy to get me out of hiding. I've got things under control now but it's genuinely hard to decide of I was delusional or if I was on to something, like a glitch in the matrix... 
XOYYK: I sought psychiatric help in my early thirties when i started experiencing drastic visual hallucinations that put me at risk of injuring myself. The easiest way of describing it would be that my brain had changed channel from what i was seeing to something else entirely, but i was unaware of it until it changed back to what was actually in front of me. These "channel changes" could last from a few seconds to almost half an hour. It's harder to answer when the first "not quite right" symptom was, because no one can know what actually happens in their head relative to everyone else, and it's difficult to describe to people. I distinctly remember discovering hearing my internal monologue for the first time when $\mathrm{i}$ was six and it immediately telling me not to tell anyone $\mathrm{i}$ could hear it. I've been hearing it ever since, sometimes it's helpful and other times it tries to get me hurt. Is that normal? I avoid totally quiet environments because if there is not a level of background noise the voice morphs into a torturous cacophony of noise, think the Monolith noise from 2001 but up to 11 . When having a discussion about this "disturbing thoughts" came up, violent graphic unbidden images suddenly popping into your head. I don't consider that as applying to me since i've had sudden thoughts of graphic murder about almost everyone since i can remember, so they are not "disturbing" to me. I mostly have a handle on things now though, the worst i get are illusory spiders in my peripheral vision, but spiders are cool, so I'm happy with it.

R6GZW: I always think that someone's out to kill me. I always have a weapon ready next to my bed. I couldn't sleep nor eat because of it. I also see things - at my worst I saw cockroaches crawling all over me which lead to numerous panic attacks in just the span of a week. I also thought that my cat was controlling me and almost went crazy when a voice told me to kill my family. I was always an anxious child and was always a crybaby. Maybe that was a sign. I also hallucinated smells like something was always burning. I'm on medication now.

K9HCR: I get psychotic when things are bad (not schizophrenic, either bipolar or bpd, my psychiatrists are in conflict) and I guess looking back I can pinpoint the first time something was off because I started seeing people looking at me. like I became hyperaware of people staring at me or turning their heads to look at me or even passing eye contact in the street and my brain just started building this super elaborate fantasy that I was being tracked and watched and bullied by people. it was really horrible but. haven't had paranoia like that again. now I get delusions and hallucinations about maggots in my teeth and tapeworms (I have an eating disorder so I throw up a lot and when things are bad the vomit is just FULL of worms to me, I've gotten hysterical and scooped it out of the toilet to pick through before) and skin parasites (I have dermatillomania and eczema so my skin is always itchy). sometimes I also feel like I can tell the future or hear "secret music" that has messages encoded for me. 
2JXEJ: $\quad$ Before I lost insight, I told people that either someone was messing with me in an elaborate practical joke involving the selection of songs on the radio relating to what I was doing at any given time, or I was losing my mind (I said this jokingly, never thinking for a second that something so unthinkable could be happening). I just thought something weird was happening, like it was some fluke. I didn't pay much attention to it. Anyway, I regained insight thanks to the kindness of strangers, medical professionals, and medication. I've been symptom-free for years now.

GIZ7C: $\quad$ I was diagnosed schizoaffective when I was 24, but began treatment for mental illness at 17 following symptoms since the age of eight that had gone ignored by a negligent mother. As a kid, I toe walked, was very stiff in my movements, and had no facial expressions and a flat affect. My mom made me sit in front of a mirror and practice appropriate facial expressions so I wouldn't 'look angry all the time'. When I was a kid, I heard music in my head all the time and got absorbed into playing pretend. My imaginary friends were real, and I would get so invested in 'worlds' that I became other people and lived other lives. I had my first manic break when I was twelve and regularly slept three hours a night and was generally hyperactive and manic in my behavior. I became depressive following a traumatic experience at age 15 , and began self injuring. Slowly, the self injury began to be instigated by command hallucinations, and it spiraled out of control from there. I remember distinctly my first real psychotic episode; I was walking in a graveyard in the snow and a tree wrapped in barbed wire began talking to me, asking me to set it free. I also saw a lake that wasn't there with dead little girls trapped under the ice. The scariest psychotic episode I ever had was when I was 24, shortly after watching American Horror Story: Asylum. I began hallucinating the character Bloody Face in my house and as a result slept with a butcher knife under my pillow. Additionally, I have had episodes of command hallucinations telling me to kill myself, my cat, my grandmother, and when I was a nanny, the children I cared for. I also frequently feel that I am under surveillance and think that other people are having negative thoughts and criticisms of me and my actions. I was in residential treatment as a teenager and have been hospitalized four times as an adult, most recently in 2015. I started taking antipsychotics and mood stabilizers when I was 18, but continued to struggle with positive symptoms, mood instability, and negative symptoms, the latter of which I still have a lot of trouble with. I have significant issues with ADL's, it's an ongoing problem for me to shower regularly, brush my teeth, and remember to eat and take my meds at regular intervals. However, I manage to work a full time job in healthcare and I am a full time student with a 4.0. My positive symptoms are largely under control, though I do hear music much of the time and I see shadow people.

8L0EF: This is my first real comment on Reddit so I'll do my best. Sorry it's long! I just want to preface this by saying when I tell this story sometimes people think I'm lying about the part that weed played in this or that I'm disagreeing on the medicinal properties it has, I am absolutely not, it just didn't work out for me. My doctor said it was likely that I was predisposed for all of this and that 
this sort of triggered it. Mine was a little bit different than some other people because it was all at once, with some symptoms evolving over the years. When I was about 15 I started smoking pot, I did it a few times and it always ended in panic attacks for me but I was young and wanted to fit in so I did it a few one more times and something immediately was not right. I felt so so afraid and out of my body and scared. Like I heard someone was screaming and then would focus really hard and it was me. This lasted a few days with me avoiding my parents until finally I went to my dad and told him the score. My parents were really kind about it and took me to the hospital. They didn't help at all but the problems I had In the medical system are another story. After that basically what I felt was terrified. My number one paranoia was that people were poisoning my food. I couldn't eat anything that wasn't in a sealed package because I was sure someone had poisoned it and even then I was sure that the people at the factory had poisoned it. I would literally gain the courage to eat and then lay down on my couch waiting for death which I was sure was coming. I thought ever car behind me was trying to kill me and I would drive circles around my block before I got home to "shake them". I worked a job where I had my back to the door all day at a till and every time someone walked in I was sure they would come up behind me and slit my throat. The symptoms sort of evolved over the years but another thing that was there right away was the derealization and depersonalization. Nothing ever felt real, like I was in a nightmare I couldn't wake up from. I didn't feel like myself, I felt I was watching a movie of myself or that I was watching me while standing behind myself? Sometimes in the middle of a conversation I would think to myself "who is talking??" And then realize it was me talking without really realizing it. Like I was partitioned off in a different part of my brain. There was also audio and visual hallucinations, the audio ones was either my dad yelling my name loudly and angrily (he's very nice and never yells so it was strange) and weird things like a lawn mower in winter. I also smelled this gross sickly sweet smell sometimes when there was no cause for it and saw things like people but when I looked closer they weren't there. I'm now doing a lot better but that was basically my original symptoms. I would be happy to answer any questions!

HUCRA: Well this will definitely get buried but here it goes. First time I noticed something wasn't right was the very first time I hallucinated. I'm discounting sleep paralysis as hallucinations because a lot of neurotically people experience that too and it's pretty much just dreaming. But the first waking hallucination I had was a voice saying "Don't worry he can't even hear us right now" with the "he" referring to me. My first thought was "fuck I'm crazy". You hear a lot of stories of psychotics not being able to distinguish between reality and delusions or hallucinations but for what ever reason I can, and could right of the bat. I didn't think the voices were angels or demons or spirits or other peoples thoughts or thoughts people were planting in my head, I didn't think they had access to any great truths or and information that I didn't have access too, I just knew they were hallucinations talking bullshit. 
K23XJ: Honestly I wouldn't have known what schizophrenia was if I hadn't read a fictional book about schizophrenia in 8th grade for class. I was diagnosed with schizophrenia in 9th grade. I started noticing that something was wrong when electronics were talking to me and I felt like I was always being followed by people from my past. I also had more auditory hallucinations where people were in my head. I distinctly remember breaking down in my psychologists office saying that I heard voices and that I thought I had schizophrenia. Later I started seeing a psychiatrist, got diagnosed, started treatment and got medicated. I haven't heard voices in years. It does get better, just seek treatment!

CEO59: The first major event was back when I worked at the local cinema. It'd been a slow day and I had ventured into one of the screens to watch a movie (it was a VERY casual work environment). After maybe 20mins I remember deciding to leave the screen to make sure I wasn't needed for any work (cleaning screens that had emptied, cleaning the corridor leading to the screens, seating a particularly busy screen). The screens themselves were seperated from the corridor by an 'airlock' or two sets of doors and as I passed through the second set of doors and looked down the corridor to where my co-workers were I had my first lucid delusion. I should note that my delusions/hallucinations aren't just a singular sense, but a complete 'experience'. Tactile memories, sounds, events and even taste all occur at once, it's incredibly overwhelming and the combination of them prevents me from telling them apart from reality whilst they occur. Anyways back to the story. When I looked down the corridor and saw my colleagues I felt rage for some reason that I can no longer recall. Next thing I remember is the feel of the carpetting on my hands as I ran, hunched on all fours, towards them. I saw them turn to see me and laugh until I lunged at the closest and tore his throat out with my teeth. I can tell you now that I could taste his blood in my mouth, I could hear their screams and I could see the blood spray from the open wound. I then turned and slaughtered one after another and then as soon as it had begun it stopped. I was stood outside of the screen I had emerged from, no blood, no screaming, no dead colleagues just the 'memory'. I know this all sounds far-fetched and I'll tell you this much, I doubt I'd believe anyone telling me the same story had I not experienced it myself. I first saw a doctor in response to this about 6 months later and it was diagnosed as depression, two weeks later I was escalated to the local Mental Health Team for psychiatric review which came a further month later. Original diagnosis from a psychiatrist was Paranoid Schizophrenia, Agoraphobia and Depression, over the last 10 years that diagnosis has changed (depending on the psychiatrist) to Schizotypal Disorder, Paranoia, Depression and Agoraphobia. I have also been diagnosed with Schizoeffective Disorder but, as I have never seen the same psychiatrist twice, the diagnosis often changes.

6OL9T: Diagnosed schizoaffective. Early onset here, and currently almost totally in remission (yay!) I can actually look back and see the signs in early childhood. Remembering when I was a kid 
and my mom was convinced I just had an "imaginary friend," and then couldn't understand why I was always scared and freaking out when I saw it, because I couldn't properly describe it... having to go sleep in her bed multiple times because there were "tons of maggots" in mine. I had a recurring idea (despite a very secular upbringing) that God was punishing me for various things, often totally outside of my control. I tried to talk to doctors about things a few times but my parents always stonewalled me, said there was nothing wrong with me except I was sensitive. I think I figured out something was genuinely and truly "off" in my teens while I was checking behind the paintings for recording devices. Something just felt weird about doing it, but I didn't get help then either, because I was totally enmeshed in my weird lifestyle. Didn't get help when I had to leave public events with my then-GF because I heard screaming everywhere. Didn't get help when Satan was talking to me 24/7. Didn't get help when I dropped out because my hallucinations were disrupting my time at school so badly. I saw my first therapist at age 21 when I had a blowout with some friends online. I'd gone weird again, and accused them all of trying to steal my identity and absorb pieces of my soul or something, then when I calmed down from it I decided I needed to see a psych. Not because of the constant hearing voices or visual hallucinations, just because I was being mean to my friends and didn't want it to keep happening. I've heard similar things from a lot of people - we get help because of a relatively minor quality of life issue, not because we're always aware we're delusional.

8LTEP: I was seven on Christmas Eve, I kept hearing a voice and then stared for hours out of the window to an alleyway near my house, I was convinced there were 3 demons dressed as people trying to kill people. It all started from then, I didn't say anything to anyone about it until I was 17 
'Something wasn't quite right': a novel phenomenological analysis of internet discussion posts detailing initial awareness of psychosis

\author{
Amanda Spikol and Jamie Murphy* \\ School of Psychology, Ulster University, Northern Ireland
}

*Corresponding Author:

Text body word count: 4612

Professor Jamie Murphy

Table count: 2

School of Psychology

Ulster University

Derry

Northern Ireland

BT48 7JL

Telephone: +44 (0) 2871375283

Email: ja.murphy@ulster.ac.uk 


\section{Abstract}

INTRODUCTION: A significant number of psychosis studies have focussed on and have attempted to model and frame the earliest psychosis experiences. Using a wide array of methodologies and targeting a variety of 'at risk' groups, researchers have offered much to inform our treatment responses, and understanding of psychosis onset and development. OBJECTIVES: Due to the nature of scientific investigation however and investigator led exploration, those who experience psychosis are rarely afforded ultimate free rein to dictate and direct the exchange of information or to impose their unique narrative on that which is being explored. In an attempt to address this, the current study opportunistically harvested rich self-report data from replies to the question, "People that have been diagnosed with schizophrenia, what was the first time you noticed something wasn't quite right?" on the internet discussion forum Reddit.com.

METHODS: User data was analysed using Interpretive Phenomenological Analysis to identify key themes in participants' first experiences and initial awareness of psychosis.

RESULTS: While respondents varied widely in their recounted experiences and chose to describe these experiences in a variety of ways, analysis showed that (i) respondent distress was associated with psychosis onset timeframe, negative-voice auditory hallucinations, visual hallucinations, paranoid delusions, and insight (ii) early childhood psychosis experience resulted in novel explanatory schemas and psychosis/distress progression with contributory factors in adolescence and (iii) $41.3 \%$ of the sample reported self-realisation in gaining insight and greater insight was associated with help-seeking behaviour.

CONCLUSIONS: This novel use of publicly shared experiential data might enrich our existing qualitative literature concerning early psychosis. 
Key words: early psychosis, social media, interpretative phenomenological analysis, first episode psychosis; premorbid adjustment 


\section{Introduction}

Early psychosis receives significant attention in the research literature.

Understandably, information, knowledge and clarity about the earliest signs and signals of psychotic experience afford valuable opportunities to inform and achieve successful early intervention and support. They also afford valuable opportunities to understand psychosis onset and development and the aetiological landscape that underpins such experiences. A variety of literatures have attempted to model and frame early psychosis; prodromal studies $^{1}$, first episode psychosis (FEP) studies ${ }^{2}$, ultra-high-risk (UHR) studies ${ }^{3,4}$, clinical-highrisk (CHR) studies ${ }^{5,6}$, duration of untreated psychosis (DUP) studies ${ }^{7}$, first treatment contact studies $^{8,9,10}$, continuum studies and those investigating subclinical/psychosis-like experiences (PLEs) and/or schizotypal traits ${ }^{11,12}$, each attempt to capture the earliest manifestations and expressions of psychosis in the population.

These studies in turn have afforded valuable opportunities to investigate many important clinical issues surrounding early psychosis such as e.g. the reduction of risk for $\mathrm{FEP}^{13}$, the prevention of second episodes ${ }^{14}$, pathways to care from FEP ${ }^{15,16}$, the efficacy and safety of psychopharmacological intervention in early psychosis ${ }^{17}, \operatorname{cog}$ nition and neural functioning in early psychosis ${ }^{18,19,20,21}$, premorbid adjustment, symptom development and quality of life in early psychosis ${ }^{22}$, suicide risk ${ }^{23}$, and the environmental context of early psychosis $^{24,25}$.

Our framing and operationalisation of early psychosis however has also been significantly informed by rich qualitative evidence detailing the lived experiences of those who have directly encountered and endured psychosis ${ }^{26}$. Multiple qualitative studies 
detailing e.g. the subjective experience of $\mathrm{FEP}^{27-29}$, service user views on early intervention ${ }^{30-32}$, early experiences of help seeking ${ }^{33-36}$, and issues surrounding social relationships in early psychosis ${ }^{37,38}$, have afforded invaluable insights into the personal experiences of individuals, their families and service providers.

Importantly however, much of the evidence we rely upon (both quantitative and qualitative) to inform our understanding of early psychosis, may be somewhat constrained by unavoidable researcher bias ${ }^{39,40}$. Researcher selected methodologies, researcher designed interview schedules, researcher formulated terminology, and general researcher driven enquiry may ultimately limit our understanding of early psychosis. Because researchers frame, direct and focus research, those under investigation must provide information in a manner that conforms to and is consistent with the imposed investigatory framework. Rarely are those who are under investigation afforded ultimate free rein to dictate and direct the exchange of information or to impose their unique narrative on that which is being explored.

The current study, in an attempt to explore early psychosis without the constraints of researcher design bias, opportunistically harvested rich internet discussion content linked to an AskReddit post enquiring about first experiences of psychosis. Given the absence of researcher definition, instruction or clarification regarding e.g. terminology, phenomenology, or time; the freedom to attend to and comment on any aspect of experience; and the anonymity of disclosure, we aimed to (i) more objectively examine the lived experiences and interpretations of those recounting early psychosis, (ii) enrich existing qualitative literature concerning early psychosis, and (iii) establish a coded analytic framework to support further in-depth analysis of this rich data resource. 


\section{Methods}

Medium

Data for this study was sourced from the Internet discussion site reddit

(www.reddit.com), specifically the sub-forum AskReddit (www.reddit.com/r/askreddit/).

Reddit has approximately 542 million monthly visitors and is ranked the 8th most visited site on the global Internet and 4th in the US ${ }^{41}$. AskReddit, with approximately 18.4 million subscribers, is a sub-forum where any user may post a question for general advice, openended discussion, or lived experience. Users may reply to the question or to other users' replies. Forum rules forbid posting identifying information and users post under a chosen username or create a one-use 'throwaway' account. Users may vote on comments as part of a wider 'karma' system. 'Up-votes' contribute to karma while 'down-votes' take from it, with 'up-votes' generally taken as agreement with the comment or as an expression of respect for or empathy with the poster.

Griffiths ${ }^{42}$ cites several factors supporting Internet collected qualitative data; easy access to wider recruitment, a potential global sample population, cost-effectiveness, reduction in social desirability, data in common digital formats, and accessibility for those uncomfortable with in-person participation. This allows a vulnerable population complete control over their environment and comfort level, avoiding social pressures and self-stigma. Evidence suggests individuals with schizophrenia exhibit Internet use behaviour comparable to a non-clinical sample ${ }^{43}$, incurring no additional risks participating in online research. In this study, reddit users were free to ignore the posed question, thus those who commented truly wanted to share their experiences. 
Sample

At 19:37 GMT on 13 November 2017, a reddit user posted the question "People that have been diagnosed with schizophrenia, what was the first time you noticed something wasn't quite right?" to AskReddit. This post carried a [Serious] tag, indicating off-topic or joke replies would be deleted by the moderation team. 4565 users commented, either responding directly or in nested comment threads. The post was sorted by 'top comments' by up-vote and the top 150 replies sourced. Nested comment threads were ignored. Data use permission was granted by the moderation team of AskReddit. Comments were copied without usernames and assigned a 5 character alphanumeric ID as provided by the random sequence generator at random.org ${ }^{44}$. This sample was comprised of reddit users with English fluency who felt their experiences matched the posted question. Reddit terms of service prohibit users < age 13, yielding an approximate age range of 13-90+. 43 individuals provided their age of initial psychosis awareness, showing a range of 7.5-32 years and mean age of $16.34(S D=5.63)$. User demographic information is not required for posting nor made public; therefore, gender, ethnicity and demographic factors were unknown unless a user chose to share that information. Sample homogeneity was the experience of psychosis.

\section{Measures}

The question posed was a request for lived experience by the original poster and the only measure utilised.

\section{Analysis}


Interpretive phenomenological analysis (IPA) is a method of qualitative review focusing on the individual's interpretation of their experiences ${ }^{45}$. IPA differs from other qualitative methods in its combination of philosophies, blending interpretation with psychological and ideographic analysis ${ }^{46}$. The researcher puts aside preconceived notions to review the data in a 'bottom-up' method of thematic coding, generating emergent themes rather than testing pre-existing theories.47 IPA is usually performed in a focus group or semi structured interview but can be performed with secondary data in larger samples. IPA use in psychosis research has produced "contextually rich" frameworks exploring individuals' selfdefinition of their psychotic experiences ${ }^{26,29,48}$. Transcripts were analysed for general themes in experience, which were then combined into overarching key themes and trends in the sample. 


\section{Results}

Sample

139 commenters discussed their perception of symptom onset and 4 distinct themes emerged. 20\% ( $N=30)$ described symptoms being "always present" or "as far back as I can remember", 52.7\% ( $\mathrm{N}=79)$ as "starting slowly" and building to a breakdown, $11.3 \%(\mathrm{~N}=16)$ as "sudden" onset while $8.7 \%(\mathrm{~N}=11)$ stated they were "currently" experiencing symptoms. In discussing distress related to these experiences, lower distress was interpreted as awareness to mild annoyance and moderate/high distress interpreted by descriptive language. Distress varied by onset theme, with lower distress associated with length of exposure to and severity of symptoms. The Always Present onset category showed the lowest overall distress, followed by the Started Slowly category, the Suddenly category, and the Current category (Table 1). Respondents described this distress in the context of the psychotic experience, interpreted as internal when directly related to a distressing symptom and external when related to stigma/fear of stigma/other people.

Table 1 here

12 commenters shared their age of initial symptom awareness in childhood $(\bar{m}=7.75$ years $(S D=2.8)$ ) and 43 shared their age of awareness preceding the psychotic event $(\bar{m}=16.34$ years $(S D=5.63))$. While the posted question was for 'people diagnosed with schizophrenia', most respondents interpreted this as 'people who have experienced psychosis'. 44 commenters provided their formal psychiatric diagnosis (Table 2), with only 
13 diagnosed with 'schizophrenia' and many commenting their diagnosis had changed several times. Several respondents cited little confidence in the diagnostic process and overall confusion over shifting diagnoses over time.

Table 2 here

Comorbid mental health problems and other related issues were present in the sample. $10 \%(\mathrm{~N}=15)$ mentioned anxiety and $11.3 \%(\mathrm{~N}=17)$ mentioned depression. $4.7 \%$ $(\mathrm{N}=7)$ reported panic attacks, $6 \%(\mathrm{~N}=9)$ reported insomnia/sleep problems, and $7.3 \%(\mathrm{~N}=11)$ mentioned specific trauma with $1.3 \%(\mathrm{~N}=2)$ reporting PTSD as a comorbidity. $8.7 \%(\mathrm{~N}=13)$ reported increased stress/stressful environments directly preceding onset. $6 \%(\mathrm{~N}=9)$ recounted non-alcohol drugs use (cannabis $(N=4)$, $\operatorname{LSD}(\mathrm{N}=2)$, multiple $(\mathrm{N}=2)$, other $(\mathrm{N}=1)$ ). 4.6\% $(\mathrm{N}=7)$ stated they had made at least 1 suicide attempt. Those who reported these comorbidities cited them in a manner that inferred causality for the psychotic event.

\section{Symptomology}

Auditory Hallucinations: "Hearing my dead best friend screaming for help from Hell."

Auditory hallucinations were the most prevalent symptom with $56.7 \%(\mathrm{~N}=85)$ reporting hearing either voices $(48 \%, \mathrm{~N}=72)$, noises $(3.3 \%, \mathrm{~N}=5)$, both $(12.7 \%, \mathrm{~N}=19)$, or "things that weren't there" $(5.3 \%, N=8)$. Non-voice noises were mundane in nature (television/radio, music, static, footsteps, breathing, environmental sounds) and associated with lower distress. Voice hallucinations produced higher distress, moderated by age of onset. The theme of universal experience emerged in those with childhood onset as they assumed that their experience of hearing voices was common. This subset did not feel 
distress until symptomology evolved during adolescence. Several stated that because no one ever mentioned internal voices, they concluded it was an aspect of life simply not discussed.

23IUX: "I didn't think that the voices in my head were abnormal. I thought everyone had multiple voices in their heads."

690WD: “I was terrified I would yell at them in public (I didn't know why, but that just wasn't something people did - at this point I still assumed everyone had other people in their heads)."

Several themes arose concerning voice personification and characteristics. Voice identity fell into three groups: 1) unknown voices, 2) friends or family, and 3) God, Satan, or angels/demons. Most described voices 'in their heads' but early childhood onset commenters also described voices coming from 'under the bed'. Superimposition of voice hallucinations over live conversation or television/radio also occurred and many experienced hearing someone call them from another room. While most reported single voices, some experienced multiple voices in chorus or cacophony. Voice content fell into coherent speech, mumbled/whispered gibberish, or repeated phrases. Voice characteristics were largely neutral as $29.1 \%(\mathrm{~N}=21)$ of the voices subsample reported negative characteristics versus $5.5 \%(\mathrm{~N}=4)$ positive. Voices espousing paranoid ideation were common but the commenter's perception of voice personality determined the voice's intent. Negative voices criticised, used vulgar language, and encouraged self-harm, suicide, and harm against friends/family. These voices were associated with high levels of distress, self-harm, and suicide attempts. Positive voices were described as helpful or a 
friend/companion. Voice hallucinations with established identity were salient, often resulting in the respondent viewing the experience as a relationship with the voice(s) and formation of delusional explanation around that relationship.

98II9: "I'm 19 and I've had "voices" for a long time like it will tell me to do stupid things like hit my hand against the wall really hard and that if I don't I'm weak."

69OWD: "I'd ask Him (God) questions and He'd give me answers. There was a sense of trust in that relationship; He was like a mentor."

\section{Visual Hallucinations: "Faces started appearing in my windows."} $40 \%(N=60)$ of commenters reported visual hallucinations with $6.7 \%(N=10)$ seeing 'shadow people'. Hallucinations manifested as normal or abnormal phenomena, with 'normal' being anything expected in the given environment; people walking on the street, birds/animals in an outdoor setting, etc. Normal visual hallucinations were associated with lower distress. Abnormal phenomena included shadow people, orbs/lights, frightening or disgusting visions, shadows with impossible properties, patterns in object textures, or textures in motion.

KWP7V: "Some of them were in my peripheral vision, but I used to see hands snaking over the backs of furniture, like couches or beds. It would terrify me."

Hallucinations in peripheral vision were common, as were occurrences before sleep or just after waking, though only one commenter mentioned a prior history of sleep 
paralysis. Frightening visions included demons, human/animal corpses, and supernatural creatures while disgusting visions included maggots, worms, parasites, and an instance of vivisection. Several commenters reported shadows with red eyes whose "physics seemed slightly off". Shadow people were often in motion, walking by doorways/windows, or following and lunging at the commenter. Some experienced visual hallucinations related to and reinforcing pre-existing delusions, and several described immersive, multi-modal hallucinations.

XOYYK: "The easiest way of describing it would be that my brain had changed channel from what I was seeing to something else entirely, but I was unaware of it until it changed back to what was actually in front of me."

Visual hallucinations often resulted in extensive reality-testing behaviours with the respondent unable to fully trust their senses, even during recovery periods.

\section{Paranoia: "There is always someone watching."}

$30 \%(\mathrm{~N}=45)$ of the sample reported paranoid ideation (PI). A common theme was being the victim of the attentions of authority figures including parents, the police, or the government. Parents were accused of poisoning food/drink and co-opting confederates to watch/follow/record the individual. The police and government were assumed to be utilising unmarked cars to follow and record commenters, trying to harm them, 'gathering evidence', or employing snipers.

95TEU: "Actions taken to protect myself from authority led to actions taken 
to protect myself because authority figures were trying to kill me.

UXDN6: "I would only drink bottled water because I thought the government put a canister on the water lines that was set to release chemicals when I would shower or use the sink."

Peers were implicated at a lesser level of authority. Friends were accused of conspiring, being false friends, talking/laughing behind a commenter's back, or being a paid catspaw of authority. Attempts to help were interpreted as threats, contributing to a lack of trust in others, especially mental health and medical professionals. The fear of being followed, watched, and recorded was pervasive even where no specific agent was identified. Several commenters engaged in complicated driving patterns to lose followers or carried weapons. There was a general sense that unnamed others were plotting against them, threatening physical harm, with television/radio cited as monitoring outlets as well as enabling communication between conspirators. Hidden cameras/microphones were a serious concern to some, often hidden in impossible locations.

EAHLL: "I "knew" where the cameras were. In vents, cracks in walls, old punctures from thumb tacs."

PJSDS: “I always feel like I'm being watch through tiny cameras everywhere (in door hinges, in outlets, in air vents, etc)."

\section{Delusions: "Hidden messages pertaining to me specifically."} $30 \%(\mathrm{~N}=45)$ of commenters experienced delusions, occurring covalently with paranoia in 43 cases. 7.3\% ( $\mathrm{N}=11$ ) reported religious (Judeo-Christian) delusions and 8\% 
$(\mathrm{N}=12)$ that they received a special 'message' or 'pattern' to decode. Most described the delusional state as unpleasant with language use comparable to describing dreams/nightmares. Four commenters referenced the film 'The Truman Show', describing life as a simulation where every aspect was scripted and coordinated by an unknown authority towards an unknown goal. The concept of a 'mirror' reality with a decoy population was also prevalent. Many experienced ideas of reference and felt 'special' or 'chosen'. These thematic delusions created a feeling of enhanced perception and a drive to interpret hidden 'messages' for an overarching purpose. Some described their internal world of thoughts and motivations being made public by mind reading or television/radio broadcast. The schema of thought changed on a base level, taking on metaphysical qualities and altering perceptions of reality. Several commenters had insight to these aberrant thoughts but were unable to disengage.

FUK4H: "Then I started giving too much weight to ridiculous thoughts and ideas. Normally humans can dismiss stupid ideas like their thoughts are conspiring with the universe to give people cancer, or that everyone is conspiring against you."

Q4NI3: "I suspected what was coming but when I finally had a psychotic break I still had no insight. I walked into the police station and asked to file a report about aliens mind controlling people at my work."

Religious delusions mainly focused on a relationship with God or fight against Satan. Fear of angering God and following His precepts to avoid 'punishment' factored into distress, as did fear of sin or temptation by Satan. Both were associated with protective 
ritualistic behaviour. Some experienced 'universal truth' delusions involving complex nonreligious philosophies.

NQ32L: "Seriously, my brain is an asshole, so it'd send prayers to Satan constantly, and I'd get locked in prayer battles for my poor immortal soul when I was still a kid. I covered my room with crosses. I kept holy water at my bedside."

\section{Minor Symptoms}

Several minor symptoms were present in the sample. $11.3 \%(\mathrm{~N}=17)$ reported disassociation/derealisation, $6 \%(\mathrm{~N}=9)$ reported memory/cognition issues as they approached the initial psychotic event, $4.7 \%(\mathrm{~N}=7)$ reported negative symptoms, and $3.3 \%$ $(\mathrm{N}=5)$ spoke of extreme superstition/magical thinking. 5.3\% $(\mathrm{N}=8)$ experienced tactile hallucinations and $2.7 \%(\mathrm{~N}=4)$ experienced olfactory hallucinations. $2 \%(\mathrm{~N}=3)$ shared that they had homicidal ideation during their psychotic state. 2 commenters described the synaesthesia effect of ordinal linguistic personification.

Insight

A majority of the sample discussed gaining insight in reference to their experiences. 41.3\% ( $N=62$ ) cited self-realisation that what they were experiencing "wasn't right". $18.7 \%$ $(\mathrm{N}=28)$ reported retrospective insight after their breakdown. $16.7 \%(\mathrm{~N}=25)$ shared that another person granted them insight, and $19.3 \%(\mathrm{~N}=29)$ did not discuss it. Higher distress was associated with self-realization and hindsight over those brought insight by another. Many delayed disclosing their symptoms for months or even years and expressed regret for having done so. $4.6 \%(\mathrm{~N}=7)$ reported their parents not believing them or refusing them 
psychiatric treatment. Gaining insight was most meaningful to respondents as a representation of a dividing line between 'ill' and 'well', regardless of diagnosis or recovery process.

\section{Overall Interpretation of Psychosis}

Reflections of 'I tried to ignore it,' 'I knew something was wrong but was powerless' or 'it all made sense at the time' were common. Symptomology was interpreted to fit preexisting cultural values and interpreted through a cultural lens, especially during religious/'universal truth' delusions, AV hallucinations of the supernatural, and surveillance paranoia. 'Hindsight introspection' was common with many reporting being now able to identify and understand the process that preceded their breakdown, favouring lived experiences and environment over more delusional causal theories. Individual interpretation was ultimately a product of each commenter's personal qualia and many respondents explained this in detail in language tailored for general understanding. Though they were answering 'OP' (original poster), they wrote their comments as if addressing the population at large, seeking to clearly communicate these experiences and be understood. 19.3\% ( $N=29)$ expressed they were now 'in a better place' and $6 \%(N=9)$ offered encouragement to anyone who might be afraid to seek treatment. While some respondents included their recovery process and any relapses, this was ancillary to the main point of initial awareness of symptomology. 


\section{Discussion}

Sample

Much of the shared content was consistent with what we know from the extant research literature about those who have experienced psychosis or been diagnosed with schizophrenia. For example, reddit commenters were generally typical in comorbidities ${ }^{49,50}$, drugs use ${ }^{51}$, onset age ${ }^{52,53}$, and minor symptomology $y^{54}$. Stress, trauma, and prior adverse experiences were also identified as significant contributing factors ${ }^{50,55}$ to psychosis experience for these individuals. Regarding suicidality, $4.6 \%$ of the sample described at least 1 suicide attempt, and this was largely consistent with the $5 \%$ prevalence rate that has been recorded in clinical populations ${ }^{56,57}$. Diagnostic variability due to diverse symptomology was also common, and may have reflected commonly reported confusion surrounding the 'accuracy', reliability, or validity of diagnoses of psychotic disorder ${ }^{58,59}$. Notably, while the reddit question referred to schizophrenia specifically, many in the sample opted to make reference to psychosis more generally.

During the analysis, 4 distinct onset categories emerged, each differing by duration of symptom exposure and associated distress. It has been widely recognised that most psychotic-like experiences (PLE) are often non-distressing and often do not a predict future psychopathology $^{60}$. In this sample, it was notable that early subclinical experiences were associated with lower distress until symptom 'evolution' led to increased distress and psychosis development ${ }^{61,62}$. Shared histories included multiple examples of non-distressing subclinical phenomena, which were experienced in early life, but which later became problematic in adolescence and adulthood. It would seem that such accounts may afford 
useful insight and information for those interested in understanding transitions along the psychosis continuum or charged with early identification, support and treatment.

\section{Symptomology}

Specific auditory hallucination characteristics were framed in the context of commenters' associated distress ${ }^{63,64}$; i.e. non-voice sounds were often described as experiences that evoked lower levels of distress while negative voice hallucinations evoked highest levels ${ }^{65}$. References to early childhood auditory hallucinatory experiences were accompanied by explanations of unique schemas of assumed universality and were believed to be predictive of later psychopathology when persistent ${ }^{66,67}$. Voice hallucinations in this subset of commenters also became distressing as their symptoms evolved into adolescence alongside comorbid factors. The presence also of neutral and positive voices among the sample, and the notable absence of distress in their descriptions of these experiences, seemed to be consistent with the literature regarding the hole that voice hallucination form and personal interpretation ${ }^{68}$ plays in inducing distress and promoting symptom evolution. It was notable also that while those who hear voices have often been regarded as 'troubled' in the literature ${ }^{69}$ and while researchers often 'sort' individuals using a myriad of criteria, those in the current analysis displayed remarkable variation in auditory hallucinatory experience even within common themes.

Visual hallucinations were referred to in two ways, normal and abnormal. Abnormal visual hallucinations (phenomena that included shadow people, orbs/lights, frightening or disgusting visions, shadows with impossible properties, patterns in object textures, or textures in motion) were associated with higher distress, particularly when the phenomenon was frightening, disgusting, or supernatural. These hallucinations also 
contributed to higher insight, which in turn amplified distress, as individuals interpreted their experiences as symptoms of an underlying mental illness. Normal hallucinations (which included anything expected in the given environment characterised by patterns and textures), factored into aberrant salience delusions of purpose. Diffuse in the general population $^{70,71}$, visual hallucinations have been associated with higher levels of impairment ${ }^{72}$, and this was largely consistent with what was identified among the reddit sample. Importantly, in most instances of visual hallucinations, commenters used 'not real' or 'not really there' to describe phenomena that were 'real' by nature of their experiencing it.

Two levels of paranoid ideation emerged in this sample; being the target of an authority conspiracy or a peer network conspiracy. Both were associated with high distress and defensive/protective behaviours. According to the research literature, PI has been shown to vary along a spectrum in the general population ${ }^{73,74}$, with the nature and severity of beliefs forming specific interactions ${ }^{75}$. As an example, it might be regarded as 'normal' for a person to be concerned about the prevalence of CCTV cameras and well-known government monitoring programs. However, there was little mention of these in the sample; only cameras/devices in bizarre, impossible locations. Unspecified personal harm constituted a significant threat and was consistent with Freeman et al.'s paranoia hierarchy ${ }^{73}$. Notably, in this sample, a majority of respondents used the phrase 'out to get me' and described their conspirators' methods for achieving/pursuing persecution however they offered no causal theory/explanation for their status as someone who was a target of conspiracy/persecution.

Trends in delusions included ideas of reference, religious/'universal truth', aberrant salience of purpose ${ }^{76}$, and causation seeking. Delusions used as a primary explanation for 
experiences often led to ideas of reference in the 'hasty conclusions' model ${ }^{77}$. Notably, $95 \%$

of delusions in the reddit sample occurred covalently with paranoia. Many admitted knowing their delusional thoughts were abnormal but were unable to stop the progression of their psychotic episode. Cultural bias factored into delusion formation in the case of religious/'universal truth' delusions and social authority paranoia. Moreover, reinforcing the value of communication in personal interpretation, references to the 'Truman delusion' were a cultural touchstone allowing an individual to concisely describe their experiences and be instantly understood ${ }^{78,79}$.

Insight and Interpretation

A significant portion of the sample (41.3\%) gained insight from self-realisation that their experiences were divorced from reality and an indication to seek professional help. Evidence suggests that insight is positively correlated with better health outcomes ${ }^{80}$ but in the current analysis it was associated with higher distress ${ }^{81,82,83}$, and was a predictor of helpseeking behaviour with internalised stigma ${ }^{84}$ that in turn influenced a varying DUP. Many commenters expressed regret on not seeking help sooner, though they did not provide a reason for their silence/inaction. Experiences of symptomology insight and outside involvement were largely consistent with Yung and McGorry's prodromal progression model $^{1}$ through first intervention.

Interpretation and causation seeking ${ }^{85}$ often reflected automatic processes for commenters and seemed to promote self-preservation ${ }^{86}$ with explanation facilitating hindsight acceptance ${ }^{87}$. Lived experience also directly influenced interpretation, and seemed to form a feedback continuum as symptoms evolved. This was also largely consistent with the broad literature demonstrating that life events factor into psychosis progression ${ }^{88}$. A 
majority of commenters who shared their causal theories cited adverse life events, stress, and comorbid anxiety and depression. Isolating and exploring personal meaning in psychosis has proven beneficial ${ }^{89}$ and the commenters in this sample were eager to share, with the mean comment word count at 211.14 (SD=201.13; range=10-1259).

\section{Hindsight Introspection}

The data harvested for this study was retrospective and hindsight bias ${ }^{90}$ is a significant concern in any research. However, the hindsight introspection of respondents here is valuable and comparable to introspection performed during therapy. Obviously, it is reasonable to expect an individual who has experienced psychosis symptoms, in describing the same phenomena experienced at an earlier age, to ascribe those symptoms to psychosis. Clinicians and researchers familiar with prodromal and progression models will recognise such features in the data, confirming the potentially biased assertions of the respondents concerning early experiences. Hindsight introspection into psychosis causation exposed multiple instances of trauma, parents with significant mental illnesses, and substance abuse catalysts which align with contemporary contributory theories ${ }^{50,51,91}$.

\section{Limitations}

The results of this study must be taken in light of its limitations. While the medium of the reddit website does encourage sharing, there was no opportunity for clarification or follow-up questions. The anonymity of reddit did prompt commenters to speak without fear of stigma or social repercussions but also meant little demographic or standard measure information was available, limiting some aspects of analysis. The user who posed the question was not a mental health professional using clinical language nor a researcher 
engaged in hypothesis testing; they were a curious individual who wanted to know about others' experiences and asked any who cared to answer. Finally, this was an opportunity sample and the analysis conducted was exploratory as the research question was not part of a planned methodological design.

\section{Conclusions}

This study dealt with trends and key themes in a large qualitative sample to establish a viable framework for further in-depth analysis of this dataset. With this framework in place, work on follow-up studies with this data can begin, covering a variety of issues. The above findings warrant examination into early childhood subclinical experience interpretation, the distress delta between sound and voice hallucinations, power dynamics in paranoia, aberrant salience in 'purpose' delusions, limited-insight prodromal progression, and specific causal interpretations. Symptoms were separated here for preliminary analysis and follow-up studies into relationships and interactions between symptoms, distress, and personal interpretation are forthcoming. As large qualitative studies are costly and timeconsuming, access to this resource can illuminate lived experiences of initial psychosis awareness, benefitting both the individual service user and wider population. While the last vestiges of psychology's history transition into a model for mental well-being, the individual must continue to take priority. Research informs paradigm and policy alike but in this study, the best method to understand the initial awareness of psychosis was simply to ask.

\section{Conflict of interest statement:}

On behalf of all authors, the corresponding author states that there is no conflict of interest. 


\section{References}

1. Yung AR, McGorry PD. The prodromal phase of first-episode psychosis: past and current conceptualizations. Schizophr Bull. 1996;22:353-70.

2. Menezes NM, Arenovich T, Zipursky RB. A systematic review of longitudinal outcome studies of first-episode psychosis. Psychol Med. 2006;36:1349-62.

3. McGorry PD, Nelson B, Amminger GP, Bechdolf, A, Francey SM, Berger G, et al. Intervention in individuals at ultra-high risk for psychosis: a review and future directions. J Clin Psychiatry. 2009;70:1206-12.

4. Yung AR, Nelson B, Stanford C, Simmons MB, Cosgrave EM, Killackey E, et al. Validation of "prodromal" criteria to detect individuals at ultra high risk of psychosis: 2 year follow-up. Schizophr Res. 2008;105:10-17.

5. Addington J, Penn D, Woods SW, Addington D, Perkins DO. Social functioning in individuals at clinical high risk for psychosis. Schizophr Res. 2008;99:119-24.

6. Cannon TD, Cadenhead K, Cornblatt B, Woods SW, Addington J, Wakler E, et al. Prediction of psychosis in youth at high clinical risk: A multisite longitudinal study in North America. Arch Gen Psychiatry. 2008;65:28-37.

7. Marshall M, Lewis S, Lockwood A, Drake R, Jones $P$, Croudace T. Association between duration of untreated psychosis and outcome in cohorts of first-episode patients: $A$ systematic review. Arch Gen Psychiatry. 2005;62:975-83.

8. Baldwin P, Browne D, Scully PJ, Quinn JF, Morgan MG, Kinsella A, et al. Epidemiology of first-episode psychosis: Illustrating the challenges across diagnostic boundaries through the Cavan-Monaghan Study at 8 years. Schizophr Bull. 2005;31:624-38.

9. Morgan C, Dazzan P, Morgan K, Jones P, Harrison G, Leff J, et al. First episode psychosis and ethnicity: Initial findings from the AESOP study. World Psychiatry. 2006;5:40-6.

10. Craig TKJ, Garety P, Power P, Rahaman N, Colbert S, Fornells-Ambrojo M, et al. The Lambeth Early Onset (LEO) Team: Randomised controlled trial of the effectiveness of specialized care for early psychosis. BMJ. 2004;329:1067.

11. van Os J, Hanssen M, Bijl RV, Ravelli A. Strauss (1969) revisited: A psychosis continuum in the general population? Schizophr Res. 2000;45:11-20.

12. Linscott RJ, van Os J. An updated and conservative systematic review and meta-analysis of epidemiological evidence on psychotic experiences in children and adults: On the pathway from proneness to persistence to dimensional expression across mental 
disorders. Psychol Med. 2013;43:1133-49.

13. McGorry PD, Yung AR, Phillips $\amalg$, Yuen HP, Francey S, Cosgrave EM, et al. Randomized controlled trial of interventions designed to reduce the risk of progression to firstepisode psychosis in a clinical sample with subthreshold symptoms. Arch Gen Psychiatry. 2002;59:921-8.

14. Alvarez-Jiménez M, Parker AG, Hetrick SE, McGorry PD, Gleeson J F. Preventing the second episode: a systematic review and meta-analysis of psychosocial and pharmacological trials in first-episode psychosis. Schizophr Bull. 2009;37:619-30.

15. Singh SP, Grange T. Measuring pathways to care in first-episode psychosis: a systematic review. Schizophr Res. 2006;81:75-82.

16. Anderson KK, Fuhrer R, Malla AK. The pathways to mental health care of first-episode psychosis patients: a systematic review. Psychol Med. 2010;40:1585-97.

17. Zhang JP, Gallego JA, Robinson DG, Malhotra AK, Kane JM, Correll CU. Efficacy and safety of individual second-generation vs. first-generation antipsychotics in firstepisode psychosis: a systematic review and meta-analysis. Int J Neuropsychopharmacol. 2013;16:1205-18.

18. Bozikas VP, Andreou C. Longitudinal studies of cognition in first episode psychosis: A systematic review of the literature. Aust N Z J Psychiatry. 2011;45:93-108.

19. Mesholam-Gately RI, Giuliano AJ, Goff KP, Faraone SV, Seidman LJ. Neurocognition in first-episode schizophrenia: A meta-analytic review. Neuropsychology. 2009;23:315-36.

20. Steen RG, Mull C, McClure R, Hamer RM, Lieberman JA. Brain volume in first-episode schizophrenia: Systematic review and meta-analysis of magnetic resonance imaging studies. Br J Psychiatry. 2006;188:510-18.

21. Borges S, Gayer-Anderson C, Mondelli V. A systematic review of the activity of the hypothalamic-pituitary-adrenal axis in first episode psychosis.

Psychoneuroendocrinology. 2013;38:603-11.

22. MacBeth A, Gumley A. Premorbid adjustment, symptom development and quality of life in first episode psychosis: a systematic review and critical reappraisal. Acta Psychiatr Scan. 2008;117:85-99.

23. Pompili M, Serafini G, Innamorati M, Lester D, Shrivastava A, Girardi P, et al. Suicide risk in first episode psychosis: A selective review of the current literature. Schizophr Res. 2011;129:1-11.

24. Hoy K, Barrett S, Shannon C, Campbell C, Watson D, Rushe T, et al. Childhood trauma and hippocampal and amygdalar volumes in first-episode psychosis. Schizophr Bull. 
2011;38:1162-9.

25. Aas M, Navari S, Gibbs A, Mondelli V, Fisher HL, Morgan C, et al. Is there a link between childhood trauma, cognition, and amygdala and hippocampus volume in firstepisode psychosis? Schizophr Res. 2012;137:73-9.

26. Boydell KM, Stasiulis E, Volpe T, Gladstone B. A descriptive review of qualitative studies in first episode psychosis. Early Interv Psychiatry. 2010;4:7-24.

27. Corcoran C, Davidson L, Sills-Shahar R, Nickou C, MalaspinaD, McGlashan T. A qualitative research study of the evolution of symptoms in individuals identified as prodromal to psychosis. Psychiatr Q. 2003;4:313-32.

28. Moller $\mathrm{P}$, Husby R. The initial prodrome in schizophrenia: Searching for naturalistic core dimensions of experience and behaviour. Schizophr Bull. 2000;26:217-32.

29. Perry BM, Taylor D, Shaw SK. 'You've got to have a positive state of mind': An interpretive phenomenological analysis of hope and first episode psychosis. J Ment Health. 2007;16:781-93.

30. Fisher A, Savin-Baden M. The benefits to young people experiencing psychosis, and their families, of an early intervention programme: Evaluating a service from the consumers' and the providers' perspectives. Br J Occup Ther. 2001;64:58-65.

31. Larsen JA. Understanding a complex intervention: person-centred ethnography in early psychosis. J Ment Health. 2007;16:333-45.

32. O'Toole MS, Ohlsen RI, Taylor TM, Walters J, Pilowsky LS. Treating first episode psychosis - the service users' perspective: A focus group evaluation. J Psychiatr Ment Health Nurs. 2004;11:319-26.

33. Bergner E, Leiner AS, Carter T, Franz L, Thompson NJ, Compton MT. The period of untreated psychosis before treatment initiation: A qualitative study of family members' perspectives. Compr Psychiatry. 2008;49:530-6.

34. Boydell KM, Gladstone BM, Volpe T. Understanding help seeking delay in the prodrome to first episode psychosis: A secondary analysis of the perspectives of young people. Psychiatr Rehabil J. 2006;30:54-60.

35. Corcoran C. Trajectory to a first episode of psychosis: A qualitative research study with families. Early Interv Psychiatry. 2007;1:54-60.

36. Gladstone B, Volpe T, Boydell K. Issues encountered in a qualitative secondary analysis of help-seeking in the prodrome to psychosis. J Behav Health Serv Res. 2007;34:43142.

37. Mackrell L, Lavender T. Peer relationships in adolescents experiencing a first episode of 
psychosis. J Ment Health. 2004;13:467-79.

38. Woodside H, Krupa T, Pocock K. How people negotiate for success as psychosis emerges. Early Interv Psychiatry. 2008;2:50-4.

39. Haslam N. Bias in psychopathology research. Curr Opinion Psychiatry. 2006;19:625-630.

40. Garb HN. (1998). Studying the clinician: Judgment research and psychological assessment. Washington, DC, US: American Psychological Association; 1998.

41. Alexa Internet Inc. Reddit.com Web Traffic Statistics [Internet]. Alexa c1996-2018 [cited 2017 Nov 25]. Available from: https://www.alexa.com/siteinfo/reddit.com.

42. Griffiths $M$. The use of online methodologies in data collection for gambling and gambling addictions. Int J Ment Health Addiction, 2009;8:8-20.

43. Schrank B, Klose T, Szmukler G, Lloyd K, Koivunen M. How patients with schizophrenia use the Internet: Qualitative study. J Med Internet Res. 2010;12:e70.

44. Haahr M. True Random Number Service [Internet]. Random Org c1998-2018 [cited 2017 Nov 25]. Available from: https://www.random.org/.

45. Smith J, Jarman M, Osborn M. Doing Interpretative Phenomenological Analysis. In Murray M, Chamberlin K, eds. Qualitative Health Psychology. Thousand Oaks, California, US: Sage; 1999: 218-40.

46. Gill J. The possibilities of phenomenology for organizational research. Organ Res Meth. 2014;17:118-37.

47. Pietkiewicz I, Smith J. A practical guide to using Interpretative Phenomenological Analysis in qualitative research psychology. C Psychologic. 2012;18:361-9.

48. Knight M, Wykes T, Hayward P. 'People don't understand': An investigation of stigma in schizophrenia using Interpretative Phenomenological Analysis (IPA). J Ment Health. 2003;12:209-22.

49. Hanssen M, Peeters F, Krabbendam L, Radstake S, Verdoux H, van Os J. How psychotic are individuals with non-psychotic disorders? Soc Psychiatry Psychiatr Epidemiol. 2003;38:149-54.

50. Read J, van Os J, Morrison A, Ross C. Childhood trauma, psychosis and schizophrenia: A literature review with theoretical and clinical implications. Acta Psychiatr Scan. 2005;112:330-50.

51. Moore T, Zammit S, Lingford-Hughes A, et al. Cannabis use and risk of psychotic or affective mental health outcomes: A systematic review. Lancet. 2007;370:319-28. 
52. Häfner N, Maurer K, Löffler W, Fätenheuer B, an der Heiden W, Riecher-Rössler A, et al. The epidemiology of early schizophrenia: Influence of age and gender on onset and early course. Br J Psychiatry Suppl. 1994;164:29-38.

53. Schultze-Lutter F, Michel C, Ruhrmann S, Schimmelmann B. Prevalence and clinical significance of DSM-5-attenuated psychosis syndrome in adolescents and young adults in the general population: The Bern Epidemiological At-Risk (BEAR) study. Schizophr Bull. 2014;40:1499-1508.

54. Kendler K, Gallagher T, Abelson J, Kessler R. Lifetime prevalence, demographic risk factors, and diagnostic validity of nonaffective psychosis as assessed in a US community sample: The National Comorbidity Survey. Arch Gen Psychiatry. 1996;53:1022-31.

55. Read J, Bentall R, Fosse R Time to abandon the bio-bio-bio model of psychosis: Exploring the epigenetic and psychological mechanisms by which adverse life events lead to psychotic symptoms. Epidemiol Psichiatr Soc. 2009;18:299-310.

56. Palmer B, Pankratz S, Bostwick J. The lifetime risk of suicide in schizophrenia: A reexamination. Arch Gen Psychiatry. 2005;62:247-53.

57. Hor K, Taylor M. Suicide and schizophrenia: A systematic review of rates and risk factors. J Psychopharmacol. 2010;24:81-90.

58. Cooke A, Kinderman P. "But what about real mental illnesses?" Alternatives to the disease model approach to "schizophrenia". J Human Psychol. 2018;58:47-71.

59. Jablensky A. Psychiatric classifications: validity and utility. World Psychiatry, 2016;15:2631.

60. van Os J, Linscott R, Myin-Germeys I, Delespaul P, Krabbendam L. A systematic review and meta-analysis of the psychosis continuum: Evidence for a psychosis pronenesspersistence-impairment model of psychotic disorder. Psychol Med. 2009;39:179-95.

61. Dominguez $M$, Wichers $M$, Lieb R, Wittchen $\mathrm{H}-\mathrm{U}$, van Os J. Evidence that onset of clinical psychosis is an outcome of progressively more persistent subclinical psychotic experiences: An 8-year cohort study. Schizophr Bull. 2011;37:84-93.

62. Murphy J, McBride O, Fried E, Shevlin M. Distress, impairment and the extended psychosis phenotype: A network analysis of psychotic experiences in an US general population sample. Schizophr Bull. 2017;sbx134.

63. Nayani T, David A. The auditory hallucination: A phenomenological survey. Psychol Med. 1996;26:177-89 
64. Mawson A, Cohen K, Berry K. Reviewing evidence for the cognitive model of auditory hallucinations: The relationship between cognitive voice appraisals and distress during psychosis. Clin Psychol Rev. 2010;30:248-58.

65. Wong Z, Öngür D, Cohen B, Ravichandran C, Noam G, Murphy B. Command hallucinations and clinical characteristics of suicidality in patients with psychotic spectrum disorders. Compr Psychiatry. 2013;54:611-7.

66. Bartels-Velthuis A, van de Willige G, Jenner J, van Os J, Wiersma D. Course of auditory vocal hallucinations in childhood: 5-year follow-up study. Br J Psychiatry. 2011;199:296-302.

67. Bartels-Velthuis A, van de Willige G, Jenner J, van Os J. Auditory hallucinations in childhood: Associations with adversity and delusional ideation. Psychol Med. 2012;42:583-93.

68. Woods A, Jones N, Alderson-Day B, Callard F, Fernyhough C. Experiences of hearing voices: Analysis of a novel phenomenological survey. Lancet Psychiatry. 2015;2:32331.

69. Link BG, Phelan JC, Bresnahan M, Stueve A, Pescosolido BA. Public conceptions of mental illness: labels, causes, dangerousness, and social distance. Am J Pub Health. 1999;89:1328-33.

70. Bentall R. The illusion of reality: A review and integration of psychological research on hallucinations. Psychol Bull. 1990;107:82-95.

71. Ohayon M. Prevalence of hallucinations and their pathological associations in the general population. Psychiatry Res. 2000;97:153-64.

72. David C, Greenstein D, Clasen L, Gochman P, Miller R, Tossell JW, et al. Childhood onset schizophrenia: High rate of visual hallucinations. J Am Acad Child Adolesc Psychiatry. 2011;50:681-6.

73. Freeman D, Garety P, Bebbington P, Smith B, Rollinson R, Fowler D, et al. Psychological investigation of the structure of paranoia in a non-clinical population. Br J Psychiatry. 2005;186:427-35.

74. Freeman D, McManus S, Brugha T, Meltzer H, Jenkins R, Bebbington P. Concomitants of paranoia in the general population. Psychol Med. 2011;41:923-36.

75. Bebbington $P$, McBride O, Steel C, Kuipers E, Radovanovic M, Brugha T, et al. The structure of paranoia in the general population. Br J Psychiatry. 2013;202:419-27.

76. Kapur S. Psychosis as a state of aberrant salience: A framework linking biology, 
phenomenology, and pharmacology in schizophrenia. Am J Psychiatry. 2003;160:1323.

77. Freeman D, Garety P, Fowler D, Kuipers E, Bebbington P, Dunn G. Why do people with delusions fail to choose more realistic explanations for their experiences? An empirical investigation. J Consult Clin Psychol. 2004;72:671-80.

78. Gold J, Gold I. The "Truman Show" delusion: Psychosis in the global village. Cogn Neuropsychiatry. 2012;17:455-72.

79. Mishara A, Fusar-Poli P. The phenomenology and neurobiology of delusion formation during psychosis onset: Jaspers, Truman symptoms, and aberrant salience. Schizophr Bull. 2013;39:278-86.

80. Lincoln T, Lüllmann E, Rief W. Correlates and long-term consequences of poor insight in patients with schizophrenia: A systematic review. Schizophr Bull. 2007;33:1324-42.

81. Cooke M, Peters E, Fannon D, Anilkumar A, Aasen I, Kuipers E, et al. Insight, distress and coping styles in schizophrenia. Schizophr Res. 2007;94:12-22.

82. Cooke M, Peters E, Fannon D, Aasen I, Kuipers E, Kumari V. Cognitive insight in psychosis: The relationship between self-certainty and self-reflection dimensions and neuropsychological measures. Psychiatry Res. 2010;178:284-9.

83. Peters E, Lataster T, Greenwood K, Kuipers E, Williams S, et al. Appraisals, psychotic symptoms and affect in daily life. Psychol Med. 2011;42:1013-23.

84. Lysaker P, Roe D, Yanos P. Toward understanding the insight paradox: internalized stigma moderates the association between insight and social functioning, hope, and self-esteem among people with schizophrenia spectrum disorders. Schizophr Bull. 2007;33:192-9.

85. Carter L, Read J, Pyle M, Morrison A. The impact of causal explanations on outcome in people experiencing psychosis: A systematic review. Clin Psychol Psychother. 2017;24:332-47.

86. Larsen J. Finding meaning in first episode psychosis: Experience, agency, and the cultural repertoire. Med Anthropol Q. 2004;18:447-71.

87. Heriot-Maitland C, Knight M, Peters E. A qualitative comparison of psychotic-like phenomena in clinical and non-clinical populations. Br J Clin Psychol. 2012;51:37-53.

88. Read J, Dillon J. Models of Madness: Psychological, Social and Biological Approaches to Psychosis. London, United Kingdom: Routledge; 2013.

89. Windell D, Norman R, Lal S, Malla A. Subjective experiences of illness recovery in 
individuals treated for first-episode psychosis. Soc Psychiatry Psychiatr Epidemiol. 2015;50:1069-77.

90. Fischhoff B, Beyth R. I knew it would happen: Remembered probabilities of once-future things. Org Behav Hum Perform. 1975;13:1-16.

91. Rasic D, Hajek T, Alda M, Uher R. Risk of mental illness in offspring of parents with schizophrenia, bipolar disorder, and major depressive disorder: a meta-analysis of family high-risk studies. Schizophr Bull. 2014;40:28-38. 